\title{
Combining Genome Wide Association Studies and Differential Gene Expression Data Analyses Identifies Candidate Genes Affecting Mastitis Caused by Two Different Pathogens in the Dairy Cow
}

\author{
Xing Chen 1,2, Zhangrui Cheng1, Shujun Zhang1,2, Dirk Werling3, D. Claire Wathes ${ }^{{ }^{*}}$ \\ ${ }^{1}$ Department of Production and Population Health, Royal Veterinary College, Hatfield, UK \\ ${ }^{2}$ Key Laboratory of Agricultural Animal Genetics, Breeding and Reproduction, Education Ministry of China, \\ College of Animal Science and Technology, Huazhong Agricultural University, Wuhan, China \\ ${ }^{3}$ Department of Pathology and Pathogen Biology, Royal Veterinary College, Hatfield, UK \\ Email: ${ }^{*}$ dcwathes@rvc.ac.uk
}

Received 13 July 2015; accepted 20 September 2015; published 23 September 2015

Copyright @ 2015 by authors and Scientific Research Publishing Inc.

This work is licensed under the Creative Commons Attribution International License (CC BY). http://creativecommons.org/licenses/by/4.0/ (c) (i) Open Access

\begin{abstract}
Mastitis is a costly disease which hampers the dairy industry. Inflammation of the mammary gland is commonly caused by bacterial infection, mainly Escherichia coli, Streptococcus uberis and Staphylococcus aureus. As more bacteria become multi-drug resistant, one potential approach to reduce the disease incidence rate is to breed selectively for the most appropriate and potentially protective innate immune response. The genetic contribution to effective disease resistance is, however, difficult to identify due to the complex interactions that occur. In the present study two published datasets were searched for common differentially expressed genes (DEGs) with similar changes in expression in mammary tissue following intra-mammary challenge with either $E$. coli or $S$. uberis. Additionally, the results of seven published genome-wide association studies (GWAS) on different dairy cow populations were used to compile a list of SNPs associated with somatic cell count. All genes located within $2 \mathrm{Mbp}$ of significant SNPs were retrieved from the Ensembl database, based on the UMD3.1 assembly. A final list of 48 candidate genes with a role in the innate immune response identified from both the DEG and GWAS studies was further analyzed using Ingenuity Pathway Analysis. The main signalling pathways highlighted in the response of the bovine mammary gland to both bacterial infections were 1) granulocyte adhesion and diapedesis, 2) ephrin receptor signalling, 3) RhoA signalling and 4) LPS/IL1 mediated inhibition of RXR function. These
\end{abstract}

${ }^{*}$ Corresponding author.

How to cite this paper: Chen, X., et al. (2015) Combining Genome Wide Association Studies and Differential Gene Expression Data Analyses Identifies Candidate Genes Affecting Mastitis Caused by Two Different Pathogens in the Dairy Cow. Open Journal of Animal Sciences, 5, 358-393. http://dx.doi.org/10.4236/ojas.2015.54040 
pathways comprised a network regulating the activity of leukocytes, especially neutrophils, during mammary gland inflammation. The timely and properly controlled movement of leukocytes to infection loci seems particularly important in achieving a good balance between pathogen elimination and excessive tissue damage. These results suggest that polymorphisms in key genes in these pathways such as SELP, SELL, BCAR1, ACTR3, CXCL2, CXCL6, CXCL8 and FABP may influence the ability of dairy cows to resist mastitis.

\section{Keywords}

Innate Immunity, Disease Resistance, E. coli, S. Uberis, SNP, Somatic Cell Count

\section{Introduction}

Mastitis in dairy cows, characterized by a high cell count in the milk, is one of the most economically serious diseases of livestock worldwide. In the UK there are around 40 cases of clinical mastitis per 100 cows. It is estimated that $70 \%$ of these are mild (being treated by the farmer), $29 \%$ are severe (requiring a visit from the veterinarian) and $1 \%$ are fatal [1]. Continuous genetic selection for milk production in modern high yielding dairy cows has been associated with an increased incidence of mastitis [2] [3]. Poor health reduces longevity and causes serious economic losses [4]. The bacteriological aetiology of mastitis has changed over recent years from primarily contagious forms (such as Staphylococcus (St.) aureus) to environmental pathogens (such as Escherichia (E.) coli and Streptococcus (S.) uberis) [5]. Conventional treatment requires antibiotic therapy but traditional mastitis control strategies are not fully efficient against environmental pathogens [6]. This raises major concerns over antibiotic residues in food products as well as an ever increasing rate of antimicrobial resistance [7]. Alternative options are urgently needed for efficiency, health and sustainability of the dairy industry. This need will be even more urgent in future as antibiotic usage in farm livestock becomes increasingly restricted.

Many studies have indicated that the host defence status is a key factor determining the severity of mastitis [8] [9]. The innate response offers the first line of defence in the bovine mammary gland, potentially helping the host to eliminate invading pathogens at an early stage, thus minimizing adverse effects [10]. This rapid early response is of key importance as adaptive immune responses seem to fail to induce long-lasting protection [11]. A more sustainable approach to decrease the incidence of disease and improve health in dairy cattle is thus by genetic selection, utilizing gene polymorphisms for enhanced innate immunity [12]. Such genetic improvement could potentially result in cumulative, permanent and cost-effective change. The candidate genes for genetic selection are, however, difficult to identify due to the complex interactions that must occur for effective disease resistance.

A recent UK survey showed that $S$. uberis and E. coli were the predominant pathogens isolated from clinical mastitis cases and S. uberis from subclinical cases [13]. Different bacterial species lead to different host responses [14]. Differentially expressed gene (DEGs) profile studies have provided much useful information for understanding dairy cow mastitis. These profiles have been derived from cattle challenged in vivo with St. aureus [15], E. coli [16] [17] and S. uberis [18] [19]. Additional in vitro studies have investigated the responses of bovine monocyte-derived macrophages to St. aureus [20] and mammary epithelial cells to both St. aureus and E. coli [21] [22]. These studies have revealed some important differences between Gram-negative and Gram-positive bacterial species in terms of both the time course and magnitude of the response as well as which genes are differentially expressed. Gram-negative $E$. coli infections are generally of short duration with a high bacterial count and induce a rapid and strong rise in the pro-inflammatory cytokines TNF $\alpha$ IL1 $\beta$ and IL6 in mammary tissue via TLR4-dependent lipopolysaccharide (LPS) induced signalling. This results in a fast influx of neutrophils to inhibit bacterial growth [11]. On the other hand, Gram-positive bacteria such as $S$. uberis cause a slower and less dramatic response [23] while St. aureus is better able to evade the host immune response leading to a more persistent infection. In these instances, TLR signalling increases IL6 expression but does not up-regulate TNF $\alpha$ and IL1 $\beta$ [11]. Despite these species-specific responses, similarities still exist across bacterial species, such as the up-regulation of genes related to the innate immune response and down-regulation of genes related to fat metabolism [16] [18]. Indeed, several innate immune response pathways show evolutionary conservation independent of the infecting pathogens [24]. This increases the feasibility of finding common defence mechanisms against 
mastitic infections caused by different bacterial species, which is necessary to develop a more efficient breeding strategy for dairy cows.

Allele-phenotype association studies, especially genome-wide association studies (GWAS), offer another source of valuable information for understanding genetic mechanisms underlying different dairy cow phenotypes. This provides a powerful tool to map QTL of important dairy traits onto the genome. Several GWAS using bovine SNP chips have investigated associations between mastitis incidence and somatic cell count (SCC) in different dairy cow populations [25]-[33]. SCC is generally more informative than clinical case recording for this purpose as it is recorded regularly and consistently from all cows in the herd in a more extensive and reliable manner. In general, mastitis incidence increases with increasing SCC [34] and the genetic correlation between SCC and clinical or subclinical mastitis is positive [35] [36]. There is however a U shaped distribution as cows with a very low SCC may have fewer immune cells present in their udders, making them more susceptible to infection [11]. Results from GWAS studies thus present us with a fragmented but key insight into which areas of the genome may be associated with improved resistance to mastitis.

We hypothesize that important common innate immune defence mechanisms exist in dairy cows to different sources of intra-mammary infection and that variance in the key genes associated with these mechanisms can lead to differences in disease resistance. Identifying these common and bacterial-species independent pathways is an essential step in developing an appropriate future breeding strategy. Supporting that this approach is feasible comes from a comparison of the responses of mammary epithelial cells derived from two groups of German Holstein heifers which are selected for high or low susceptibility to mastitis using marker assisted selection for a haplotype on BTA18 which is associated with SCC [22] [37]. Gene expression profiles found that the more resistant animals showed a quicker and stronger response to both E. coli and St. aureus with greater expression of the cytokines $I L 1 \beta, I L 6, I L 8$ and $T N F \alpha$, and the chemokines $C X C L 2$ and $C X C L 3$ and NFKB1A. These studies suggested that $R E L B$, a transcription regulator in the NF- $\mathrm{kB}$ family, was the gene most likely to be responsible for the quantitative trait locus (QTL).

In the present paper, we have undertaken a systematic integrated analysis on expression and association profiling to search for such potential common defence mechanisms (innate immunity) and different genetic mechanisms (gene polymorphisms) existing in dairy cows which alter their responses to invading pathogens within the mammary gland.

\section{Materials and Methods}

\subsection{Data and Differential Expression Analysis}

Two gene expression profiles from the Gene Expression Omnibus (GEO) database (accession numbers GSE15025 and GSE15344) were used to search for common DEGs whose expression in mammary tissue samples was altered following intra-mammary challenge with either E. coli (using Affymetrix Bovine Genome Array, platform GPL2112) [17] or S. uberis (using UIUC Bostaurus 13.2 K 70-mer oligoarray (condensed), made by W.M. Keck Center, University of Illinois Urbana-Champaign, platform GPL8776) [18]. The results of these two studies were chosen for analysis because: 1) E. coli and S. uberis are representative gram negative and gram positive bacteria respectively; 2) they are both common environmental pathogens causing mastitis [5] [13]; 3) the expression profiles were generated at similar times after the start of infection $(20-24 \mathrm{~h})$, which is the stage associated with innate immunity. The microarray data were analysed using a moderated student $t$-test with the Benjamini-Hochberg (BH) adjustment for false discovery rate (FDR) control using GeneSpring GX12.5 software (Agilent Technologies, Santa Clara, CA), according to gene accession number and experimental group as described in the GEO database and related articles [17] [18]. Fold changes were calculated as: Infected/Control where Infected $\geq$ Control (up-regulation) and -Control/Infected where Infected $<$ Control (down-regulation). P values were calculated based on a moderated t-test (tow sided) built in GeneSpring V12.5. The moderated variance was calculated as following where $S_{m 1-m 2}$ is the variance across the conditions, $m 1$ and $m 2$ are the mean expression values for gene g within groups, $d f_{(m 1-m 2)}=n 1+n 2-2, S_{\text {global }}$ and $d_{\text {global }}$ are the prior variance and degrees of freedom, respectively:

$$
S_{\text {mod }}=\frac{S_{M 1-M 2} \times d f_{(m 1-m 2)}+S_{\text {global }} \times d_{\text {global }}}{d f_{(m 1-m 2)}+d_{\text {global }}}
$$


The moderated $t$ value was calculated as:

$$
t_{\text {gmod }}=\frac{m 1-m 2}{S_{\text {mod }}}
$$

The data obtained at $20 \mathrm{~h}$ and $24 \mathrm{~h}$ respectively following intra-mammary bacterial inoculation were used for the analysis. At this time point it was considered that the treatment would have triggered an innate immune response in defence against the invading pathogens. However, as relatively few neutrophils had invaded the mammary gland by $20 \mathrm{~h}$ following S. uberis infection [18], DEG data may reflect mainly differences in gene expression of mammary epithelial cells. All the DEGs with similar expression patterns in both data sets and fold changes in response to E. coli infection $>1.5$ or S. uberis infection $>2$ were selected (Table S1). These different cut-off values were chosen due to the different microarray platforms used in the two previous experiments $(E$. coli: Affymetrix one colour/channel array; S. uberis: two colour/channel customised array) [17] [18]. Based on the nature of the microarray platforms, the data for the Affymetrix array were normalised using the Robust Multi-array Average (RMA) method whereas those for the two colour array were normalised with Lowess regression. Use of the different cut-off values in our study thus provided an appropriate number of genes for further analysis from each of the original data sets.

\subsection{Candidate Genes Based on Genome-Wide Association Study (GWAS)}

Significant SNPs identified by GWAS in seven different dairy cow populations were used to select candidate genes associated with somatic cell count (SCC) (Table 1). Genes located within 2 Mbp upstream and downstream of significant SNPs were retrieved from the Ensembl database with the position based on the UMD3.1 assembly at http://www.ensembl.org. The SNPs located on the same chromosome within $2 \mathrm{Mbp}$ were considered as a block when looking for candidate genes. All the SNPs and adjacent genes included are listed in Table S2.

\subsection{Data Integration of Gene Expression and GWAS}

The two datasets from the differential expression and GWAS analyses were integrated. The 48 common genes which appeared on both lists represented genes with a putative role in responding to infection with organisms causing mastitis (Figure 1 and Table 2).

\subsection{Selection of Candidate Genes Involved in the Innate Immune Response}

Annotation was initially provided by GeneSpring Technology files updated on May 2014 and gene function clustering via Ingenuity Pathway Analysis (IPA, Ingenuity Systems, Redwood City, CA.

http://www.ingenuity.com). The 48 shortlisted candidate genes were further annotated using a number of databases available online, including the NetAff ${ }^{\mathrm{TM}}$ analysis center toolbar on the Affymetrix website

(http://www.affymetrix.com) and GeneCard (http://www.genecards.org). The genes were also compared with the innate immune genes database InnateDB (http://www.innatedb.com). After screening, only genes contributing to "inflammatory response" or "innate immunity response" were considered for further analysis.

Table 1. Summary of studies using GWAS to identify SNPs associated with somatic cell count in different dairy cow populations.

\begin{tabular}{|c|c|c|c|}
\hline Population & SNP chip & No. significant SNPs & Reference \\
\hline Canadian Holsteins & 1536 SNP Marker Chip & 11 & Kolbehdari et al. [26] \\
\hline U.S. Holsteins & BovineSNP50 Bead Chip & 20 & Cole et al. [28] \\
\hline Norwegian Red cattle & Affymetrix 25K MIP Array & 29 & Sodeland et al. [29] \\
\hline Netherlands Holsteins & BovineSNP50 Bead Chip & 1 & Wijga et al. [30] \\
\hline Irish Holstein-Friesian & BovineSNP50 Bead Chip & 5 & Meredith et al. [31] \\
\hline Nordic Holsteins & BovineSNP50 Bead Chip & 21 & Sahana et al. [32] \\
\hline German Holstein & Unknown & 10 & Abdel-Shafy et al. [33] \\
\hline
\end{tabular}


Table 2. List of 48 candidate genes with significant changes in expression in mammary tissue in response to both $E$. coli and S. uberis and which were also located close to significant SNPs in gene association studies with SCC. See Materials and

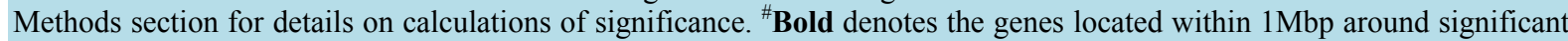
SNPs associated with SCC. The remainder were within $2 \mathrm{Mbp}$.

\begin{tabular}{|c|c|c|c|c|c|}
\hline \multirow{2}{*}{ Gene symbol $^{\#}$} & \multicolumn{2}{|c|}{ E. coli } & \multicolumn{2}{|c|}{ S. uberis } & \multirow{2}{*}{ Significant SNPs } \\
\hline & $\mathrm{P}$ & Fold change & $\mathrm{P}$ & Fold change & \\
\hline$F A S N$ & $2.40 \mathrm{E}-06$ & -4.39 & $8.83 \mathrm{E}-03$ & -2.51 & rs41257403 \\
\hline FABP4 & $3.18 \mathrm{E}-05$ & -2.89 & $2.85 \mathrm{E}-05$ & -2.93 & rs41629827 \\
\hline RHPN2 & $3.52 \mathrm{E}-06$ & -2.71 & $5.48 \mathrm{E}-04$ & -2.73 & rs 29020544 \\
\hline ACSS2 & $4.86 \mathrm{E}-06$ & -2.48 & $7.37 \mathrm{E}-03$ & -2.27 & rs 41576572 \\
\hline NOV & $8.64 \mathrm{E}-05$ & -2.10 & $4.87 \mathrm{E}-03$ & -2.36 & rs41629827 \\
\hline ROGDI & $4.29 \mathrm{E}-05$ & -2.08 & $6.60 \mathrm{E}-03$ & -2.32 & Hapmap25382-BTC-000577 \\
\hline CBFA2T3 & $7.95 \mathrm{E}-06$ & -2.06 & $2.93 \mathrm{E}-03$ & -2.23 & rs110754697 \\
\hline SORBS1 & $2.09 \mathrm{E}-04$ & -2.03 & $9.37 \mathrm{E}-03$ & -2.46 & rs41650611 \\
\hline$A L D H 18 A 1$ & $7.01 \mathrm{E}-07$ & -1.88 & $2.36 \mathrm{E}-03$ & -2.34 & rs41650611 \\
\hline$B D H 2$ & $1.03 \mathrm{E}-04$ & -1.82 & $5.96 \mathrm{E}-03$ & -2.40 & rs41664497 \\
\hline$F A M 110 A$ & $9.80 \mathrm{E}-04$ & -1.62 & $1.08 \mathrm{E}-03$ & -2.30 & rs41601522 \\
\hline$H S F 1$ & $1.75 \mathrm{E}-05$ & -1.61 & $7.46 \mathrm{E}-03$ & -2.15 & rs 109421300 \\
\hline$E M X 2$ & $1.63 \mathrm{E}-03$ & -1.55 & $5.62 \mathrm{E}-03$ & -2.37 & rs41606777 \\
\hline GNAS & $2.59 \mathrm{E}-04$ & -1.52 & $9.46 \mathrm{E}-03$ & -2.27 & rs41694067 \\
\hline CST6 & $5.04 \mathrm{E}-04$ & -1.52 & $6.63 \mathrm{E}-03$ & -2.21 & rs 29027496 \\
\hline$S R L$ & $2.89 \mathrm{E}-03$ & 1.51 & $1.05 \mathrm{E}-03$ & 2.21 & Hapmap25382-BTC-000577 \\
\hline$S L C 25 A 16$ & $7.48 \mathrm{E}-03$ & 1.52 & $1.50 \mathrm{E}-04$ & 2.31 & rs41655339 \\
\hline MRPL12 & $6.69 \mathrm{E}-03$ & 1.53 & $8.58 \mathrm{E}-03$ & 2.27 & rs41636878 \\
\hline$E I F 4 E$ & $2.24 \mathrm{E}-05$ & 1.54 & $2.11 \mathrm{E}-03$ & 2.35 & rs110927426 \\
\hline MAPRE1 & $1.44 \mathrm{E}-04$ & 1.58 & $3.23 \mathrm{E}-04$ & 2.44 & rs 29022774 \\
\hline GSPT1 & $7.42 \mathrm{E}-04$ & 1.59 & $5.60 \mathrm{E}-03$ & 2.42 & BFGL-NGS-119848 \\
\hline$C R N K L 1$ & $1.49 \mathrm{E}-04$ & 1.62 & $4.51 \mathrm{E}-03$ & 2.26 & rs41628293 \\
\hline$D D X 27$ & $1.15 \mathrm{E}-04$ & 1.63 & $4.46 \mathrm{E}-04$ & 2.33 & rs109934030 \\
\hline BCAR1 & $2.77 \mathrm{E}-03$ & 1.66 & $3.06 \mathrm{E}-05$ & 2.54 & rs 29014958 \\
\hline TRIP10 & $1.78 \mathrm{E}-04$ & 1.72 & $1.61 \mathrm{E}-04$ & 2.71 & rs110066189 \\
\hline RBM14 & $4.16 \mathrm{E}-05$ & 1.76 & $6.57 \mathrm{E}-04$ & 2.35 & rs 29027496 \\
\hline$T A R S$ & $3.15 \mathrm{E}-04$ & 1.78 & $5.80 \mathrm{E}-04$ & 2.39 & rs41578305 \\
\hline$Z N F X 1$ & $9.71 \mathrm{E}-05$ & 1.81 & $9.50 \mathrm{E}-04$ & 2.53 & rs 109934030 \\
\hline$S U L F 2$ & $1.81 \mathrm{E}-05$ & 1.89 & $3.73 \mathrm{E}-03$ & 2.33 & rs 109934030 \\
\hline B4GALT5 & $1.21 \mathrm{E}-03$ & 1.93 & $7.58 \mathrm{E}-05$ & 2.53 & rs 109934030 \\
\hline$C D C 42 S E 2$ & $3.07 \mathrm{E}-07$ & 1.99 & $6.06 \mathrm{E}-04$ & 2.37 & rs41657989 \\
\hline RSL1D1 & $1.75 \mathrm{E}-06$ & 2.00 & $1.20 \mathrm{E}-04$ & 2.65 & BFGL-NGS-119848 \\
\hline$S L C 6 A 9$ & $1.11 \mathrm{E}-05$ & 2.16 & $6.49 \mathrm{E}-03$ & 2.35 & rs41628293 \\
\hline TPM4 & $7.88 \mathrm{E}-06$ & 2.22 & $4.11 \mathrm{E}-03$ & 2.39 & rs110213141 \\
\hline$S E L P$ & $2.57 \mathrm{E}-03$ & 2.24 & $1.03 \mathrm{E}-04$ & 4.69 & rs41579632 \\
\hline$S P R Y 1$ & $1.59 \mathrm{E}-04$ & 2.27 & $8.90 \mathrm{E}-04$ & 2.32 & rs41616806 \\
\hline ANTXR2 & $2.80 \mathrm{E}-06$ & 2.41 & $3.73 \mathrm{E}-03$ & 2.35 & rs41653149 \\
\hline ACTR3 & $1.26 \mathrm{E}-07$ & 2.49 & $1.89 \mathrm{E}-05$ & 2.69 & BTA-47902 \\
\hline ZFP36L2 & $2.08 \mathrm{E}-07$ & 2.75 & $3.29 \mathrm{E}-04$ & 2.91 & rs43673004 \\
\hline$E H B P 1 L 1$ & $2.58 \mathrm{E}-07$ & 2.76 & $8.50 \mathrm{E}-04$ & 2.92 & rs 29027496 \\
\hline$P I K 3 A P 1$ & $3.10 \mathrm{E}-06$ & 3.03 & $4.64 \mathrm{E}-05$ & 2.44 & rs41650611 \\
\hline CTSZ & $1.31 \mathrm{E}-07$ & 3.10 & $1.31 \mathrm{E}-03$ & 2.25 & rs41694067 \\
\hline$P G S 1$ & $3.22 \mathrm{E}-08$ & 3.51 & $5.73 \mathrm{E}-03$ & 2.42 & rs41636878 \\
\hline$S E L L$ & $3.70 \mathrm{E}-09$ & 9.41 & $4.88 \mathrm{E}-05$ & 2.63 & rs41579632 \\
\hline CXCL6 & $3.54 \mathrm{E}-10$ & 36.81 & $6.16 \mathrm{E}-04$ & 4.01 & rs41617692 \\
\hline$E M R 1$ & $2.94 \mathrm{E}-11$ & 63.30 & $8.90 \mathrm{E}-05$ & 6.02 & rs110066189 \\
\hline CXCL8 & $1.02 \mathrm{E}-09$ & 82.99 & $1.33 \mathrm{E}-04$ & 5.64 & rs41617692 \\
\hline CXCL2 & $2.02 \mathrm{E}-09$ & 94.97 & $4.47 \mathrm{E}-04$ & 3.08 & rs41617692 \\
\hline
\end{tabular}




\subsection{Gene Function and Pathway Analysis by IPA}

The two separate and one combined gene lists were each analysed using IPA to mine the relationships via grouping DEG into known functions, pathways, and networks. Information in IPA is based primarily on human and rodent studies but is still relevant to the cow. The fold change in response to $E$. coli infection and the associated P-value data were used for the IPA analysis. All the DEGs were included without fold-change cut-off. Most genes were mapped to their corresponding gene object in the IPA Knowledge Base considering both the direct and indirect relationship. Several analyses were run including Functional Analysis, Network Generation, Canonical Pathway Analysis and Upstream Regulators Effects Analysis.Fisher's exact test with BH-FDR control at $\mathrm{P}<0.05$ was used to determine the biological functions and canonical pathways significantly altered by the treatment. These analyses integrate data from a variety of experimental platforms and provide insight into the most likely molecular and chemical interactions between the DEG which have been identified.

\section{Results}

\subsection{Differential Expression of Genes Following Intra-Mammary Infection with E. coli or $S$, uberis}

The comparison of the list of genes identified by expression microarrays at 20 - $24 \mathrm{~h}$ after intra-mammary infection with either $E$. coli or $S$. uberis yielded 505 common genes with a significant fold change $(>1.5)$ in a similar direction and p-values $<0.001$. Of these, 348 genes were up-regulated and 157 genes were down-regulated (Table S1). When these genes were imported into IPA, 504 genes were mapped based on annotation to human or mouse within the IPA Knowledge. The top ten most significant signalling pathways are listed in Table S2. These included IL-10 and IL-6, glucocorticoid- and ephrin-receptor signalling and activation of LXR/RXR and PPAR $\alpha / R X R \alpha$. The primary function analysis is given in Table S3. As expected, the most significant functions were associated with inflammatory responses, connective tissue disorders and immune cell trafficking and cell death, survival, proliferation and movement.

\subsection{Candidate Genes from Mastitis Association Studies on Different Dairy Cow Populations}

Based on the seven different GWAS studies listed in Table 1 that looked for associations with SCC, a total of 94 significant SNPs were identified (Table S4). One SNP (BTB-00495251) could not be found in the NCBI SNP database, so 93 were used in this study. These SNPs were distributed on most chromosomes but with higher density attributed to BTA6 $(n=27)$, BTA13 $(n=11)$, BTA20 $(n=9)$, BTA2 $(n=7)$, BTA14 $(n=7)$ and BTA7 $(\mathrm{n}=5)$. Four SNPs located in BTA6 were selected in 2 different populations (rs41588957, rs110707460, rs108988814, rs42766480). The nearest genes to these were TMPRSS11F, DCK, GC and NPFFR2 respectively.

A total of 1635 protein-coding genes were located within $2 \mathrm{Mbp}$ of the 93 significant SNPs (Table S4). These were input for IPA analysis and 1568 of them were mapped and used for further analysis. Function analysis indicated that 209 genes were related with infectious disease and 73 were involved in inflammatory responses including the genes NFKB1 and CXCR2. Primary function analysis of Molecular and Cellular Functions showed that 76 genes were involved in Cell-to-Cell Signalling and Interaction and 76 genes were related to Cellular Movement. At the Physiological System Development and Function level, 181 genes were involved in Haematological System Development and Function and 53 in Immune Cell Trafficking (Table S5).The top 10 canonical pathways included both agranulocyte (mononuclear leukocytes) and granulocyte adhesion and diapedesis (Table S6).

\subsection{Common Genes from Both the Gene Expression and SCC Association Studies}

When the gene lists from the two sources were compared (Figure 1), 48 common genes emerged. Those genes located around the significant SNPs had similar changes in expression in response to intra-mammary infection caused by either E. coli or $S$. uberis. Of these genes, 30 were located within $1 \mathrm{Mbp}$ around the significant SNPs (Table 2). These included 5 genes of particular interest, FABP4, SELE, SELP, CXCL2 and CXCL6, since some other genes with similar function from the same families are located in close chromosome areas (Table 3 ).

Seven genes (EIF4E, HSF1, PIK3AP1, PRMT1, BCAR1, CXCL8, CXCL2) were annotated as having a role in the innate immune response by the innateDB database (http://www.innatedb.com). IPA function analysis indi- 


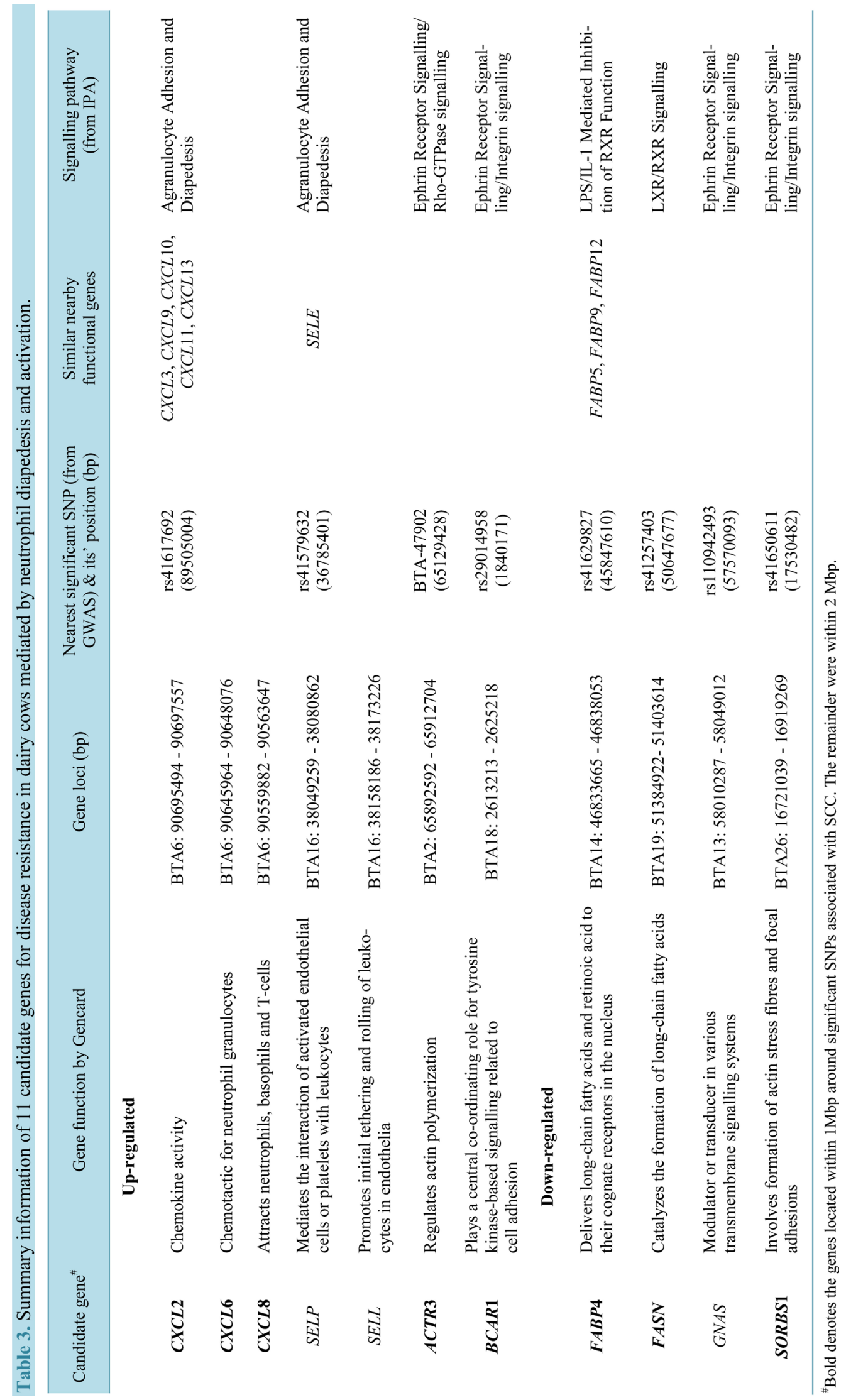


cated that 13 genes (CST6, CXCL2, CXCL6, CXCL8, EMR1, FABP4, HSF1, SELL, SELP, CTSZ, SORBS, GNAS, $Z F P 36 L 2)$ were clustered into inflammatory responses. Of these 18 genes with a role in innate immunity and inflammation, 11 were mapped in Network 1 and/or the signalling pathways Granulocyte Adhesion and Diapedesis and Ephrin Receptor Signalling. This included seven genes located within 1 Mbp around the significant SNPs (Table 3).

When this final list of 48 genes was analysed by IPA the results remained similar to those initially detected from the 504 genes with common responses to E. coli and S. uberis (Table 4). Inflammatory responses were

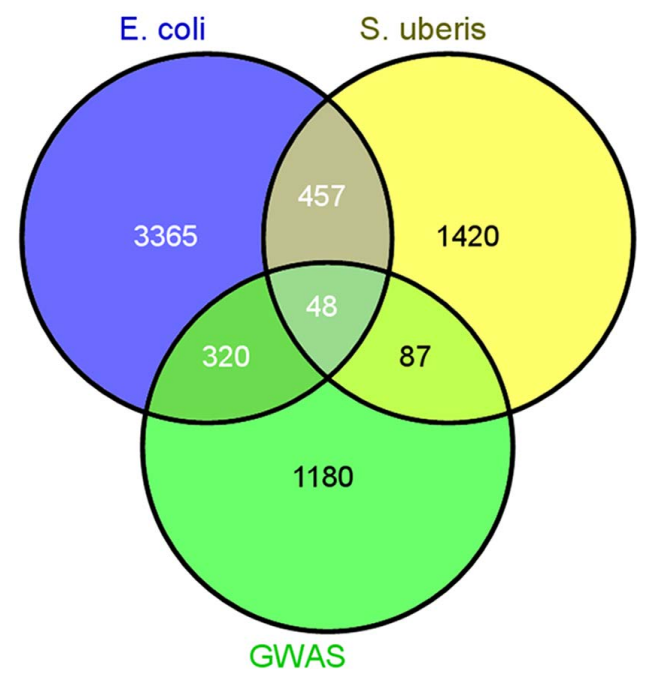

Figure 1. Venn diagram showing common genes associated with responses to mastitis in dairy cows. Candidate genes were identified using three different experimental approaches. Differential gene expression from mammary tissue infected with (a) E. coli (blue) [17] or (b) S. uberis (yellow) [18]. (c) A combined set of candidate genes set from seven different association studies with SCC (green) (see Table 1 for references). A common set of 48 genes existed among the three different gene sets.

Table 4. IPA function analysis on the 48 candidate genes associated with mastitis in dairy cows in the studies of both gene expression and GWAS*.

\begin{tabular}{cc}
\hline Name & Molecules \\
Diseases and Disorders & 13 \\
Inflammatory Response & 9 \\
Dermatological Diseases and Conditions & 23 \\
Organismal Injury and Abnormalities & 28 \\
Gastrointestinal Disease & 14 \\
Hepatic System Disease & 17 \\
Molecular and Cellular Functions & 13 \\
Cellular Movement & 9 \\
Cell-To-Cell Signalling and Interaction & 24 \\
Cell Cycle & 18 \\
Cellular Development & 16 \\
Cell Death and Survival & 9 \\
Physiological System Development and Function & 20 \\
Hematological System Development and Function & 16 \\
Immune Cell Trafficking & 3 \\
Tissue Development & Tissue Morphology \\
Cell-mediated Immune Response & \\
\hline
\end{tabular}

\footnotetext{
${ }^{*}$ All functions were identified using a Fisher's exact test with BH-FDR control at $\mathrm{P}<0.05$.
} 
identified as the most significant in the Diseases and Disorders category, and Cellular movement, Cell-to-cell signalling and interaction, Cell death and survival and Cellular growth and proliferation were all important under the Molecular and Cellular Functions category. Haematological system development and function and Immune cell trafficking were the most significant under physiological system development and function. Table $\mathbf{5}$ shows the top five canonical pathways. These included Granulocyte adhesion and diapedesis and Ephrin receptor signalling.

The physiological responses triggered by Granulocyte adhesion and diapedesis are illustrated in Figure 2. This shows that the neutrophil recruitment cascade is initiated by exposure of macrophages and epithelial cells

Table 5. Top canonical pathways from IPA on the 48 candidate genes associated with mastitis in dairy cows which were common in the studies of both gene expression and GWAS*

\begin{tabular}{|c|c|}
\hline Top canonical pathways $^{+}$ & Changed genes found in both datasets ${ }^{\#}$ \\
\hline Granulocyte Adhesion and Diapedesis & CXCL8, SELL, SELP, CXCL2, CXCL6 \\
\hline Agranulocyte Adhesion and Diapedesis & CXCL8, SELL, SELP, CXCL2, CXCL6 \\
\hline Role of IL-17A in Psoriasis & CXCL8, CXCL6 \\
\hline Ephrin Receptor Signalling & ACTR3, BCAR1, GNAS, SORBS1 \\
\hline Stearate Biosynthesis I (Animals) & $\underline{B D H 2}, \underline{F A S N}$ \\
\hline
\end{tabular}

${ }^{+}$All pathways were identified using a Fisher's exact test with BH-FDR control at $\mathrm{P}<0.05$.

\#Bold denotes up-regulation and underscore denotes down-regulation of the gene.

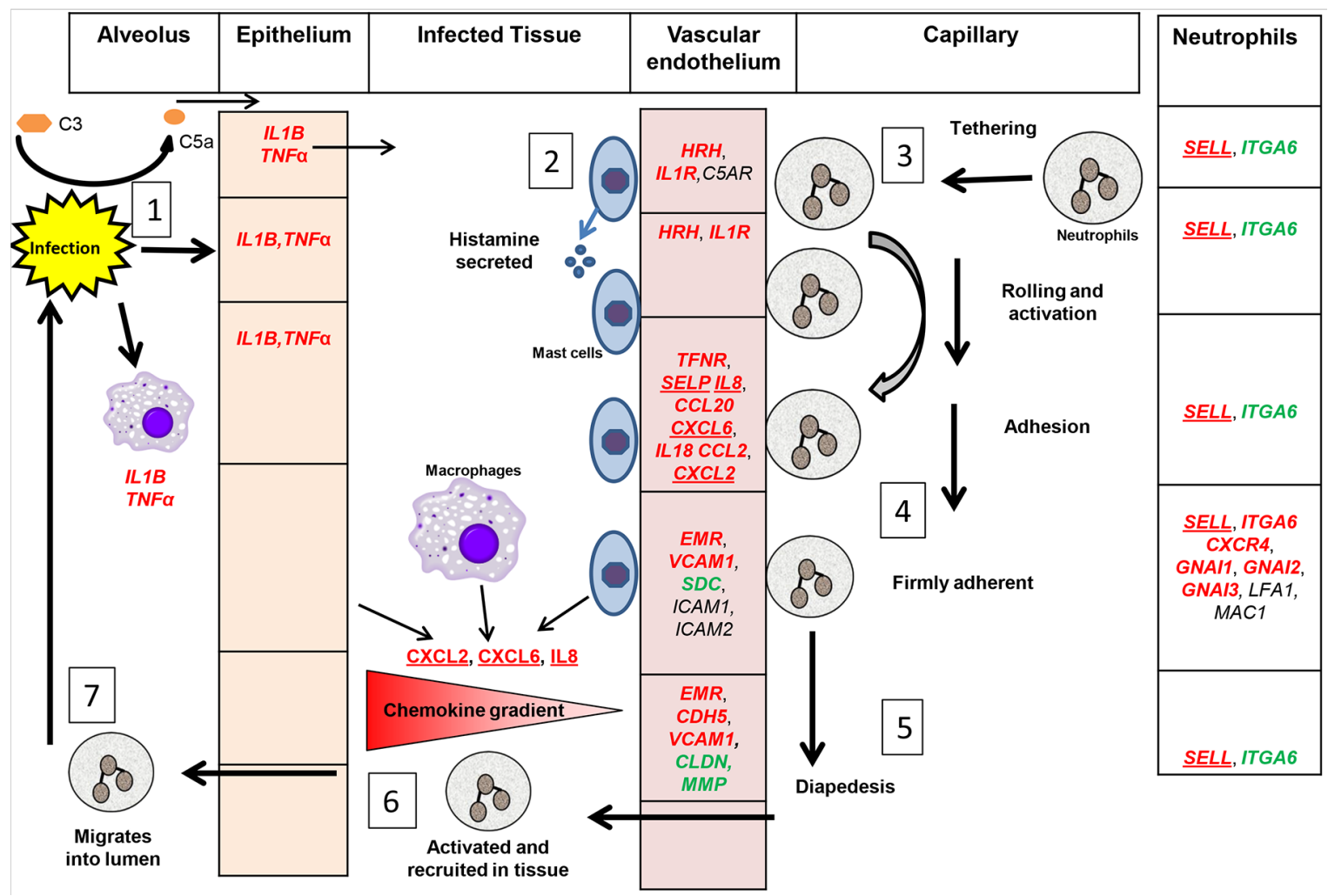

Figure 2. Summary diagram showing neutrophil adhesion and diapedesissignalling following intra-mammary infection. The 505 common DEGs following infection with either $S$. uberis or E. coli were mapped in IPA. Red denotes gene up-regulation and green denotes gene down-regulation. Underscore denotes genes located around significant SNPs. ((1), (2)) initiation of the neutrophil recruitment cascade by exposure of macrophages and epithelial cells to LPS or LTA inducing cytokine and complement C5a up-regulation together with histamine release from mast cells. (3) Tethering of neutrophils to the endothelium followed by rolling and activation. (4) Integrins binding to their ligands make firm adhesion between neutrophils and endothelial cells. (5) Diapedesis: neutrophils crawl to an endothelial junction then transmigrate using multiple adhesion molecules. (6) Emigrated neutrophils are recruited by moving up a new chemotactic gradient then migrating into the lumen of the mammary gland through the epithelium. (7) Activated neutrophils then play a key role in pathogen elimination. 
to LPS (from Gram-negative bacteria) or lipoteichoic acid (LTA, from Gram-positive bacteria) that both induce expression of TNF $\alpha$ and IL1B. Complement C5a is also increased during infection and induces histamine release from mast cells [38]. TNF $\alpha, \mathrm{IL} 1 \beta, \mathrm{C} 5 \mathrm{a}$ and histamine interact with their respective receptors on vascular endothelial cells and trigger their response [39] [40]. There is increased expression of the adhesion molecule P-selectin (SELP) following both E. Coli and S. uberis infection and during E. coli infection E-selectin (SELE) is also increased. Selectins binds their glycosylated ligands, including P-selectin glycoprotein ligand 1 (PSGL1) on the neutrophils, leading to tethering and subsequent rolling. L-selectin expression by circulating neutrophils may facilitate their secondary tethering to an already rolling neutrophil. The rolling of neutrophils facilitates their contact with the chemokine-decorated endothelium to induce activation of integrins (LFA1, MAC1). Activated integrins present higher affinity for their ligands, including immunoglobulin-like cell adhesion molecules (CAMs) [41]. Integrins binding to their ligands make firm adhesion between neutrophils and endothelial cells. Note that the crucial integrin LFA1 increases significantly in E. coli infection but not in S. uberis [16] [17]. Neutrophils then crawl to an endothelial junction by co-action of blood shear and adhesion before diapedesis (transmigration) using multiple adhesion molecules [42]. Emigrated neutrophils move up a new chemotactic gradient then migrate into the lumen of the mammary gland through the epithelium where they play a key role in pathogen elimination [43].

The physiological responses triggered by Ephrin receptor signalling are illustrated in Figure 3. Cytokines such as TNF $\alpha$ are released into the tissue where signalling via ephrin receptors causes changes in vascular endothelial cells promoting leukocytes to become adherent. This leads to cytoskeleton reorganization and neutrophil migration mainly mediated by the Rho family of small GTPases (RhoA, Cdc42, Rac) and CAS [44] [45]. Such a process would be essential in the recruitment of leucocytes into infected mammary tissue.

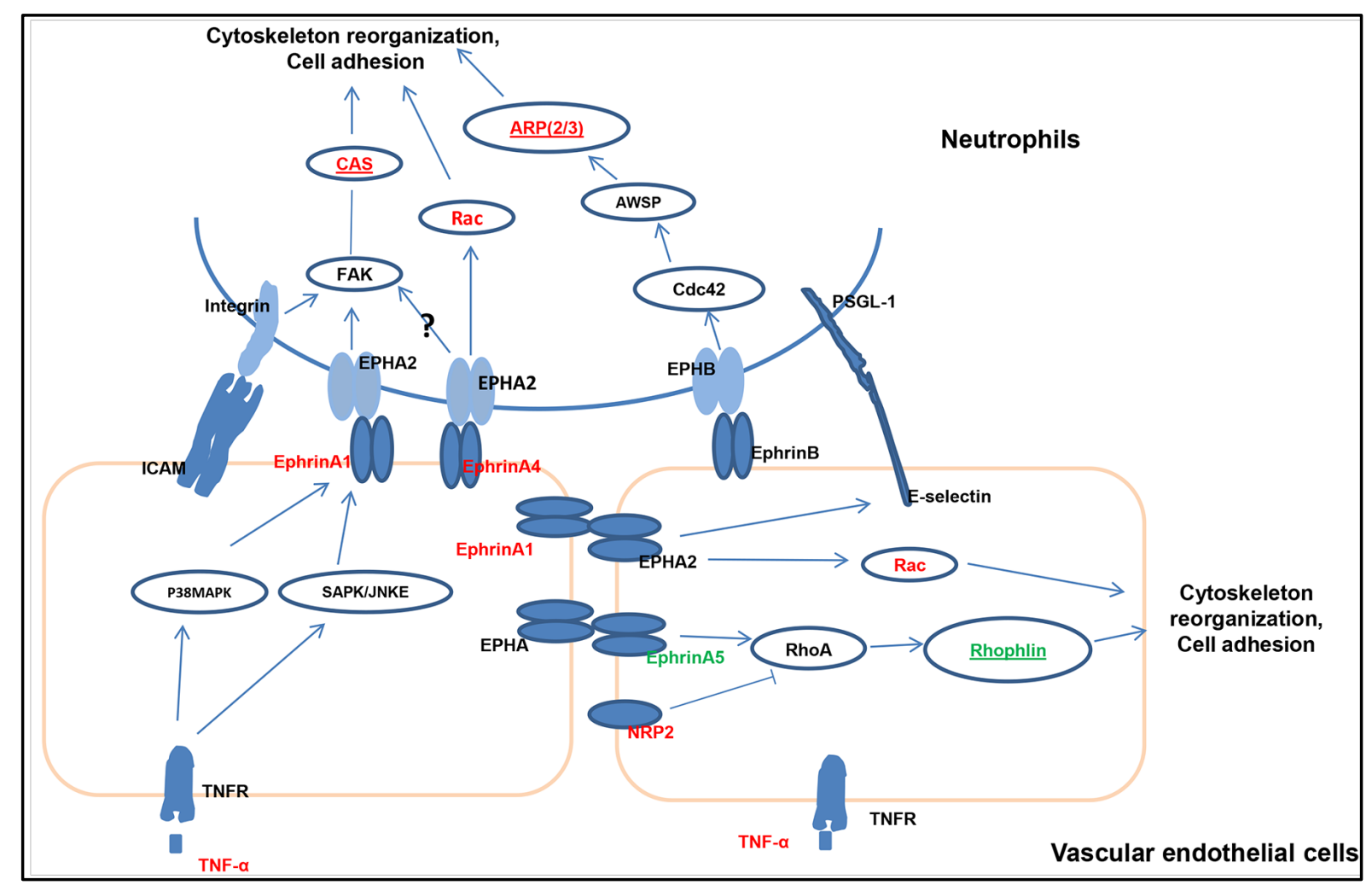

Figure 3. Summary diagram showing ephrin receptor signalling in vascular endothelial cells and neutrophils after their adhesion. The genes shown were among the common 505 DEGs following intra-mammary infection with either $S$. uberis or $E$. coli. Red denotes gene up-regulation and green denotes gene down-regulation. Underscore denotes genes located around significant SNPs. Ephrin receptor signalling changes in vascular endothelial cells in response to cytokines (e.g. TNF $\alpha$ ) being released into the tissue and leukocytes becoming adherent to the endothelial cells. This leads to cytoskeleton reorganization and neutrophil migration mainly mediated by Rho family of small GTPases (RhoA, Cdc42, Rac) and CAS). Leukocyte migration into the mammary gland is a crucial step in the immune response. 
Upstream Regulator Effect Analysis of the 48 candidate genes in IPA presented the cytokine TNF $\alpha$ as the one important regulator which significantly influences chemotaxis of neutrophils and their predicted activation though the transcription factor EGR1. This agrees with the finding that these two genes were both significantly up-regulated after infection by $E$. coli or $S$. uberis (Table S1). EGR1 in turn causes up-regulation of CXCL2, CXCL6 and CXCL8.

The 48 common genes which were identified from both the gene expression and GWAS studies were all contained in four main networks as revealed by IPA analysis (Table 6). The two most significant networks with scores $>37$ were involved in: 1) Cancer, Organismal Survival, Cellular Movement and 2) Haematological System Development and Function, Humoral Immune Response, Lymphoid Tissue Structure and Development. Most of the genes annotated as innate immunity by GO terms, for example CXCL2, CXCL6, CXCL8, SELL, SELP and FABP4, were included in Network 1(Figure S1).

Several of the analytical approaches indicated an important role for lipid signalling, specifically long chain fatty acids (LCFA). FASN and FABP4 were the two most highly down-regulated genes from the expression studies (Table 2). Both these genes are involved in mammary gland lipid metabolism and are associated with SNPs identified from the GWAS studies (Table 3). They also both appear in Network 1 (Table 6). The IPA analysis of the 504 genes common to the expression studies listed LXR/RXR activation and $\operatorname{PPAR} \alpha / \operatorname{RXR} \alpha$ activation in the top 10 signalling pathways (Table S2). These three nuclear receptors are all known to play a role in the regulation of inflammation and in fasting mediated changes in metabolism involved in switching from utilization of glucose to LCFAs as the main source of energy [46].

\section{Discussion}

\subsection{Experimental Approach Used}

In the present study we have used the combined approach of examining previous results from both differential gene expression analysis and GWAS studies to identify the key pathways and candidate genes which potentially confer a different degree of genetic resistance to mastitis caused by bacterial pathogens in dairy cows. While this approach may be somewhat controversial, we believe that it has two main benefits. Firstly it helps to select those genes which contribute to a generalised response against all species/strains of bacteria which can cause mastitis from among the many hundreds of genes which are up- or down-regulated following a bacterial challenge. Secondly it aids in the identification of the gene(s) most likely to be causative for a QTL when examining the relevant chromosomal region. Our analysis has suggested that there are sequence variations in genes which control

Table 6. Top 4 IPA networks involving the 48 genes selected in the studies of both gene expression and GWAS.

\begin{tabular}{|c|c|c|c|}
\hline ID & Molecules in network $^{\#}$ & Score & Top diseases and functions \\
\hline 1 & $\begin{array}{l}\text { Alpha Actinin, Alpha catenin, ANTXR2, BCAR1, CBFA2T3, Cg, Collagen type } \\
\text { IV, Collagen(s), CXCL2, CXCL6, CXCL8, EIF4E,EMX2,ERK1/2, FABP4, } \\
\text { FASN, Growth hormone, } \underline{H S F 1}, \mathrm{Hsp} 27, \text { CXCL8r, LDL, Mek, N-cor, NOV,Nr1h, } \\
\text { Pdgf (complex), PDGF BB, Rock, SELL, SELP, } \underline{\text { SORBS1 }}, \text { Sos, SPRY1, SULF2, } \\
\text { Tnf (family) }\end{array}$ & 40 & $\begin{array}{l}\text { Cancer, Organismal Survival, } \\
\text { Cellular Movement }\end{array}$ \\
\hline 2 & $\begin{array}{l}\text { ACKR3, ACSS2, AIMP1, ALDH18A1, BDH2, BRD4, CRNKL1, CSF } 2 R B, \\
\text { DDX27, DNAJA3, EHBP1L1, FAM110A, GRB2, GSN, GSPT1, IRF6, KRT14, } \\
\text { KRT17, LAT2, MAPRE1, MAVS, MRPL12, PGS1, PIK } 3 C D, P T P R E, P T P R J, \\
\text { RBM14, RHPN2, RSL1D1, S100A6, SH3BP2, TARS, TPM1, TPM4, UBC }\end{array}$ & 37 & $\begin{array}{l}\text { Hematological System Devel- } \\
\text { opment and Function, Humoral } \\
\text { Immune Response, Lymphoid } \\
\text { Tissue Structure and Develop- } \\
\text { ment }\end{array}$ \\
\hline 3 & $\begin{array}{l}\text { ACTR3, ADCY, Akt, AMPK, Ap1, B4GALT5, BCR (complex), CD3, } \\
\text { CDC42SE2, Creb, CTSZ, ERK, estrogen receptor, GNAS, Histone h3, Ige, IgG, } \\
\text { IL1, IL12 (complex), Immunoglobulin, Insulin, Interferon alpha, Mapk, Nfat } \\
\text { (family), P38 MAPK, p85 (pik3r), PIJK (complex), PIK3AP1, Pka, } \\
\text { Pro-inflammatory Cytokine, Ras, TCR, TRIP10, Vegf, ZNFX1 }\end{array}$ & 14 & $\begin{array}{l}\text { Carbohydrate Metabolism, Small } \\
\text { Molecule Biochemistry, } \\
\text { Cell-To-Cell Signalling and } \\
\text { Interaction }\end{array}$ \\
\hline 4 & $\begin{array}{l}A P O E, C 5 A R 2, C A R D 9 \text {, chemokine, } C k 2, C L E C 4 E, C S T 6 \text {, dihydrotestosterone, } \\
\text { EMR1, FFAR4, FAK, G protein, Gsk3, Hdac, hemoglobin, hydroquinone, IL } 36 G \text {, } \\
\text { II3r, Jnk, KSR2, NFkB (complex), P2RY6, PELI2, Pik3r, PIK } 3 R 5, P k c(s), \mathrm{RNA} \\
\text { polymerase II, ROGDI, S1PR2, S1PR3, SIGIRR, SLC25A16, SLC6A9, SRL, } \\
\text { ZFP36L2 }\end{array}$ & 13 & $\begin{array}{l}\text { Cell Death and Survival, Cellular } \\
\text { Compromise, Neurological Dis- } \\
\text { ease }\end{array}$ \\
\hline
\end{tabular}

${ }^{*}$ Bold denotes up-regulation and underscore denotes down-regulation of the gene. 
the movement of leukocytes, especially neutrophils, from blood to the infected mammary tissue and milk. The initial up-regulation of TNF $\alpha$ in response to infection induces expression of the transcription factor EGR1 [47] which plays a key role in regulating the subsequent innate immune response by in turn increasing expression of the chemokines CXCL8, CXCL2 and CXCL6. Both Gram-positive and Gram-negative bacteria can induce EGR1 expression in the mammary gland (Table S1). In the original gene expression studies analysed [17] [18], EGR1 expression was increased to a similar extent at 20 - $24 \mathrm{~h}$ following E. coli or S. uberis infection (3.05- and 2.53fold respectively). However the downstream responses to the two pathogens were much more extreme following E. coli [17] with increases in CXCL2, CXCL6 and CXCL8 ranging from 37- to 95-fold whereas the same chemokine genes only increased by 3-5- to 6-fold following exposure to S. uberis [18] (Table S1).

Macrophages are the major cell type found in the milk of healthy bovine mammary glands while during infection an influx of neutrophils enters the infected site and plays a key role in the control of most mastitis pathogens [48]. IPA analysis showed that two pathways, Granulocyte Adhesion and Diapedesis Signalling and Ephrin Receptor Signalling seem particularly important. Granulocyte Adhesion and Diapedesis Signalling is crucial for granulocyte movement from blood vessels via the blood-udder barrier into the udder tissue [49] whereas Ephrin receptor signalling is important for mammary gland development and maintenance of function [50]. In addition, changes to lipid metabolism and/or lipid signalling through nuclear receptors are clearly also involved [11] [18]. Therefore only these three aspects of an immune response are discussed further here.

\subsection{Granulocyte Adhesion and Diapedesis Signalling}

Neutrophils derived from blood must experience a multistep process to reach the site of inflammation, including capture, rolling, activation and slow rolling, arrest, adhesion strengthening, intra luminal crawling followed by paracellular and transcellular migration [51]. Many of the DEGs identified in our study are known to facilitate this process (Figure 2). It is initiated by efficient interaction between selectins and their ligands on endothelial cells and neutrophils [52]. Increased $\mathrm{TNF} \alpha, \operatorname{IL} 1 \beta, \mathrm{C} 5 \mathrm{a}$ and histamine release could happen at a very early phase of mammary infection [53] [54]. These ligands then interact with their respective receptors TFNR, IL1R and HRH1 on the vascular endothelial cells, whose expression is also up-regulated. Such stimulation results in expression of the adhesion molecule P-selectin and VCAMs [55] [56]. P-selectin then interacts with P-selectin glycoprotein ligand 1 (PSGL-1) on the surface of neutrophils which makes them roll [57] and also primes neutrophil integrin activation for neutrophil adhesion during inflammation [58]. Integrin activation and normal function is crucial for neutrophils to develop firm adhesion after rolling. The key importance of integrinsin this process is shown by the development of the disease bovine leukocyte adhesion deficiency (BLAD) in Holstein cattle with a genetic deficiency of CD18, the $\beta 2$-integrin chain [59].

L-Selectin gene expression was also significantly induced during infection. Increased L-selectin expression by circulating neutrophils could facilitate their secondary tethering to an already rolling neutrophil through attaching the PSGL-1 [60] [61]. PSGL-1 and L-selectin on the same neutrophil can interact and form a complex which is necessary to trigger integrin activation [62]. Neutrophil function was clearly associated with peripartum metritis and mastitis susceptibility [63], while glucocorticoid induced down-regulation of neutrophil L-selectin is regarded as an important reason for neutrophil dysfunction during the peripartum period [64].

The bovine selectin genes (SELP, SELL, SELE) are located near each other in the putative mastitis-related QTL screened by Sodeland et al. [29]. The QTL peak location is at $44.91 \mathrm{cM}$ on BTA 16 . In comparison between the two gene expression studies, SELL was up-regulated to a greater extent than SELP following $E$. coli infection (9.41- v 2.24-fold) [17] whereas the reverse was true for S. uberis (2.63- v 4.69-fold) [18]. The fold changes in both studies were, however, of a similar order of magnitude. This putative mastitis-related region was also reported in other QTL studies [65] [66]. Furthermore, we recently found that these three genes have a high degree of polymorphism by sequencing a population of UK Holstein cows (D.C. Wathes et al., unpublished data). Further study will focus on determining whether these genetic variations are indeed associated with mastitis incidence rates in dairy cows.

Another important chromosomal region was located around $90 \mathrm{Mb}$ on BTA6 containing the three chemokine genes $C X C L 8, C X C L 2$ and $C X C L 6$. This area has been reported to show a significant relationship with mastitis in several different dairy cow populations [28] [29] [32]. All three chemokines signal via CXCR2 to activate neutrophils and subsequently promote their adhesion to the endothelium, before guiding them to move to sites of infection [67] [68]. CXCL8, released by epithelial cells, endothelial cells and macrophages is crucial for neu- 
trophil activation and recruitment and has been shown to have a significant association with dairy cow mastitis [69] [70]. CXCL2, released by mast cells and macrophages, is important to control the early stage of neutrophil recruitment during tissue inflammation [71]. Indeed, a recent gene expression study revealed that $C X C L 2$ was among the few significantly changed genes after experimental intra-mammary infection with $E$. coli in lactating dairy cows treated with either the antibiotic cefapirin alone, in combination with the corticosteroid prednisolone or left untreated [72]. CXCL6 released by macrophages and epithelial cells exerts neutrophil-activating and angiogenic activities [73]. Besides, it also contributes to direct antibacterial activity during localized infection [74]. Together these different studies add weight to the key importance of CXCL2 and CXCR2 in influencing the ability of the mammary gland to overcome bacterial infections successfully.

\subsection{Ephrin Receptor Signalling Pathway and Its Role in Cytoskeletal Re-Organization}

Ephrin receptors constitute the largest family of tyrosine kinase receptors. They may be partly responsible for the phenotypic changes to the vascular endothelium in inflammation, which allows fluid and inflamed cells to pass from the vascular space into the interstitial tissues (Figure 3) [75]. During infection, many cytokines are released into the mammary gland causing changed contact and signal transmission among leukocytes and vascular endothelial cells. Genes identified from our expression and association study indicated that this ephrin receptor signal can modify the cell's cytoskeleton and adhesion when leukocytes and vascular endothelial cell attract each other.

A number of genes affecting ephrin receptor signalling (TNF $\alpha, I L 1 \beta$, EphrinA1, SELE, VCAM-1, BCAR 1 and $A C T R 3)$ were all up-regulated after intra-mammary infection with $E$. coli [17]. The cascade activation of the ephrin receptor signalling process seems clear. $T N F \alpha$ is the key cytokine increased sharply by $E$. coli, which then induces EphrinA1 in endothelial cells mediated through both p38MAPK and SAPK/JNKE pathways [76]. EphA2 activation by enhanced ephrinA1 stimulates leukocyte adhesion through: 1) inducing pro-inflammatory gene expression (SELE, VCAM-1) [77]; 2) increasing vascular permeability by moving the tight and adherens junction proteins VE-cadherin and claudin-5 away from the cell surface [78]; 3) activating FAK (the protein tyrosine kinase PTK 2) and Cas (the BCAR1 gene product) to regulate the actin cytoskeleton and cell migration [44] [79] [80]. VCAM-1 also activates Rac1 and leads to loosening of adherens junctions [81] and induces cytoskeletal re-organization. In contrast EhrinA1 and SELE did not show increased expression after S. uberis intra-mammary infection [18] but instead only EphrinA4 was increased. One possible reason is that S. uberis infection induced a lower level of TNF $\alpha$ at an earlier time point that the $20 \mathrm{~h}$ used in this study [82]. Discrepant ephrin receptor signalling in response to different pathogens may cause a different clinical response: this needs to be confirmed by further study.

A significant increase in NRP2 and decrease in EphrinA5 after both types of bacterial infection [17] [18] indicated an inhibition of RhoA function [83] [84]. RhoA inactivation regulates cell migration by promoting membrane protrusion and polarity [85]. Two other important Rho-GTPases Rac1 and Cdc42 were activated during infection, maybe through EPHB receptor signalling: these in turn affect the actin polymerizing complex ARP2/3 (product of the $A C T R 3$ gene) whose activation occurs through WAVE and WASP [45] [86]. ARP2/3 is crucial for cell migration by regulating the actin cytoskeleton [87] [88]. On the other hand, Rac1 and Cdc 42 activation and RhoA inactivation can also stabilize actin and help maintain endothelial cell integrity [89], which indicated that small GTPases (RhoA, Rac1, Cdc42) play an important role to maintain balance between endothelial barrier-stabilizing and increased permeability during inflammation.

\subsection{Fatty Acid Metabolism and Control of Neutrophil Diapedesis}

When dairy cows suffer mastitis, many genes involved in mammary gland lipid metabolism are down-regulated including FASN, SCP1, ACC, LPL, FABP3 and FABP4. Indeed, the majority of genes down-regulated by $>1.5$ fold following $S$. uberis infection have been associated with lipid metabolism [18]. Of these, the two genes highlighted from the GWAS studies due to their associations with SCC were FASN and FABP4 [29] [33]. The chromosome area near FABP4 including the tandem FABP family of genes (Table 2) is thus of great interest. FABP4 belongs to a family of intra-cellular lipid chaperones which bind saturated and unsaturated fatty acids, eicosanoids and other lipids with high affinity. They then transport them to specific organelles including the mitochondria for lipid oxidation, the nucleus for transcriptional regulation, theendoplasmic reticulum for membrane synthesis or lipid droplets for storage [90]. FABPs also play a role in the production of lipid mediators in- 
cluding lipoxins (LXs), resolvins and protectins which have anti-inflammatory and pro-resolution properties [91] [92]. Both FABP3 and FABP4 are highly expressed in bovine mammary glands and FABP4 haplotypes have been associated with altering the proportions of saturated to unsaturated fatty acids in milk [93]. In human medicine FABP4 is attracting increasing attention as a clinical marker of metabolic disease involving insulin resistance and inflammation [90].

FASN encodes fatty acid synthase, which plays a central role in de novo lipogenesis in mammals. Polymorphisms in the bovine $F A S N$ gene also contribute to variations in milk-fat content and influence the milk fat globule composition [94]. LXRs regulate $F A S N$ expression through direct interaction with the FAS promoter as well as through an indirect mechanism of activation of SREBP-1c expression [95]. The milk fat globule membrane contains proteins including MFG-EGF8, which may mediate macrophage phagocytosis of apoptotic cells [96].

It is not yet clear why bacterial infection causes such a major shut-down in milk production including milk fat synthesis. One possibility would be to minimize energy loss into milk so sparing it for an effective immune response [97]. In mammary tumours, restricted access to fatty acids reduces tumour proliferation as they are essential for providing energy and for growth of the cell membrane [98]. Non-esterified fatty acids (NEFAs) and various fatty acid metabolites can also bind to and regulate the activity of PPARs, LXRs and HNF-4 [99]. A previous review indicated that FABP could combine with LTA (Leukotriene A) and stabilize it, which is helpful for the transport and transcellular biosynthesis of lipid mediators such as lipoxin A4 [100]. IPA analysis indicated that the LPS/IL1 mediated inhibition of RXR function may weaken two other metabolic signalling pathways involving LXR/RXR and PPAR/RXR. Since activation of PPAR/RXR by fatty acids can reduce inflammatory responses by many mechanisms [101], inhibition of RXR function may enhance the inflammation signal in the early stages of infection. On the other hand, direct activation of lipoxin A4 receptor (ALX) by the lipid mediator LXA4 leads to cell-type-specific signalling events that stop neutrophil migration while at the same time stimulating macrophage activation [91]. Activated macrophages enhanced phagocytosis of apoptotic neutrophils in tissue, which can weaken the IL23/IL17/G-CSF cascade for neutrophil production from bone marrow [102]. Lipid mediators may thus function as a feedback system to control an excess influx of neutrophils and so avoid tissue damage. Further work is clearly required to determine exactly how polymorphisms in FABP4 and $F A S N$ contribute to a reduction in SCC in cows.

\section{Conclusion}

Through integrated analysis, this study has suggested that some common innate immune signalling pathways are involved in the response of the bovine mammary gland to different types of bacterial infection. These included granulocyte adhesion and diapedesis, ephrin receptor signalling, RhoA signalling and LPS/IL1 mediated inhibition of RXR function. These signalling pathways comprised a network regulating the activity of leukocytes especially neutrophils. Many promising genes in this network are known to control a series of neutrophil functions including adhesion (SELP, SELL), diapedsis (BCAR1, ACTR3), movement (CXCL2, CXCL6, CXCL8) and control $(F A B P, F A S N)$. Polymorphisms in these genes may thus possibly contribute to differences in disease resistance. When dairy cows suffer a mammary gland infection, the population of neutrophils in the milk and mammary gland increases significantly. Neutrophils play key roles against pathogens via diapedesis, bacterial killing and apoptosis before a final return to homeostasis. Dysfunction of each step may cause greater damage to the mammary gland. Therefore, the timely and properly controlled movement of leukocytes to infection loci seems particularly important in achieving a good balance between pathogen elimination and excessive tissue damage.

\section{Acknowledgements}

This study was supported by EU FP7 projects (PIIF-GA-2012-328205, and PIIFR-GA-2012-912205) and grants from the Chinese government (2014030709020305) and the Huanghe Yingcai Project.

\section{References}

[1] Kossaibati, M.A. and Esslemont, R.J. (2000) The Cost of Production Diseases in Dairy Herds in England. The Veterinary Journal, 154, 41-51. http://dx.doi.org/10.1016/S1090-0233(05)80007-3

[2] Bertrand, J.A., Berger, P.J., Freeman, A.E. and Kelley, D.H. (1985) Profitability in Daughters of High versus Average Holstein Sires Selected for Milk-Yield of Daughters. Journal of Dairy Science, 68, 2287-2294. 
http://dx.doi.org/10.3168/jds.S0022-0302(85)81101-2

[3] Oltenacu, P. and Broom, D. (2010) The Impact of Genetic Selection for Increased Milk Yield on the Welfare of Dairy Cows. Animal Welfare, 19, 39-49.

[4] Geary, U., Lopez-Villalobos, N., Begley, N., Mccoy, F., O’Brien B, et al. (2012) Estimating the Effect of Mastitis on the Profitability of Irish Dairy Farms. Journal of Dairy Science, 95, 3662-3673. http://dx.doi.org/10.3168/jds.2011-4863

[5] Pyorala, S. (2002) New Strategies to Prevent Mastitis. Reproduction in Domestic Animals, 37, 211-216. http://dx.doi.org/10.1046/j.1439-0531.2002.00378.x

[6] Pyorala, S.H.K. and Pyorala, E.O. (1998) Efficacy of Parenteral Administration of Three Antimicrobial Agents in Treatment of Clinical Mastitis in Lactating Cows: 487 Cases (1989-1995). Journal of the American Veterinary Medical Association, 212, 407-412.

[7] Stanton, T.B. (2013) A Call for Antibiotic Alternatives Research. Trends in Microbiology, 21, 111-113. http://dx.doi.org/10.1016/j.tim.2012.11.002

[8] Burvenich, C., Van Merris, V., Mehrzad, J., Diez-Fraile, A. and Duchateau, L. (2003) Severity of E. coli Mastitis Is Mainly Determined by Cow Factors. Veterinary Research, 34, 521-564. http://dx.doi.org/10.1051/vetres:2003023

[9] Pullinger, G.D., Coffey, T.J., Maiden, M.C. and Leigh, J.A. (2007) Multilocus-Sequence Typing Analysis Reveals Similar Populations of Streptococcus uberis Are Responsible for Bovine Intramammary Infections of Short and Long Duration. Veterinary Microbiology, 119, 194-204. http://dx.doi.org/10.1016/j.vetmic.2006.08.015

[10] Rainard, P. and Riollet, C. (2006) Innate Immunity of the Bovine Mammary Gland. Veterinary Research, 37, 369-400. http://dx.doi.org/10.1051/vetres:2006007

[11] Schukken, Y.H., Gunther, J., Fitzpatrick, J., Fontaine, M.C., Goetze, L., et al. (2011) Host-Response Patterns of Intramammary Infections in Dairy Cows. Veterinary Immunology and Immunopathology, 144, 270-289. http://dx.doi.org/10.1016/j.vetimm.2011.08.022

[12] Pighetti, G.M. and Elliott, A.A. (2011) Gene Polymorphisms: The Keys for Marker Assisted Selection and Unraveling Core Regulatory Pathways for Mastitis Resistance. Journal of Mammary Gland Biology and Neoplasia, 16, 421-432. http://dx.doi.org/10.1007/s10911-011-9238-9

[13] Bradley, A.J., Leach, K.A., Breen, J.E., Green, L.E. and Green, M.J. (2007) Survey of the Incidence and Aetiology of Mastitis on Dairy Farms in England and Wales. Veterinary Record, 160, 253-258. http://dx.doi.org/10.1136/vr.160.8.253

[14] Oviedo-Boyso, J., Valdez-Alarcon, J.J, Cajero-Juarez, M., Ochoa-Zarzosa, A., Lopez-Meza, J.E., et al. (2007) Innate Immune Response of Bovine Mammary Gland to Pathogenic Bacteria Responsible for Mastitis. Journal of Infection, 54, 399-409. http://dx.doi.org/10.1016/i.jinf.2006.06.010

[15] Lutzow, Y.C., Donaldson, L., Gra,y C.P., Vuocolo, T., Pearson, R.D., et al. (2008) Identification of Immune Genes and Proteins Involved in the Response of Bovine Mammary Tissue to Staphylococcus aureus Infection. BMC Veterinary Research, 4, 18. http://dx.doi.org/10.1186/1746-6148-4-18

[16] Buitenhuis, B., Rontved, C.M., Edwards, S.M., Ingvartsen, K.L. and Sorensen, P. (2011) In Depth Analysis of Genes and Pathways of the Mammary Gland Involved in the Pathogenesis of Bovine Escherichia coli-Mastitis. BMC Genomics, 12, 130. http://dx.doi.org/10.1186/1471-2164-12-130

[17] Mitterhuemer, S., Petzl, W., Krebs, S., Mehne, D., Klanner, A., et al. (2010) Escherichia coli Infection Induces Distinct Local and Systemic Transcriptome Responses in the Mammary Gland. BMC Genomics, 11, 138. http://dx.doi.org/10.1186/1471-2164-11-138

[18] Moyes, K.M., Drackley, J.K., Morin, D.E., Bionaz, M., Rodriguez-Zas, S.L., et al. (2009) Gene Network and Pathway Analysis of Bovine Mammary Tissue Challenged with Streptococcus uberis Reveals Induction of Cell Proliferation and Inhibition of PPARgamma Signalling as Potential Mechanism for the Negative Relationships between Immune Response and Lipid Metabolism. BMC Genomics, 10, 542. http://dx.doi.org/10.1186/1471-2164-10-542

[19] Lawless, N., Reinhardt, T.A., Bryan, K., Baker, M., Pesch, B., et al. (2014) MicroRNA Regulation of Bovine Monocyte Inflammatory and Metabolic Networks in an in Vivo Infection Model. G3 (Bethesda), 4, 957-971. http://dx.doi.org/10.1534/g3.113.009936

[20] Lewandowska-Sabat, A.M., Boman, G.M., Downing, A., Talbot, R., Storset, A.K., et al. (2013) The Early Phase Transcriptome of Bovine Monocyte-Derived Macrophages Infected with Staphylococcus aureus in Vitro. BMC Genomics, 14, 891. http://dx.doi.org/10.1186/1471-2164-14-891

[21] Gunther, J., Esch, K., Poschadel, N., Petzl, W., Zerbe, H., et al. (2011) Comparative Kinetics of Escherichia coli- and Staphylococcus aureus-Specific Activation of Key Immune Pathways in Mammary Epithelial Cells Demonstrates That S. aureus Elicits a Delayed Response Dominated by Interleukin-6 (IL-6) but Not by IL-1A or Tumor Necrosis Factor Alpha. Infection and Immunity, 79, 695-707. http://dx.doi.org/10.1128/IAI.01071-10 
[22] Brand, B., Hartmann, A., Repsilber, D., Griesbeck-Zilch, B., Wellnitz, O., et al. (2011) Comparative Expression Profiling of E. coli and S. aureus Inoculated Primary Mammary Gland Cells Sampled from Cows with Different Genetic Predispositions for Somatic Cell Score. Genetics Selection Evolution, 43, 24. http://dx.doi.org/10.1186/1297-9686-43-24

[23] Bannerman, D.D. (2009) Pathogen-Dependent Induction of Cytokines and Other Soluble Inflammatory Mediators during Intramammary Infection of Dairy Cows. Journal of Animal Science, 87, 10-25. http://dx.doi.org/10.2527/jas.2008-1187

[24] Kimbrell, D.A. and Beutler, B. (2001) The Evolution and Genetics of Innate Immunity. Nature Reviews Genetics, 2 , 256-267. http://dx.doi.org/10.1038/35066006

[25] Lund, M.S, Sahana, G., Andersson-Eklund, L., Hastings, N., Fernandez, A., et al. (2007) Joint Analysis of Quantitative Trait Loci for Clinical Mastitis and Somatic Cell Score on Five Chromosomes in Three Nordic Dairy Cattle Breeds. Journal of Dairy Science, 90, 5282-5290. http://dx.doi.org/10.3168/jds.2007-0177

[26] Kolbehdari, D., Wang, Z., Grant, J.R., Murdoch, B., Prasad A, et al. (2009) A Whole Genome Scan to Map QTL for Milk Production Traits and Somatic Cell Score in Canadian Holstein Bulls. Journal of Animal Breeding and Genetics, 126, 216-227. http://dx.doi.org/10.1111/j.1439-0388.2008.00793.x

[27] Schulman, N.F., Sahana, G., Iso-Touru, T., Lund, M.S., Andersson-Eklund, L., et al. (2009) Fine Mapping of Quantitative Trait Loci for Mastitis Resistance on Bovine Chromosome 11. Animal Genetics, 40, 509-515. http://dx.doi.org/10.1111/j.1365-2052.2009.01872.x

[28] Cole, J.B., Wiggans, G.R., Ma, L., Sonstegard, T.S., Lawlor, T.J., et al. (2011) Genome-Wide Association Analysis of Thirty One Production, Health, Reproduction and Body Conformation Traits in Contemporary U.S. Holstein Cows. BMC Genomics, 12, 408. http://dx.doi.org/10.1186/1471-2164-12-408

[29] Sodeland, M., Kent, M.P., Olsen, H.G., Opsal, M.A., Svendsen, M., et al. (2011) Quantitative Trait Loci for Clinical Mastitis on Chromosomes 2, 6, 14 and 20 in Norwegian Red Cattle. Animal Genetics, 42, 457-465. http://dx.doi.org/10.1111/j.1365-2052.2010.02165.x

[30] Wijga, S., Bastiaansen, J.W., Wall E., Strandberg, E., de Haas, Y., et al. (2012) Genomic Associations with Somatic Cell Score in First-Lactation Holstein Cows. Journal of Dairy Science, 95, 899-908. http://dx.doi.org/10.3168/jds.2011-4717

[31] Meredith, B.K, Kearney, F.J., Finlay, E.K., Bradley, D.G., Fahey, A.G., et al. (2012) Genome-Wide Associations for Milk Production and Somatic Cell Score in Holstein-Friesian Cattle in Ireland. BMC Genetics, 13, 21. http://dx.doi.org/10.1186/1471-2156-13-21

[32] Sahana, G., Guldbrandtsen, B., Thomsen, B. and Lund, M.S. (2013) Confirmation and Fine-Mapping of Clinical Mastitis and Somatic Cell Score QTL in Nordic Holstein Cattle. Animal Genetics, 44, 620-626. http://dx.doi.org/10.1111/age.12053

[33] Abdel-Shafy, H., Bortfeldt, R.H., Reissmann, M. and Brockmann, G.A. (2014) Short Communication: Validation of Somatic Cell Score-Associated Loci Identified in a Genome-Wide Association Study in German Holstein Cattle. Journal of Dairy Science, 97, 2481-2486. http://dx.doi.org/10.3168/jds.2013-7149

[34] Bradley, A.J. (2002) Bovine Mastitis: An Evolving Disease. The Veterinary Journal, 164, 116-128. http://dx.doi.org/10.1053/tvj1.2002.0724

[35] de Haas, Y., Ouweltjes, W., ten Napel, J., Windig, J.J. and de Jong, G. (2008) Alternative Somatic Cell Count Traits as Mastitis Indicators for Genetic Selection. Journal of Dairy Science, 91, 2501-2511. http://dx.doi.org/10.3168/jds.2007-0459

[36] Bloemhof, S., de Jong, G. and de Haas, Y. (2009) Genetic Parameters for Clinical Mastitis in the First Three Lactations of Dutch Holstein Cattle. Veterinary Microbiology, 134, 165-171. http://dx.doi.org/10.1016/j.vetmic.2008.09.024

[37] Griesbeck-Zilch, B., Osman, M., Kuhn, C., Schwerin, M., Bruckmaier, R.H., et al. (2009) Analysis of Key Molecules of the Innate Immune System in Mammary Epithelial Cells Isolated from Marker-Assisted and Conventionally Selected Cattle. Journal of Dairy Science, 92, 4621-4633. http://dx.doi.org/10.3168/jds.2008-1954

[38] Rainard, P. (2003) The Complement in Milk and Defense of the Bovine Mammary Gland against Infections. Veterinary Research, 34, 647-670. http://dx.doi.org/10.1051/vetres:2003025

[39] Miki, I., Kusano, A., Ohta, S., Hanai, N., Otoshi, M., et al. (1996) Histamine Enhanced the TNF-Alpha-Induced Expression of E-Selectin and ICAM-1 on Vascular Endothelial Cells. Cellular Immunology, 171, 285-288. http://dx.doi.org/10.1006/cimm.1996.0205

[40] Albrecht, E.A., Chinnaiyan, A.M., Varambally, S., Kumar-Sinha, C., Barrette, T.R., et al. (2004) C5a-Induced Gene Expression in Human Umbilical Vein Endothelial Cells. The American Journal of Pathology, 164, 849-859. http://dx.doi.org/10.1016/S0002-9440(10)63173-2

[41] Campbell, I.D. and Humphries M.J. (2011) Integrin Structure, Activation, and Interactions. Cold Spring Harb Perspect 
Biol, 3:pii: a004994. http://dx.doi.org/10.1101/cshperspect.a004994

[42] Phillipson, M. and Kubes, P. (2011) The Neutrophil in Vascular Inflammation. Nature Medicine, 17, 1381-1390. http://dx.doi.org/10.1038/nm.2514

[43] Paape, M.J., Bannerman, D.D., Zhao, X. and Lee, J.W. (2003) The Bovine Neutrophil: Structure and Function in Blood and Milk. Veterinary Research, 34, 597-627. http://dx.doi.org/10.1051/vetres:2003024

[44] Carter, N., Nakamoto, T., Hirai, H. and Hunter, T. (2002) Ephrin A1-Induced Cytoskeletal Re-Organization Requires FAK and p130(cas). Nature Cell Biology, 4, 565-573.

[45] Noren, N.K. and Pasquale, E.B. (2004) Eph Receptor-Ephrin Bidirectional Signals That Target Ras and Rho Proteins. Cell signaling, 16, 655-666. http://dx.doi.org/10.1016/j.cellsig.2003.10.006

[46] Nakamura, M.T, Yudell, B.E. and Loor, J.J. (2014) Regulation of Energy Metabolism by Long-Chain Fatty Acids. Progress in Lipid Research, 53, 124-144. http://dx.doi.org/10.1016/j.plipres.2013.12.001

[47] Xu, Z., Dziarski, R., Wang, Q., Swartz, K., Sakamoto, K.M., et al. (2001) Bacterial Peptidoglycan-Induced tnf-Alpha Transcription Is Mediated through the Transcription Factors Egr-1, Elk-1, and NF-KappaB. The Journal of Immunology, 167, 6975-6982. http://dx.doi.org/10.4049/jimmunol.167.12.6975

[48] Paape, M., Mehrzad, J., Zhao, X., Detilleux, J. and Burvenich, C. (2002) Defense of the Bovine Mammary Gland by Polymorphonuclear Neutrophil Leukocytes. Journal of Mammary Gland Biology and Neoplasia, 7, 109-121. http://dx.doi.org/10.1023/A:1020343717817

[49] Borregaard, N. (2010) Neutrophils, from Marrow to Microbes. Immunity, 33, 657-670. http://dx.doi.org/10.1016/j.immuni.2010.11.011

[50] Vaught, D., Chen, J. and Brantley-Sieders, D.M. (2009) Regulation of Mammary Gland Branching Morphogenesis by EphA2 Receptor Tyrosine Kinase. Molecular Biology of the Cell, 20, 2572-2581. http://dx.doi.org/10.1091/mbc.E08-04-0378

[51] Ley, K., Laudanna, C., Cybulsky, M.I. and Nourshargh, S. (2007) Getting to the Site of Inflammation: The Leukocyte Adhesion Cascade Updated. Nature Reviews Immunology, 7, 678-689. http://dx.doi.org/10.1038/nri2156

[52] Ley, K. (2003) The Role of Selectins in Inflammation and Disease. Trends in Molecular Medicine, 9, $263-268$. http://dx.doi.org/10.1016/S1471-4914(03)00071-6

[53] Strandberg, Y., Gray, C., Vuocolo, T., Donaldson, L., Broadway, M., et al. (2005) Lipopolysaccharide and Lipoteichoic Acid Induce Different Innate Immune Responses in Bovine Mammary Epithelial Cells. Cytokine, 31, 72-86. http://dx.doi.org/10.1016/j.cyto.2005.02.010

[54] Shuster, D.E., Kehrli, M.E., Rainard, P. and Paape, M. (1997) Complement Fragment C5a and Inflammatory Cytokines in Neutrophil Recruitment during Intramammary Infection with Escherichia coli. Infection and Immunity, 65, 32863292.

[55] Asako, H., Kurose, I., Wolf, R., DeFrees, S., Zheng, Z.L., et al. (1994) Role of H1 Receptors and P-Selectin in Histamine-Induced Leukocyte Rolling and Adhesion in Postcapillary Venules. Journal of Clinical Investigation, 93, 15081515. http://dx.doi.org/10.1172/JCI117129

[56] Gotsch, U., Jager, U., Dominis, M. and Vestweber, D. (1994) Expression of P-Selectin on Endothelial Cells Is Upregulated by LPS and TNF-Alpha in Vivo. Cell Communication and Adhesion, 2, 7-14. http://dx.doi.org/10.3109/15419069409014198

[57] Norman, K.E., Katopodis, A.G., Thoma, G., Kolbinger, F., Hicks, A.E., et al. (2000) P-Selectin Glycoprotein Ligand-1 Supports Rolling on E- and P-Selectin in Vivo. Blood, 96, 3585-3591.

[58] Wang, H.B., Wang, J.T., Zhang, L., Geng, Z.H., Xu, W.L., et al. (2007) P-Selectin Primes Leukocyte Integrin Activation during Inflammation. Nature Immunology, 8, 882-892. http://dx.doi.org/10.1038/ni1491

[59] Nagahata, H. (2004) Bovine Leukocyte Adhesion Deficiency (BLAD): A Review. Journal of Veterinary Medical Science, 66, 1475-1482. http://dx.doi.org/10.1292/jvms.66.1475

[60] Bargatze, R.F., Kurk, S., Butcher, E.C. and Jutila, M.A. (1994) Neutrophils Roll on Adherent Neutrophils Bound to Cytokine-Induced Endothelial-Cells via L-Selectin on the Rolling Cells. Journal of Experimental Medicine, 180, 1785 1792. http://dx.doi.org/10.1084/jem.180.5.1785

[61] Sperandio, M., Smith, M.L., Forlow, S.B., Olson, T.S., Xia, L., et al. (2003) P-Selectin Glycoprotein Ligand-1 Mediates L-Selectin-Dependent Leukocyte Rolling in Venules. Journal of Experimental Medicine, 197, 1355-1363. http://dx.doi.org/10.1084/jem.20021854

[62] Stadtmann, A., Germena, G., Block, H., Boras, M., Rossaint, J., et al. (2013) The PSGL-1-L-Selectin Signalling Complex Regulates Neutrophil Adhesion under Flow. Journal of Experimental Medicine, 210, 2171-2180. http://dx.doi.org/10.1084/jem.20130664

[63] Cai, T-Q., Weston, P., Lund, L., Brodie, B., McKenna, D., et al. (1994) Association between Neutrophil Functions and 
Periparturient Disorders in Cows. American Journal of Veterinary Research, 55, 934-943.

[64] Weber, P.S., Madsen, S.A., Smith, G.W., Ireland, J.J. and Burton, J.L. (2001) Pre-Translational Regulation of Neutrophil L-Selectin in Glucocorticoid-Challenged Cattle. Veterinary Immunology and Immunopathology, 83, 213-240. http://dx.doi.org/10.1016/S0165-2427(01)00381-6

[65] Sorensen, L.P., Guldbrandtsen, B., Thomasen, J.R. and Lund, M.S. (2008) Pathogen-Specific Effects of Quantitative Trait Loci Affecting Clinical Mastitis and Somatic Cell Count in Danish Holstein Cattle. Journal of Dairy Science, 91, 2493-2500. http://dx.doi.org/10.3168/jds.2007-0583

[66] Klungland, H., Sabry, A., Heringstad, B., Olsen, H.G., Gomez-Raya, L., et al. (2001) Quantitative Trait Loci Affecting Clinical Mastitis and Somatic Cell Count in Dairy Cattle. Mammalian Genome, 12, 837-842. http://dx.doi.org/10.1007/s00335001-2081-3

[67] Olson, T.S. and Ley, K. (2002) Chemokines and Chemokine Receptors in Leukocyte Trafficking. American Journal of Physiology-Regulatory, Integrative and Comparative Physiology, 283, R7-R28. http://dx.doi.org/10.1152/ajpregu.00738.2001

[68] Kolaczkowska, E. and Kubes, P. (2013) Neutrophil Recruitment and Function in Health and Inflammation. Nature Reviews Immunology, 13, 159-175. http://dx.doi.org/10.1038/nri3399

[69] Li, F., Zhang, X.B., Mizzi, C. and Gordon J.R. (2002) CXCL8((3-73))K11R/G31P Antagonizes the Neutrophil Chemoattractants Present in Pasteurellosis and Mastitis Lesions and Abrogates Neutrophil Influx into Intradermal Endotoxin Challenge Sites in Vivo. Veterinary Immunology and Immunopathology, 90, 65-77. http://dx.doi.org/10.1016/S0165-2427(02)00223-4

[70] Chen, R.J., Yang, Z.P., Ji, D.J., Mao, Y.J., Chen, Y., et al. (2011) Polymorphisms of the IL8 Gene Correlate with Milking Traits, SCS and mRNA Level in Chinese Holstein. Molecular Biology Reports, 38, 4083-4088. http://dx.doi.org/10.1007/s11033-010-0528-x

[71] De Filippo, K., Dudeck, A., Hasenberg M., Nye, E., van Rooijen, N., et al. (2013) Mast Cell and Macrophage Chemokines CXCL1/CXCL2 Control the Early Stage of Neutrophil Recruitment during Tissue Inflammation. Blood, 121, 4930-4937. http://dx.doi.org/10.1182/blood-2013-02-486217

[72] Sipka, A., Klaessig, S., Duhamel, G.E., Swinkels, J., Rainard, P., et al. (2014) Impact of Intramammary Treatment on Gene Expression Profiles in Bovine Escherichia coli Mastitis. PLoS ONE, 9, e85579. http://dx.doi.org/10.1371/journal.pone.0085579

[73] Gijsbers, K., Gouwy, M., Struyf, S., Wuyts, A., Proost, P., et al. (2005) GCP-2/CXCL6 Synergizes with Other Endothelial Cell-Derived Chemokines in Neutrophil Mobilization and Is Associated with Angiogenesis in Gastrointestinal Tumors. Experimental Cell Research, 303, 331-342. http://dx.doi.org/10.1016/j.yexcr.2004.09.027

[74] Linge, H.M., Collin, M., Nordenfelt, P., Morgelin, M., Malmsten, M., et al. (2008) The Human CXC Chemokine Granulocyte Chemotactic Protein 2 (GCP-2)/CXCL6 Possesses Membrane-Disrupting Properties and Is Antibacterial. Antimicrobial Agents and Chemotherapy, 52, 2599-2607. http://dx.doi.org/10.1128/AAC.00028-08

[75] Coulthard, M.G., Morgan, M., Woodruff, T.M., Arumugam, T.V., Taylor, S.M., et al. (2012) Eph/Ephrin Signalling in Injury and Inflammation. The American Journal of Pathology, 181, 1493-1503. http://dx.doi.org/10.1016/j.ajpath.2012.06.043

[76] Cheng, N. and Chen, J. (2001) Tumor Necrosis Factor-Alpha Induction of Endothelial Ephrin A1 Expression Is Mediated by a 38 MAPK- and SAPK/JNK-Dependent but Nuclear Factor-Kappa B-Independent Mechanism. The Journal of Biological Chemistry, 276, 13771-13777.

[77] Funk, S.D., Yurdagul, A., Albert, P., Traylor, J.G., Jin, L., et al. (2012) EphA2 Activation Promotes the Endothelial Cell Inflammatory Response a Potential Role in Atherosclerosis. Arteriosclerosis, Thrombosis, and Vascular Biology, 32, 686-695. http://dx.doi.org/10.1161/atvbaha.111.242792

[78] Larson, J., Schomberg, S., Schroeder, W. and Carpenter, T.C. (2008) Endothelial EphA Receptor Stimulation Increases Lung Vascular Permeability. American Journal of Physiology-Lung Cellular and Molecular Physiology, 295, L431L439. http://dx.doi.org/10.1152/ajplung.90256.2008

[79] Bouton, A.H., Riggins, R.B. and Bruce-Staskal, P.J. (2001) Functions of the Adapter Protein Cas: Signal Convergence and the Determination of Cellular Responses. Oncogene, 20, 6448-6458. http://dx.doi.org/10.1038/sj.onc.1204785

[80] Ivanov, A.I. and Romanovsky, A.A. (2006) Putative Dual Role of Ephrin-Eph Receptor Interactions in Inflammation. IUBMB Life, 58, 389-394.

[81] Cook-Mills, J.M., Johnson, J.D., Deem, T.L., Ochi, A., Wang, L., et al. (2004) Calcium Mobilization and Rac1 Activation Are Required for VCAM-1 (Vascular Cell Adhesion Molecule-1) Stimulation of NADPH Oxidase Activity. Biochemical Journal, 378, 539-547. http://dx.doi.org/10.1042/bj20030794

[82] Rambeaud, M., Almeida, R.A., Pighetti, G.M. and Oliver, S.P. (2003) Dynamics of Leukocytes and Cytokines during Experimentally Induced Streptococcus uberis Mastitis. Veterinary Immunology and Immunopathology, 96, 193-205. 
http://dx.doi.org/10.1016/j.vetimm.2003.08.008

[83] Wahl, S., Barth, H., Ciossek, T., Aktories, K. and Mueller, B.K. (2000) Ephrin-A5 Induces Collapse of Growth Cones by Activating Rho and Rho Kinase. The Journal of Cell Biology, 149, 263-270. http://dx.doi.org/10.1083/jcb.149.2.263

[84] Shimizu, A., Mammoto, A., Italiano, J.E., Pravda, E., Dudley, A.C., et al. (2008) ABL2/ARG Tyrosine Kinase Mediates SEMA3F-Induced RhoA Inactivation and Cytoskeleton Collapse in Human Glioma Cells. The Journal of Biological Chemistry, 283, 27230-27238. http://dx.doi.org/10.1074/jbc.M804520200

[85] Arthur, W.T. and Burridge, K. (2001) RhoA Inactivation by p190RhoGAP Regulates Cell Spreading and Migration by Promoting Membrane Protrusion and Polarity. Molecular Biology of the Cell, 12, 2711-2720. http://dx.doi.org/10.1091/mbc.12.9.2711

[86] Buricchi, F., Giannoni, E., Grimaldi, G., Parri, M., Raugei, G., et al. (2007) Redox Regulation of Ephrin/Integrin Cross-Talk. Cell Adhesion \& Migration, 1, 33-42.

[87] Suraneni, P., Rubinstein, B., Unruh, J.R., Durnin, M., Hanein, D., et al. (2012) The Arp2/3 Complex Is Required for Lamellipodia Extension and Directional Fibroblast Cell Migration. The Journal of Cell Biology, 197, 239-251. http://dx.doi.org/10.1083/jcb.201112113

[88] Goley, E.D. and Welch, M.D. (2006) The ARP2/3 Complex: An Actin Nucleator Comes of Age. Nature Reviews Molecular Cell Biology, 7, 713-726. http://dx.doi.org/10.1038/nrm2026

[89] Spindler, V., Schlegel, N. and Waschke, J. (2010) Role of GTPases in Control of Microvascular Permeability. Cardiovascular Research, 87, 243-253. http://dx.doi.org/10.1093/cvr/cvq086

[90] Furuhashi, M., Saitoh, S., Shimamoto, K. and Miura, T. (2014) Fatty Acid-Binding Protein 4 (FABP4): Pathophysiological Insights and Potent Clinical Biomarker of Metabolic and Cardiovascular Diseases. Clinical Medicine Insights: Cardiology, 8, 23-33.

[91] Maderna, P. and Godson, C. (2009) Lipoxins: Resolutionary Road. British Journal of Pharmacology, 158, 947-959. http://dx.doi.org/10.1111/j.1476-5381.2009.00386.x

[92] Serhan, C.N., Chiang, N. and Van Dyke, T.E. (2008) Resolving Inflammation: Dual Anti-Inflammatory and Pro-Resolution Lipid Mediators. Nature Reviews Immunology, 8, 349-361. http://dx.doi.org/10.1038/nri2294

[93] Nafikov, R.A., Schoonmaker, J.P., Korn, K.T., Noack, K., Garrick, D.J., et al. (2013) Association of Polymorphisms in Solute Carrier Family 27, Isoform A6 (SLC27A6) and Fatty Acid-Binding Protein-3 and Fatty Acid-Binding Protein-4 (FABP3 and FABP4) with Fatty Acid Composition of Bovine Milk. Journal of Dairy Science, 96, 6007-6021. http://dx.doi.org/10.3168/jds.2013-6703

[94] Roy, R., Ordovas, L., Zaragoza, P., Romero, A., Moreno, C., et al. (2006) Association of Polymorphisms in the Bovine FASN Gene with Milk-Fat Content. Animal Genetics, 37, 215-218. http://dx.doi.org/10.1111/j.1365-2052.2006.01434.x

[95] Joseph, S.B., Laffitte, B.A., Patel, P.H., Watson, M.A., Matsukuma, K.E., et al. (2002) Direct and Indirect Mechanisms for Regulation of Fatty Acid Synthase Gene Expression by Liver X Receptors. The Journal of Biological Chemistry, 277, 11019-11025. http://dx.doi.org/10.1074/jbc.M111041200

[96] Hanayama, R., Tanaka, M., Miwa, K., Shinohara, A., Iwamatsu, A., et al. (2002) Identification of a Factor That Links Apoptotic Cells to Phagocytes. Nature, 417, 182-187. http://dx.doi.org/10.1038/417182a

[97] Fox, C.J., Hammerman, P.S. and Thompson, C.B. (2005) Fuel Feeds Function: Energy Metabolism and the T-cell Response. Nature Reviews Immunology, 5, 844-852. http://dx.doi.org/10.1038/nri1710

[98] Cheng, C.S., Wang, Z. and Chen, J. (2014) Targeting FASN in Breast Cancer and the Discovery of Promising Inhibitors from Natural Products Derived from Traditional Chinese Medicine. Evidence-Based Complementary and Alternative Medicine, 2014, Article ID: 232946. http://dx.doi.org/10.1155/2014/232946

[99] Jump, D.B. (2002) The Biochemistry of n-3 Polyunsaturated Fatty Acids. The Journal of Biological Chemistry, 277, 8755-8758. http://dx.doi.org/10.1074/jbc.R100062200

[100] Folco, G., Murphy, R.C. (2006) Eicosanoid Transcellular Biosynthesis: From Cell-Cell Interactions to in Vivo Tissue Responses. Pharmacological Reviews, 58, 375-388. http://dx.doi.org/10.1124/pr.58.3.8

[101] Wahli, W. and Michalik, L. (2012) PPARs at the Crossroads of Lipid Signalling and Inflammation. Trends in Endocrinology \& Metabolism, 23, 351-363. http://dx.doi.org/10.1016/j.tem.2012.05.001

[102] Stark, M.A., Huo, Y.Q., Burcin, T.L., Morris, M.A., Olson, T.S., et al. (2005) Phagocytosis of Apoptotic Neutrophils Regulates Granulopoiesis via IL-23 and IL-17. Immunity, 22, 285-294. http://dx.doi.org/10.1016/j.immuni.2005.01.011 


\section{Supporting Information}

Table S1. Summary list of 505 common genes with similar differential gene expression in mammary tissue after intramammary infection with E. coli or S. uberis. Data are from references [17] [18].

\begin{tabular}{|c|c|c|c|c|}
\hline \multirow{2}{*}{ Gene symbol } & \multicolumn{2}{|c|}{ E. coli } & \multicolumn{2}{|c|}{ S. uberis } \\
\hline & $\mathrm{P}$ & Fold change & $\mathrm{P}$ & Fold change \\
\hline$T R A F 3 I P 3$ & $9.335 \mathrm{E}-06$ & -2.65 & $2.481 \mathrm{E}-06$ & -4.76 \\
\hline$L P I N 1$ & $5.972 \mathrm{E}-03$ & -1.74 & $5.295 \mathrm{E}-05$ & -3.83 \\
\hline SLC $31 A 2$ & $1.933 \mathrm{E}-06$ & -2.58 & $4.977 \mathrm{E}-05$ & -3.38 \\
\hline PEG3 & $1.865 \mathrm{E}-04$ & -1.93 & $2.232 \mathrm{E}-04$ & -3.26 \\
\hline$C D 36$ & $6.142 \mathrm{E}-10$ & -3.82 & $5.321 \mathrm{E}-05$ & -3.25 \\
\hline$S L C 34 A 2$ & $5.118 \mathrm{E}-10$ & -7.01 & $1.370 \mathrm{E}-04$ & -3.21 \\
\hline$S C D$ & $2.713 \mathrm{E}-06$ & -2.25 & $2.693 \mathrm{E}-04$ & -3.11 \\
\hline GPAM & $2.251 \mathrm{E}-07$ & -6.12 & $1.583 \mathrm{E}-06$ & -2.97 \\
\hline DNAJC12 & $1.111 \mathrm{E}-08$ & -4.66 & $4.942 \mathrm{E}-05$ & -2.95 \\
\hline$F A B P 4$ & $3.177 \mathrm{E}-05$ & -2.89 & $2.853 \mathrm{E}-05$ & -2.93 \\
\hline$A A K 1$ & $2.566 \mathrm{E}-05$ & -1.68 & $1.490 \mathrm{E}-04$ & -2.92 \\
\hline$T P D 52 L 1$ & $2.175 \mathrm{E}-04$ & -1.59 & $8.359 \mathrm{E}-04$ & -2.90 \\
\hline CLSTN1 & $5.645 \mathrm{E}-05$ & -1.91 & $1.222 \mathrm{E}-05$ & -2.87 \\
\hline PNPLA2 & $1.543 \mathrm{E}-03$ & -1.58 & $1.895 \mathrm{E}-04$ & -2.86 \\
\hline$A S B 11$ & $7.854 \mathrm{E}-03$ & -2.04 & $8.502 \mathrm{E}-04$ & -2.83 \\
\hline$D H R S 3$ & $4.169 \mathrm{E}-04$ & -1.99 & $5.055 \mathrm{E}-04$ & -2.82 \\
\hline$C L M N$ & $1.033 \mathrm{E}-06$ & -2.52 & $6.735 \mathrm{E}-05$ & -2.77 \\
\hline$F A B P 3$ & $1.644 \mathrm{E}-05$ & -2.98 & $1.164 \mathrm{E}-04$ & -2.75 \\
\hline$C O G 2$ & $1.221 \mathrm{E}-04$ & -1.51 & $3.650 \mathrm{E}-04$ & -2.75 \\
\hline TMEM70 & $1.026 \mathrm{E}-07$ & -2.82 & $9.733 \mathrm{E}-05$ & -2.74 \\
\hline$A S P N$ & $9.090 \mathrm{E}-06$ & -3.06 & $2.407 \mathrm{E}-03$ & -2.73 \\
\hline$R H P N 2$ & $3.520 \mathrm{E}-06$ & -2.71 & $5.479 \mathrm{E}-04$ & -2.73 \\
\hline$M U C 15$ & $2.826 \mathrm{E}-07$ & -2.26 & $3.685 \mathrm{E}-03$ & -2.70 \\
\hline CIDEA & $1.352 \mathrm{E}-06$ & -7.65 & $2.019 \mathrm{E}-04$ & -2.69 \\
\hline ITGA6 & $8.882 \mathrm{E}-04$ & -1.56 & $1.222 \mathrm{E}-03$ & -2.67 \\
\hline$S L C 17 A 5$ & $3.714 \mathrm{E}-03$ & -1.58 & $9.864 \mathrm{E}-04$ & -2.65 \\
\hline$M O S P D 1$ & $6.276 \mathrm{E}-06$ & -2.61 & $1.756 \mathrm{E}-04$ & -2.63 \\
\hline PER 1 & $2.920 \mathrm{E}-03$ & -1.72 & $4.145 \mathrm{E}-05$ & -2.62 \\
\hline STX8 & $1.417 \mathrm{E}-02$ & -1.57 & $2.552 \mathrm{E}-04$ & -2.62 \\
\hline$S L C 16 A 1$ & $5.595 \mathrm{E}-06$ & -2.71 & $1.415 \mathrm{E}-03$ & -2.62 \\
\hline$L P L$ & $2.276 \mathrm{E}-07$ & -22.16 & $1.742 \mathrm{E}-04$ & -2.62 \\
\hline$P I K 3 C 2 G$ & $1.457 \mathrm{E}-05$ & -1.68 & $8.524 \mathrm{E}-03$ & -2.60 \\
\hline$N E L L 2$ & $2.098 \mathrm{E}-08$ & -5.15 & $1.865 \mathrm{E}-03$ & -2.60 \\
\hline$T M C C 1$ & $9.431 \mathrm{E}-05$ & -1.50 & $3.434 \mathrm{E}-03$ & -2.59 \\
\hline$P R K A R 2 B$ & $9.905 \mathrm{E}-04$ & -1.70 & $1.500 \mathrm{E}-03$ & -2.58 \\
\hline$M R C 2$ & $1.465 \mathrm{E}-04$ & -1.96 & $2.044 \mathrm{E}-04$ & -2.56 \\
\hline WIPI1 & $4.049 \mathrm{E}-03$ & -1.57 & $4.833 \mathrm{E}-05$ & -2.54 \\
\hline$M Y B P C 1$ & $1.715 \mathrm{E}-07$ & -2.81 & $1.187 \mathrm{E}-03$ & -2.53 \\
\hline DHCR 24 & $2.414 \mathrm{E}-04$ & -1.66 & $1.184 \mathrm{E}-04$ & -2.53 \\
\hline$A B C G 2$ & $1.573 \mathrm{E}-04$ & -2.01 & $4.777 \mathrm{E}-04$ & -2.52 \\
\hline$S H 3 B P 4$ & $2.457 \mathrm{E}-08$ & -2.78 & $1.273 \mathrm{E}-04$ & -2.52 \\
\hline$F A S N$ & $2.401 \mathrm{E}-06$ & -4.39 & $8.828 \mathrm{E}-03$ & -2.51 \\
\hline$H N R P L L$ & $3.186 \mathrm{E}-06$ & -2.13 & $1.970 \mathrm{E}-04$ & -2.51 \\
\hline$A B L I M 1$ & $7.130 \mathrm{E}-04$ & -1.59 & $2.732 \mathrm{E}-04$ & -2.51 \\
\hline
\end{tabular}




\section{Continued}

\begin{tabular}{|c|c|c|c|c|}
\hline PRKAA2 & $1.021 \mathrm{E}-03$ & -1.63 & $2.181 \mathrm{E}-04$ & -2.51 \\
\hline$T B C 1 D 5$ & $1.547 \mathrm{E}-03$ & -1.68 & $2.093 \mathrm{E}-03$ & -2.51 \\
\hline$V L D L R$ & $4.323 \mathrm{E}-03$ & -1.95 & $2.147 \mathrm{E}-03$ & -2.50 \\
\hline$I T G B 5$ & $1.213 \mathrm{E}-02$ & -1.60 & $4.420 \mathrm{E}-03$ & -2.50 \\
\hline$E H F$ & $8.660 \mathrm{E}-03$ & -1.50 & $2.412 \mathrm{E}-03$ & -2.50 \\
\hline STK $17 A$ & $3.119 \mathrm{E}-06$ & -2.03 & $1.001 \mathrm{E}-03$ & -2.49 \\
\hline$O R M D L 3$ & $8.373 \mathrm{E}-06$ & -2.00 & $2.788 \mathrm{E}-03$ & -2.49 \\
\hline$I D H 1$ & $1.560 \mathrm{E}-06$ & -2.36 & $7.090 \mathrm{E}-04$ & -2.48 \\
\hline$P P M 1 K$ & $2.937 \mathrm{E}-05$ & -1.64 & $1.490 \mathrm{E}-03$ & -2.47 \\
\hline$R A P G E F 1$ & $1.894 \mathrm{E}-06$ & -1.89 & $5.957 \mathrm{E}-04$ & -2.47 \\
\hline$S O D 1$ & $6.628 \mathrm{E}-04$ & -2.21 & $2.019 \mathrm{E}-04$ & -2.47 \\
\hline ESR 1 & $2.182 \mathrm{E}-04$ & -1.57 & $1.010 \mathrm{E}-04$ & -2.47 \\
\hline$A N P E P$ & $4.824 \mathrm{E}-07$ & -2.19 & $1.047 \mathrm{E}-04$ & -2.47 \\
\hline PTHLH & $1.068 \mathrm{E}-08$ & -9.73 & $5.374 \mathrm{E}-03$ & -2.46 \\
\hline SORBS1 & $2.089 \mathrm{E}-04$ & -2.03 & $9.370 \mathrm{E}-03$ & -2.46 \\
\hline KIAA1370 & $8.537 \mathrm{E}-08$ & -2.48 & $7.122 \mathrm{E}-04$ & -2.46 \\
\hline$A G R N$ & $1.631 \mathrm{E}-04$ & -1.92 & $3.104 \mathrm{E}-04$ & -2.46 \\
\hline$B R P 44 L$ & $3.224 \mathrm{E}-05$ & -2.51 & $1.871 \mathrm{E}-03$ & -2.46 \\
\hline SERTAD4 & $1.191 \mathrm{E}-06$ & -2.99 & $2.089 \mathrm{E}-03$ & -2.45 \\
\hline$O S B P L 1 A$ & $4.526 \mathrm{E}-07$ & -2.58 & $9.569 \mathrm{E}-04$ & -2.45 \\
\hline RECQL5 & $2.916 \mathrm{E}-05$ & -1.73 & $4.821 \mathrm{E}-04$ & -2.45 \\
\hline$L R I G 1$ & $2.639 \mathrm{E}-05$ & -1.67 & $7.424 \mathrm{E}-03$ & -2.45 \\
\hline EFNA5 & $3.052 \mathrm{E}-03$ & -1.52 & $6.255 \mathrm{E}-03$ & -2.45 \\
\hline$M M P 15$ & $3.190 \mathrm{E}-04$ & -1.57 & $2.981 \mathrm{E}-05$ & -2.45 \\
\hline$H S D 11 B 1 L$ & $5.775 \mathrm{E}-04$ & -1.59 & $3.627 \mathrm{E}-03$ & -2.43 \\
\hline$C O B L L 1$ & $2.420 \mathrm{E}-05$ & -2.20 & $1.890 \mathrm{E}-03$ & -2.43 \\
\hline$P R L$ & $2.587 \mathrm{E}-04$ & -1.60 & $2.479 \mathrm{E}-03$ & -2.43 \\
\hline$S L C 9 A 3 R 2$ & $1.483 \mathrm{E}-04$ & -1.56 & $4.334 \mathrm{E}-03$ & -2.42 \\
\hline ZNF330 & $3.556 \mathrm{E}-04$ & -1.86 & $9.074 \mathrm{E}-04$ & -2.42 \\
\hline$G P 2$ & $5.675 \mathrm{E}-03$ & -1.77 & $7.272 \mathrm{E}-03$ & -2.42 \\
\hline GALM & $1.447 \mathrm{E}-07$ & -6.95 & $2.480 \mathrm{E}-04$ & -2.42 \\
\hline$N F I B$ & $1.899 \mathrm{E}-03$ & -1.61 & $5.204 \mathrm{E}-03$ & -2.41 \\
\hline$I G F B P 5$ & $1.769 \mathrm{E}-05$ & -2.50 & $1.214 \mathrm{E}-03$ & -2.41 \\
\hline$F A M 46 B$ & $1.360 \mathrm{E}-04$ & -1.61 & $1.457 \mathrm{E}-04$ & -2.41 \\
\hline$G G T 1$ & $7.573 \mathrm{E}-05$ & -1.85 & $1.449 \mathrm{E}-03$ & -2.41 \\
\hline RASSF4 & $3.602 \mathrm{E}-06$ & -3.29 & $5.306 \mathrm{E}-03$ & -2.41 \\
\hline MTHFR & $7.328 \mathrm{E}-04$ & -1.55 & $3.461 \mathrm{E}-03$ & -2.40 \\
\hline$S P T B N 1$ & $3.971 \mathrm{E}-04$ & -1.57 & $2.440 \mathrm{E}-04$ & -2.40 \\
\hline$B D H 2$ & $1.026 \mathrm{E}-04$ & -1.82 & $5.961 \mathrm{E}-03$ & -2.40 \\
\hline$B A Z 2 B$ & $3.091 \mathrm{E}-04$ & -1.62 & $6.260 \mathrm{E}-03$ & -2.40 \\
\hline$K L H L 21$ & $1.051 \mathrm{E}-04$ & -1.52 & $9.846 \mathrm{E}-04$ & -2.39 \\
\hline$H L F$ & $4.224 \mathrm{E}-07$ & -2.97 & $5.134 \mathrm{E}-03$ & -2.39 \\
\hline$C D 109$ & $2.074 \mathrm{E}-03$ & -1.98 & $4.360 \mathrm{E}-03$ & -2.39 \\
\hline$D L G 3$ & $7.619 \mathrm{E}-04$ & -1.55 & $4.292 \mathrm{E}-03$ & -2.39 \\
\hline$A N G$ & $2.699 \mathrm{E}-06$ & -3.21 & $4.176 \mathrm{E}-03$ & -2.37 \\
\hline GTF $2 H 5$ & $1.433 \mathrm{E}-02$ & -1.56 & $2.333 \mathrm{E}-03$ & -2.37 \\
\hline$E M X 2$ & $1.633 \mathrm{E}-03$ & -1.55 & $5.618 \mathrm{E}-03$ & -2.37 \\
\hline CRISPLD2 & $8.866 \mathrm{E}-07$ & -2.13 & $1.374 \mathrm{E}-03$ & -2.37 \\
\hline
\end{tabular}




\section{Continued}

\begin{tabular}{|c|c|c|c|c|}
\hline GRID1 & $4.686 \mathrm{E}-05$ & -1.73 & $4.128 \mathrm{E}-04$ & -2.36 \\
\hline $\mathrm{NOV}$ & $8.641 \mathrm{E}-05$ & -2.10 & $4.874 \mathrm{E}-03$ & -2.36 \\
\hline$S D C 2$ & $1.457 \mathrm{E}-06$ & -3.23 & $5.085 \mathrm{E}-05$ & -2.36 \\
\hline$C Y B 5 D 2$ & $1.795 \mathrm{E}-04$ & -1.94 & $1.651 \mathrm{E}-03$ & -2.36 \\
\hline ZBTB4 & $5.760 \mathrm{E}-05$ & -1.65 & $8.425 \mathrm{E}-03$ & -2.36 \\
\hline$T I M M 8 B$ & $1.269 \mathrm{E}-02$ & -1.79 & $8.813 \mathrm{E}-05$ & -2.35 \\
\hline$M I B 2$ & $3.084 \mathrm{E}-05$ & -1.75 & $3.074 \mathrm{E}-03$ & -2.35 \\
\hline$G A B R B 3$ & $3.532 \mathrm{E}-03$ & -1.51 & $2.399 \mathrm{E}-03$ & -2.35 \\
\hline TENC1 & $2.248 \mathrm{E}-05$ & -1.97 & $6.986 \mathrm{E}-04$ & -2.34 \\
\hline$A L D H 18 A 1$ & $7.008 \mathrm{E}-07$ & -1.88 & $2.358 \mathrm{E}-03$ & -2.34 \\
\hline ENPP4 & $2.721 \mathrm{E}-07$ & -2.50 & $9.008 \mathrm{E}-03$ & -2.34 \\
\hline TMEM9 & $7.726 \mathrm{E}-04$ & -1.51 & $4.526 \mathrm{E}-03$ & -2.33 \\
\hline$G U C Y 2 D$ & $2.993 \mathrm{E}-03$ & -1.52 & $3.144 \mathrm{E}-04$ & -2.33 \\
\hline$P A R D 3 B$ & $3.810 \mathrm{E}-05$ & -1.66 & $4.392 \mathrm{E}-03$ & -2.33 \\
\hline$A S B 8$ & $2.329 \mathrm{E}-03$ & -1.64 & $7.994 \mathrm{E}-04$ & -2.32 \\
\hline$R O G D I$ & $4.294 \mathrm{E}-05$ & -2.08 & $6.599 \mathrm{E}-03$ & -2.32 \\
\hline$B E X 2$ & $4.654 \mathrm{E}-04$ & -1.62 & $9.350 \mathrm{E}-04$ & -2.30 \\
\hline$F A M 110 A$ & $9.800 \mathrm{E}-04$ & -1.62 & $1.075 \mathrm{E}-03$ & -2.30 \\
\hline PATZ1 & $2.338 \mathrm{E}-02$ & -1.58 & $9.499 \mathrm{E}-03$ & -2.30 \\
\hline$T N R C 6 C$ & $1.513 \mathrm{E}-04$ & -1.72 & $6.307 \mathrm{E}-04$ & -2.30 \\
\hline$F X Y D 2$ & $1.151 \mathrm{E}-06$ & -1.88 & $1.609 \mathrm{E}-03$ & -2.30 \\
\hline$F X Y D 1$ & $4.829 \mathrm{E}-03$ & -1.94 & $7.062 \mathrm{E}-03$ & -2.30 \\
\hline COL6A1 & $3.349 \mathrm{E}-05$ & -1.63 & $4.749 \mathrm{E}-03$ & -2.30 \\
\hline HES1 & $2.168 \mathrm{E}-02$ & -1.77 & $4.650 \mathrm{E}-03$ & -2.30 \\
\hline STARD13 & $1.808 \mathrm{E}-03$ & -1.61 & $1.833 \mathrm{E}-03$ & -2.30 \\
\hline FXYD6 & $6.317 \mathrm{E}-04$ & -1.86 & $3.714 \mathrm{E}-03$ & -2.29 \\
\hline$G P R 162$ & $9.402 \mathrm{E}-04$ & -1.66 & $3.412 \mathrm{E}-03$ & -2.28 \\
\hline CHRNB4 & $1.286 \mathrm{E}-04$ & -1.69 & $6.077 \mathrm{E}-03$ & -2.27 \\
\hline$C G N$ & $4.160 \mathrm{E}-04$ & -1.71 & $4.032 \mathrm{E}-03$ & -2.27 \\
\hline$G N A S$ & $2.585 \mathrm{E}-04$ & -1.52 & $9.458 \mathrm{E}-03$ & -2.27 \\
\hline PRKCA & $1.503 \mathrm{E}-05$ & -1.58 & $6.079 \mathrm{E}-03$ & -2.27 \\
\hline$S H F$ & $7.071 \mathrm{E}-04$ & -1.54 & $7.206 \mathrm{E}-04$ & -2.27 \\
\hline$A C S S 2$ & $4.862 \mathrm{E}-06$ & -2.48 & $7.371 \mathrm{E}-03$ & -2.27 \\
\hline$K C N M A 1$ & $4.481 \mathrm{E}-05$ & -1.64 & $3.408 \mathrm{E}-03$ & -2.27 \\
\hline$C L D N 16$ & $8.120 \mathrm{E}-03$ & -1.58 & $7.603 \mathrm{E}-04$ & -2.26 \\
\hline$M A G I X$ & $5.245 \mathrm{E}-04$ & -1.53 & $5.549 \mathrm{E}-03$ & -2.26 \\
\hline$C D H 17$ & $2.611 \mathrm{E}-04$ & -1.54 & $9.139 \mathrm{E}-05$ & -2.26 \\
\hline$X D H$ & $2.213 \mathrm{E}-03$ & -1.55 & $8.817 \mathrm{E}-03$ & -2.25 \\
\hline CYFIP2 & $4.761 \mathrm{E}-04$ & -1.98 & $3.079 \mathrm{E}-04$ & -2.25 \\
\hline$A C A C A$ & $8.734 \mathrm{E}-08$ & -2.52 & $6.830 \mathrm{E}-03$ & -2.25 \\
\hline$D P Y D$ & $3.994 \mathrm{E}-05$ & -2.32 & $1.369 \mathrm{E}-03$ & -2.25 \\
\hline$F M O D$ & $6.440 \mathrm{E}-03$ & -1.81 & $5.443 \mathrm{E}-03$ & -2.25 \\
\hline$V G L L 1$ & $1.362 \mathrm{E}-02$ & -1.55 & $2.613 \mathrm{E}-03$ & -2.25 \\
\hline$N T 5 E$ & $8.932 \mathrm{E}-03$ & -1.87 & $7.080 \mathrm{E}-03$ & -2.24 \\
\hline$T L N 2$ & $9.384 \mathrm{E}-06$ & -1.90 & $2.325 \mathrm{E}-03$ & -2.24 \\
\hline$S L C 25 A 21$ & $6.866 \mathrm{E}-08$ & -8.53 & $4.211 \mathrm{E}-03$ & -2.24 \\
\hline$C B F A 2 T 3$ & $7.948 \mathrm{E}-06$ & -2.06 & $2.934 \mathrm{E}-03$ & -2.23 \\
\hline TREX 1 & $7.512 \mathrm{E}-03$ & -1.77 & $9.250 \mathrm{E}-03$ & -2.23 \\
\hline
\end{tabular}




\section{Continued}

\begin{tabular}{|c|c|c|c|c|}
\hline TRPM4 & $7.061 \mathrm{E}-04$ & -1.70 & $4.594 \mathrm{E}-03$ & -2.22 \\
\hline OS9 & $2.494 \mathrm{E}-05$ & -1.61 & $5.856 \mathrm{E}-03$ & -2.22 \\
\hline$P M M 2$ & $3.968 \mathrm{E}-05$ & -1.60 & $3.819 \mathrm{E}-03$ & -2.22 \\
\hline$E F H C 1$ & $4.414 \mathrm{E}-08$ & -3.64 & $4.868 \mathrm{E}-03$ & -2.22 \\
\hline$K H K$ & $2.421 \mathrm{E}-05$ & -2.18 & $2.390 \mathrm{E}-03$ & -2.22 \\
\hline$S L C 6 A 3$ & $2.766 \mathrm{E}-05$ & -1.56 & $8.602 \mathrm{E}-03$ & -2.21 \\
\hline ТОР $3 B$ & $6.568 \mathrm{E}-04$ & -1.56 & $2.844 \mathrm{E}-03$ & -2.21 \\
\hline$F C H S D 1$ & $1.205 \mathrm{E}-05$ & -1.61 & $2.894 \mathrm{E}-03$ & -2.21 \\
\hline CST3 & $2.151 \mathrm{E}-02$ & -1.65 & $2.854 \mathrm{E}-03$ & -2.21 \\
\hline$M A G E D 2$ & $4.760 \mathrm{E}-04$ & -1.51 & $6.760 \mathrm{E}-03$ & -2.21 \\
\hline CST6 & $5.042 \mathrm{E}-04$ & -1.52 & $6.631 \mathrm{E}-03$ & -2.21 \\
\hline$F G F R L 1$ & $1.201 \mathrm{E}-06$ & -2.27 & $3.069 \mathrm{E}-03$ & -2.20 \\
\hline$A C O 1$ & $1.120 \mathrm{E}-04$ & -1.81 & $7.728 \mathrm{E}-03$ & -2.20 \\
\hline CUL7 & $3.015 \mathrm{E}-05$ & -1.75 & $3.656 \mathrm{E}-03$ & -2.19 \\
\hline$C L E C 3 B$ & $4.206 \mathrm{E}-04$ & -2.38 & $4.631 \mathrm{E}-03$ & -2.18 \\
\hline PON3 & $2.001 \mathrm{E}-02$ & -1.97 & $5.873 \mathrm{E}-04$ & -2.15 \\
\hline$H S F 1$ & $1.753 \mathrm{E}-05$ & -1.61 & $7.465 \mathrm{E}-03$ & -2.15 \\
\hline$R A B 7 A$ & $1.967 \mathrm{E}-05$ & 1.54 & $3.073 \mathrm{E}-03$ & 2.15 \\
\hline ZDHHC2 & $6.175 \mathrm{E}-06$ & 2.74 & $6.004 \mathrm{E}-03$ & 2.16 \\
\hline TSPO & $1.888 \mathrm{E}-06$ & 3.40 & $6.837 \mathrm{E}-03$ & 2.16 \\
\hline$C A 2$ & $5.311 \mathrm{E}-03$ & 2.07 & $6.661 \mathrm{E}-03$ & 2.16 \\
\hline$S M U 1$ & $4.949 \mathrm{E}-06$ & 1.91 & $9.046 \mathrm{E}-03$ & 2.17 \\
\hline ZNF677 & $1.070 \mathrm{E}-03$ & 1.51 & $8.562 \mathrm{E}-03$ & 2.17 \\
\hline ZFYVE26 & $3.997 \mathrm{E}-04$ & 1.54 & $4.610 \mathrm{E}-03$ & 2.18 \\
\hline$C D V 3$ & $7.402 \mathrm{E}-04$ & 1.74 & $6.053 \mathrm{E}-03$ & 2.18 \\
\hline PLEKHO1 & $1.524 \mathrm{E}-08$ & 2.99 & $8.724 \mathrm{E}-03$ & 2.19 \\
\hline MIA3 & $8.766 \mathrm{E}-04$ & 1.53 & $5.597 \mathrm{E}-03$ & 2.19 \\
\hline$R E L B$ & $3.622 \mathrm{E}-06$ & 2.08 & $8.819 \mathrm{E}-03$ & 2.19 \\
\hline$N R P 2$ & $6.655 \mathrm{E}-04$ & 1.83 & $2.940 \mathrm{E}-03$ & 2.19 \\
\hline GRHPR & $1.439 \mathrm{E}-05$ & 2.11 & $4.284 \mathrm{E}-03$ & 2.20 \\
\hline SERPINH 1 & $2.098 \mathrm{E}-04$ & 1.82 & $4.659 \mathrm{E}-03$ & 2.20 \\
\hline$M A D 2 L 2$ & $3.173 \mathrm{E}-03$ & 1.51 & $1.564 \mathrm{E}-03$ & 2.20 \\
\hline$T L R 4$ & $1.043 \mathrm{E}-04$ & 2.24 & $6.966 \mathrm{E}-03$ & 2.21 \\
\hline PCNA & $7.218 \mathrm{E}-05$ & 1.53 & $5.080 \mathrm{E}-04$ & 2.21 \\
\hline$C A P Z A 2$ & $8.058 \mathrm{E}-05$ & 1.60 & $8.863 \mathrm{E}-03$ & 2.21 \\
\hline$S R L$ & $2.891 \mathrm{E}-03$ & 1.51 & $1.051 \mathrm{E}-03$ & 2.21 \\
\hline$B E C N 1$ & $3.667 \mathrm{E}-04$ & 1.65 & $6.811 \mathrm{E}-03$ & 2.21 \\
\hline$C O X 10$ & $2.089 \mathrm{E}-05$ & 2.03 & $3.098 \mathrm{E}-03$ & 2.22 \\
\hline$W H S C 1 L 1$ & $5.287 \mathrm{E}-04$ & 1.59 & $6.964 \mathrm{E}-03$ & 2.22 \\
\hline$S R I$ & $2.066 \mathrm{E}-07$ & 3.16 & $7.708 \mathrm{E}-03$ & 2.22 \\
\hline$C A 8$ & $1.917 \mathrm{E}-02$ & 1.59 & $8.083 \mathrm{E}-03$ & 2.23 \\
\hline GNAI2 & $8.706 \mathrm{E}-07$ & 2.10 & $7.527 \mathrm{E}-03$ & 2.24 \\
\hline IFNAR 2 & $2.013 \mathrm{E}-06$ & 2.99 & $1.245 \mathrm{E}-03$ & 2.24 \\
\hline$G R B 2$ & $5.888 \mathrm{E}-06$ & 1.62 & $3.736 \mathrm{E}-03$ & 2.24 \\
\hline MIER 1 & $7.274 \mathrm{E}-03$ & 1.51 & $2.500 \mathrm{E}-03$ & 2.24 \\
\hline PEX11A & $1.165 \mathrm{E}-03$ & 2.05 & $8.955 \mathrm{E}-03$ & 2.24 \\
\hline$D A Z A P 2$ & $8.313 \mathrm{E}-06$ & 1.68 & $4.023 \mathrm{E}-03$ & 2.25 \\
\hline TWISTNB & $1.188 \mathrm{E}-05$ & 1.66 & $2.891 \mathrm{E}-03$ & 2.25 \\
\hline
\end{tabular}




\section{Continued}

\begin{tabular}{|c|c|c|c|c|}
\hline$S N R P B$ & $2.010 \mathrm{E}-03$ & 1.56 & $3.837 \mathrm{E}-03$ & 2.25 \\
\hline$S L C 3 A 2$ & $1.658 \mathrm{E}-03$ & 1.53 & $4.403 \mathrm{E}-03$ & 2.25 \\
\hline CTSZ & $1.306 \mathrm{E}-07$ & 3.10 & $1.307 \mathrm{E}-03$ & 2.25 \\
\hline MOCS2 & $1.362 \mathrm{E}-03$ & 1.73 & $3.602 \mathrm{E}-03$ & 2.25 \\
\hline$M F A P 3$ & $3.179 \mathrm{E}-03$ & 1.67 & $3.828 \mathrm{E}-03$ & 2.26 \\
\hline VARS & $2.488 \mathrm{E}-05$ & 1.82 & $2.930 \mathrm{E}-03$ & 2.26 \\
\hline SEC $11 A$ & $1.321 \mathrm{E}-06$ & 2.30 & $3.544 \mathrm{E}-03$ & 2.26 \\
\hline$H S P D 1$ & $9.354 \mathrm{E}-06$ & 2.64 & $9.238 \mathrm{E}-03$ & 2.26 \\
\hline FAS & $8.817 \mathrm{E}-04$ & 2.14 & $1.836 \mathrm{E}-03$ & 2.26 \\
\hline$C R N K L 1$ & $1.488 \mathrm{E}-04$ & 1.62 & $4.508 \mathrm{E}-03$ & 2.26 \\
\hline FARSB & $1.613 \mathrm{E}-05$ & 1.66 & $4.306 \mathrm{E}-03$ & 2.26 \\
\hline$A R F 4$ & $1.041 \mathrm{E}-08$ & 3.69 & $4.812 \mathrm{E}-03$ & 2.27 \\
\hline DPH5 & $1.484 \mathrm{E}-05$ & 2.09 & $8.743 \mathrm{E}-03$ & 2.27 \\
\hline$M R P L 12$ & $6.693 \mathrm{E}-03$ & 1.53 & $8.579 \mathrm{E}-03$ & 2.27 \\
\hline$C D K 5 R A P 3$ & $1.873 \mathrm{E}-04$ & 1.50 & $1.936 \mathrm{E}-03$ & 2.27 \\
\hline$V A S P$ & $1.438 \mathrm{E}-07$ & 2.28 & $8.285 \mathrm{E}-03$ & 2.27 \\
\hline PHF11 & $1.431 \mathrm{E}-07$ & 2.22 & $3.035 \mathrm{E}-03$ & 2.28 \\
\hline$H R H 1$ & $8.081 \mathrm{E}-03$ & 2.65 & $9.276 \mathrm{E}-03$ & 2.28 \\
\hline$S 100 A 11$ & $5.258 \mathrm{E}-05$ & 2.05 & $6.033 \mathrm{E}-03$ & 2.28 \\
\hline$K L F 2$ & $2.040 \mathrm{E}-04$ & 1.82 & $3.530 \mathrm{E}-03$ & 2.28 \\
\hline KCTD 10 & $7.294 \mathrm{E}-05$ & 1.68 & $1.770 \mathrm{E}-03$ & 2.28 \\
\hline$N R A S$ & $1.649 \mathrm{E}-04$ & 1.69 & $7.555 \mathrm{E}-03$ & 2.28 \\
\hline$P R D X 1$ & $7.507 \mathrm{E}-03$ & 1.51 & $1.301 \mathrm{E}-03$ & 2.29 \\
\hline$V C P$ & $5.817 \mathrm{E}-05$ & 1.79 & $1.632 \mathrm{E}-03$ & 2.29 \\
\hline ZFAND3 & $5.642 \mathrm{E}-05$ & 1.87 & $1.562 \mathrm{E}-03$ & 2.29 \\
\hline SKIL & $1.472 \mathrm{E}-03$ & 1.79 & $1.215 \mathrm{E}-03$ & 2.29 \\
\hline ZSWIM6 & $4.863 \mathrm{E}-03$ & 1.50 & $8.707 \mathrm{E}-03$ & 2.30 \\
\hline $\mathrm{CDH5}$ & $1.068 \mathrm{E}-04$ & 1.94 & $2.921 \mathrm{E}-03$ & 2.30 \\
\hline FSTL1 & $1.039 \mathrm{E}-02$ & 1.56 & $5.136 \mathrm{E}-04$ & 2.30 \\
\hline$R N F 8$ & $1.296 \mathrm{E}-03$ & 1.68 & $5.728 \mathrm{E}-03$ & 2.30 \\
\hline ZMAT2 & $2.119 \mathrm{E}-04$ & 1.54 & $8.800 \mathrm{E}-04$ & 2.31 \\
\hline$R B M S 1$ & $2.548 \mathrm{E}-06$ & 2.01 & $6.531 \mathrm{E}-03$ & 2.31 \\
\hline$S N R P G$ & $1.034 \mathrm{E}-02$ & 1.55 & $4.420 \mathrm{E}-03$ & 2.31 \\
\hline PSMD14 & $3.426 \mathrm{E}-07$ & 2.28 & $6.370 \mathrm{E}-03$ & 2.31 \\
\hline$S L C 25 A 16$ & $7.479 \mathrm{E}-03$ & 1.52 & $1.501 \mathrm{E}-04$ & 2.31 \\
\hline$K P N A 3$ & $1.404 \mathrm{E}-04$ & 1.75 & $6.568 \mathrm{E}-04$ & 2.32 \\
\hline PDIA4 & $3.298 \mathrm{E}-03$ & 1.53 & $5.377 \mathrm{E}-03$ & 2.32 \\
\hline$S P R Y 1$ & $1.586 \mathrm{E}-04$ & 2.27 & $8.901 \mathrm{E}-04$ & 2.32 \\
\hline$P S M B 2$ & $2.769 \mathrm{E}-03$ & 1.75 & $3.871 \mathrm{E}-03$ & 2.32 \\
\hline$A T P 13 A 3$ & $2.832 \mathrm{E}-03$ & 1.56 & $6.209 \mathrm{E}-04$ & 2.33 \\
\hline$E N P P 2$ & $2.497 \mathrm{E}-02$ & 1.56 & $6.808 \mathrm{E}-03$ & 2.33 \\
\hline$R N P S 1$ & $7.156 \mathrm{E}-06$ & 1.83 & $2.321 \mathrm{E}-03$ & 2.33 \\
\hline$D D X 27$ & $1.147 \mathrm{E}-04$ & 1.63 & $4.456 \mathrm{E}-04$ & 2.33 \\
\hline PRMT1 & $1.998 \mathrm{E}-03$ & 1.52 & $7.071 \mathrm{E}-03$ & 2.33 \\
\hline$D B I$ & $7.271 \mathrm{E}-04$ & 1.67 & $4.683 \mathrm{E}-04$ & 2.33 \\
\hline$F K B P 3$ & $1.764 \mathrm{E}-03$ & 1.53 & $4.260 \mathrm{E}-03$ & 2.33 \\
\hline$S U L F 2$ & $1.815 \mathrm{E}-05$ & 1.89 & $3.735 \mathrm{E}-03$ & 2.33 \\
\hline PSMB8 & $4.842 \mathrm{E}-05$ & 2.47 & $7.027 \mathrm{E}-03$ & 2.34 \\
\hline
\end{tabular}




\section{Continued}

\begin{tabular}{|c|c|c|c|c|}
\hline$R A R S$ & $2.396 \mathrm{E}-06$ & 1.98 & $2.038 \mathrm{E}-03$ & 2.34 \\
\hline GOT2 & $6.968 \mathrm{E}-03$ & 1.60 & $1.631 \mathrm{E}-03$ & 2.34 \\
\hline$M E 1$ & $9.092 \mathrm{E}-03$ & 1.68 & $6.852 \mathrm{E}-03$ & 2.34 \\
\hline$R B B P 5$ & $1.153 \mathrm{E}-02$ & 1.59 & $1.321 \mathrm{E}-03$ & 2.34 \\
\hline CXCR4 & $6.181 \mathrm{E}-06$ & 4.51 & $4.472 \mathrm{E}-03$ & 2.34 \\
\hline$R A P 2 B$ & $2.668 \mathrm{E}-05$ & 1.77 & $2.376 \mathrm{E}-03$ & 2.34 \\
\hline$U S P 12$ & $1.689 \mathrm{E}-06$ & 2.09 & $9.603 \mathrm{E}-04$ & 2.35 \\
\hline$D L G 5$ & $1.250 \mathrm{E}-03$ & 1.82 & $2.159 \mathrm{E}-04$ & 2.35 \\
\hline$C D K N 1 A$ & $7.194 \mathrm{E}-05$ & 5.18 & $4.882 \mathrm{E}-03$ & 2.35 \\
\hline$F B X L 5$ & $9.989 \mathrm{E}-06$ & 1.97 & $2.323 \mathrm{E}-04$ & 2.35 \\
\hline$S L C 6 A 9$ & $1.106 \mathrm{E}-05$ & 2.16 & $6.493 \mathrm{E}-03$ & 2.35 \\
\hline$T A P 1$ & $1.197 \mathrm{E}-06$ & 2.59 & $1.247 \mathrm{E}-03$ & 2.35 \\
\hline IFIT5 & $8.429 \mathrm{E}-06$ & 2.24 & $2.574 \mathrm{E}-05$ & 2.35 \\
\hline$R B M 22$ & $4.014 \mathrm{E}-06$ & 1.84 & $2.014 \mathrm{E}-03$ & 2.35 \\
\hline$S O A T 1$ & $5.305 \mathrm{E}-06$ & 2.54 & $1.341 \mathrm{E}-03$ & 2.35 \\
\hline$E I F 4 E$ & $2.237 \mathrm{E}-05$ & 1.54 & $2.108 \mathrm{E}-03$ & 2.35 \\
\hline$F A M 103 A 1$ & $1.258 \mathrm{E}-06$ & 2.09 & $9.365 \mathrm{E}-03$ & 2.35 \\
\hline$A N T X R 2$ & $2.796 \mathrm{E}-06$ & 2.41 & $3.734 \mathrm{E}-03$ & 2.35 \\
\hline$R B M 14$ & $4.155 \mathrm{E}-05$ & 1.76 & $6.572 \mathrm{E}-04$ & 2.35 \\
\hline CTSB & $2.620 \mathrm{E}-07$ & 2.80 & $3.950 \mathrm{E}-03$ & 2.36 \\
\hline$M E 2$ & $1.431 \mathrm{E}-07$ & 4.44 & $3.003 \mathrm{E}-03$ & 2.36 \\
\hline COTL1 & $1.094 \mathrm{E}-07$ & 3.71 & $1.556 \mathrm{E}-04$ & 2.36 \\
\hline$H S P 90 A B 1$ & $1.240 \mathrm{E}-07$ & 3.63 & $6.663 \mathrm{E}-04$ & 2.36 \\
\hline PSME3 & $4.748 \mathrm{E}-04$ & 1.81 & $2.798 \mathrm{E}-03$ & 2.36 \\
\hline PSMB4 & $1.045 \mathrm{E}-04$ & 1.76 & $1.372 \mathrm{E}-04$ & 2.36 \\
\hline$D E G S 1$ & $1.503 \mathrm{E}-05$ & 1.62 & $9.150 \mathrm{E}-04$ & 2.36 \\
\hline ZC $3 H A V 1$ & $1.779 \mathrm{E}-07$ & 3.50 & $1.930 \mathrm{E}-03$ & 2.37 \\
\hline IER3 & $1.614 \mathrm{E}-04$ & 2.86 & $5.038 \mathrm{E}-03$ & 2.37 \\
\hline TACSTD2 & $7.811 \mathrm{E}-09$ & 10.88 & $1.470 \mathrm{E}-03$ & 2.37 \\
\hline SYNCRIP & $3.443 \mathrm{E}-03$ & 1.67 & $1.880 \mathrm{E}-03$ & 2.37 \\
\hline$A R P C 5$ & $2.118 \mathrm{E}-05$ & 1.76 & $5.749 \mathrm{E}-04$ & 2.37 \\
\hline$C D C 42 S E 2$ & $3.071 \mathrm{E}-07$ & 1.99 & $6.058 \mathrm{E}-04$ & 2.37 \\
\hline$D N A J C 3$ & $3.095 \mathrm{E}-05$ & 1.81 & $4.416 \mathrm{E}-03$ & 2.37 \\
\hline PES1 & $1.935 \mathrm{E}-05$ & 1.54 & $4.557 \mathrm{E}-03$ & 2.38 \\
\hline$F B X W 2$ & $3.293 \mathrm{E}-06$ & 2.08 & $4.617 \mathrm{E}-05$ & 2.38 \\
\hline $\mathrm{DPH} 2$ & $3.106 \mathrm{E}-05$ & 1.77 & $1.713 \mathrm{E}-03$ & 2.38 \\
\hline HSPA4 & $4.265 \mathrm{E}-05$ & 1.85 & $2.294 \mathrm{E}-03$ & 2.38 \\
\hline PICALM & $3.741 \mathrm{E}-04$ & 1.82 & $2.153 \mathrm{E}-03$ & 2.38 \\
\hline$A M M E C R 1 L$ & $3.784 \mathrm{E}-04$ & 1.83 & $2.581 \mathrm{E}-03$ & 2.38 \\
\hline$C A P 1$ & $8.545 \mathrm{E}-06$ & 2.04 & $1.670 \mathrm{E}-03$ & 2.39 \\
\hline$C A P Z A 1$ & $3.759 \mathrm{E}-04$ & 1.53 & $1.233 \mathrm{E}-03$ & 2.39 \\
\hline TPM4 & $7.875 \mathrm{E}-06$ & 2.22 & $4.105 \mathrm{E}-03$ & 2.39 \\
\hline TARS & $3.153 \mathrm{E}-04$ & 1.78 & $5.801 \mathrm{E}-04$ & 2.39 \\
\hline$I L 4 R$ & $2.288 \mathrm{E}-05$ & 2.33 & $3.517 \mathrm{E}-03$ & 2.40 \\
\hline PTGES3 & $3.662 \mathrm{E}-06$ & 1.78 & $1.549 \mathrm{E}-04$ & 2.40 \\
\hline$Y W H A G$ & $3.233 \mathrm{E}-06$ & 2.07 & $1.174 \mathrm{E}-03$ & 2.40 \\
\hline$B T G 1$ & $6.532 \mathrm{E}-08$ & 2.70 & $8.086 \mathrm{E}-03$ & 2.40 \\
\hline GLUD1 & $2.363 \mathrm{E}-04$ & 1.76 & $1.060 \mathrm{E}-03$ & 2.40 \\
\hline
\end{tabular}




\section{Continued}

\begin{tabular}{|c|c|c|c|c|}
\hline$E B N A 1 B P 2$ & $1.131 \mathrm{E}-06$ & 2.38 & $2.017 \mathrm{E}-03$ & 2.40 \\
\hline XPO6 & $1.902 \mathrm{E}-07$ & 2.11 & $1.043 \mathrm{E}-03$ & 2.41 \\
\hline$J U N B$ & $4.860 \mathrm{E}-08$ & 5.21 & $1.237 \mathrm{E}-04$ & 2.41 \\
\hline DNTTIP2 & $2.495 \mathrm{E}-03$ & 1.57 & $4.512 \mathrm{E}-03$ & 2.41 \\
\hline STX6 & $9.094 \mathrm{E}-04$ & 1.79 & $3.418 \mathrm{E}-03$ & 2.41 \\
\hline$Y W H A Z$ & $7.522 \mathrm{E}-04$ & 1.64 & $3.060 \mathrm{E}-03$ & 2.42 \\
\hline$P A R P 14$ & $2.667 \mathrm{E}-08$ & 3.12 & $4.282 \mathrm{E}-03$ & 2.42 \\
\hline$C E B P B$ & $1.907 \mathrm{E}-07$ & 2.98 & $4.832 \mathrm{E}-04$ & 2.42 \\
\hline$R N F 149$ & $1.105 \mathrm{E}-06$ & 2.10 & $3.332 \mathrm{E}-04$ & 2.42 \\
\hline$R P S 6 K A 3$ & $4.263 \mathrm{E}-04$ & 2.89 & $1.932 \mathrm{E}-03$ & 2.42 \\
\hline$A P E X 1$ & $4.864 \mathrm{E}-04$ & 1.53 & $3.798 \mathrm{E}-03$ & 2.42 \\
\hline$I L 10 R B$ & $5.428 \mathrm{E}-10$ & 3.62 & $1.152 \mathrm{E}-03$ & 2.42 \\
\hline$E A F 1$ & $2.498 \mathrm{E}-05$ & 2.25 & $4.242 \mathrm{E}-03$ & 2.42 \\
\hline$S L C 39 A 6$ & $9.024 \mathrm{E}-04$ & 1.79 & $4.306 \mathrm{E}-03$ & 2.42 \\
\hline GSPT1 & $7.421 \mathrm{E}-04$ & 1.59 & $5.596 \mathrm{E}-03$ & 2.42 \\
\hline$P K I G$ & $5.177 \mathrm{E}-03$ & 1.66 & $2.364 \mathrm{E}-03$ & 2.42 \\
\hline$I Q G A P 1$ & $2.597 \mathrm{E}-06$ & 1.84 & $3.464 \mathrm{E}-03$ & 2.42 \\
\hline ZNF281 & $6.625 \mathrm{E}-07$ & 2.97 & $2.326 \mathrm{E}-03$ & 2.42 \\
\hline$P G S 1$ & $3.224 \mathrm{E}-08$ & 3.51 & $5.726 \mathrm{E}-03$ & 2.42 \\
\hline$P S M A 1$ & $1.157 \mathrm{E}-06$ & 2.25 & $1.928 \mathrm{E}-03$ & 2.42 \\
\hline TNFRSF $1 A$ & $1.580 \mathrm{E}-07$ & 2.36 & $4.401 \mathrm{E}-05$ & 2.42 \\
\hline PARP9 & $1.020 \mathrm{E}-09$ & 4.19 & $1.971 \mathrm{E}-03$ & 2.43 \\
\hline$L Y P L A 1$ & $8.530 \mathrm{E}-07$ & 2.47 & $1.166 \mathrm{E}-03$ & 2.43 \\
\hline TRIM37 & $5.108 \mathrm{E}-06$ & 2.07 & $6.723 \mathrm{E}-03$ & 2.44 \\
\hline$P I K 3 A P 1$ & $3.097 \mathrm{E}-06$ & 3.03 & $4.637 \mathrm{E}-05$ & 2.44 \\
\hline$S P G 21$ & $7.031 \mathrm{E}-07$ & 2.39 & $1.963 \mathrm{E}-03$ & 2.44 \\
\hline$T S F M$ & $2.131 \mathrm{E}-04$ & 1.71 & $6.485 \mathrm{E}-03$ & 2.44 \\
\hline$M A P R E 1$ & $1.438 \mathrm{E}-04$ & 1.58 & $3.229 \mathrm{E}-04$ & 2.44 \\
\hline$C D 44$ & $1.031 \mathrm{E}-09$ & 6.88 & $2.314 \mathrm{E}-03$ & 2.44 \\
\hline$A B L 1$ & $5.007 \mathrm{E}-03$ & 1.72 & $5.638 \mathrm{E}-04$ & 2.45 \\
\hline$P S M A 2$ & $2.987 \mathrm{E}-05$ & 2.06 & $1.131 \mathrm{E}-04$ & 2.45 \\
\hline$L E O 1$ & $7.417 \mathrm{E}-04$ & 1.60 & $9.995 \mathrm{E}-04$ & 2.45 \\
\hline$P S M A 5$ & $7.350 \mathrm{E}-04$ & 1.61 & $1.087 \mathrm{E}-03$ & 2.45 \\
\hline PREP & $1.248 \mathrm{E}-05$ & 1.96 & $3.760 \mathrm{E}-04$ & 2.45 \\
\hline$T G F B I$ & $1.135 \mathrm{E}-07$ & 5.74 & $2.525 \mathrm{E}-03$ & 2.46 \\
\hline$C D 164$ & $3.472 \mathrm{E}-04$ & 1.90 & $8.728 \mathrm{E}-05$ & 2.46 \\
\hline$U N C 93 A$ & $1.108 \mathrm{E}-03$ & 1.65 & $1.030 \mathrm{E}-04$ & 2.46 \\
\hline$G P B P 1$ & $1.232 \mathrm{E}-03$ & 1.55 & $4.448 \mathrm{E}-03$ & 2.46 \\
\hline$G N A I 3$ & $3.707 \mathrm{E}-06$ & 2.24 & $1.525 \mathrm{E}-04$ & 2.46 \\
\hline$R A B 5 C$ & $1.378 \mathrm{E}-05$ & 1.60 & $2.148 \mathrm{E}-04$ & 2.46 \\
\hline MAPK6 & $9.939 \mathrm{E}-04$ & 1.64 & $9.782 \mathrm{E}-04$ & 2.47 \\
\hline$C D O 1$ & $3.795 \mathrm{E}-06$ & 2.69 & $2.869 \mathrm{E}-05$ & 2.47 \\
\hline$A S N S D 1$ & $3.104 \mathrm{E}-05$ & 1.98 & $4.060 \mathrm{E}-03$ & 2.47 \\
\hline$N F K B 2$ & $4.783 \mathrm{E}-07$ & 5.02 & $3.360 \mathrm{E}-03$ & 2.47 \\
\hline$G A P D H$ & $7.628 \mathrm{E}-11$ & 3.76 & $7.598 \mathrm{E}-06$ & 2.47 \\
\hline$T X N$ & $1.079 \mathrm{E}-05$ & 2.98 & $1.756 \mathrm{E}-03$ & 2.47 \\
\hline$R A C 1$ & $2.337 \mathrm{E}-09$ & 2.70 & $7.588 \mathrm{E}-05$ & 2.48 \\
\hline$C C N L 1$ & $9.457 \mathrm{E}-05$ & 2.07 & $4.973 \mathrm{E}-03$ & 2.48 \\
\hline
\end{tabular}




\section{Continued}

\begin{tabular}{|c|c|c|c|c|}
\hline$A D A M 19$ & $4.315 \mathrm{E}-08$ & 3.43 & $2.584 \mathrm{E}-03$ & 2.48 \\
\hline$S H 3 R F 1$ & $5.814 \mathrm{E}-05$ & 2.48 & $2.488 \mathrm{E}-03$ & 2.49 \\
\hline$L C P 1$ & $4.898 \mathrm{E}-10$ & 7.99 & $1.107 \mathrm{E}-03$ & 2.49 \\
\hline$T N I P 1$ & $8.206 \mathrm{E}-08$ & 4.14 & $2.118 \mathrm{E}-03$ & 2.50 \\
\hline$S K A P 2$ & $7.477 \mathrm{E}-08$ & 2.77 & $8.721 \mathrm{E}-04$ & 2.50 \\
\hline GNAI1 & $1.874 \mathrm{E}-02$ & 1.70 & $1.962 \mathrm{E}-03$ & 2.50 \\
\hline LETM 1 & $4.601 \mathrm{E}-04$ & 1.77 & $1.214 \mathrm{E}-04$ & 2.50 \\
\hline$E I F 2 A K 2$ & $7.598 \mathrm{E}-06$ & 2.81 & $9.093 \mathrm{E}-04$ & 2.50 \\
\hline$P Y G L$ & $2.604 \mathrm{E}-04$ & 2.37 & $4.496 \mathrm{E}-04$ & 2.50 \\
\hline SPCS3 & $1.244 \mathrm{E}-04$ & 1.81 & $3.180 \mathrm{E}-03$ & 2.50 \\
\hline$A P B B 1 I P$ & $2.283 \mathrm{E}-07$ & 3.71 & $7.966 \mathrm{E}-04$ & 2.50 \\
\hline$M P E G 1$ & $2.572 \mathrm{E}-04$ & 2.12 & $3.364 \mathrm{E}-04$ & 2.51 \\
\hline$B C L 6$ & $7.592 \mathrm{E}-04$ & 1.78 & $7.308 \mathrm{E}-04$ & 2.51 \\
\hline TAPBP & $1.496 \mathrm{E}-06$ & 1.98 & $1.392 \mathrm{E}-04$ & 2.51 \\
\hline$M S N$ & $1.163 \mathrm{E}-06$ & 2.19 & $3.891 \mathrm{E}-03$ & 2.51 \\
\hline GFPT2 & $9.933 \mathrm{E}-05$ & 2.93 & $1.238 \mathrm{E}-03$ & 2.52 \\
\hline$B 4 G A L T 5$ & $1.215 \mathrm{E}-03$ & 1.93 & $7.578 \mathrm{E}-05$ & 2.53 \\
\hline KIAA0020 & $3.397 \mathrm{E}-06$ & 1.80 & $7.147 \mathrm{E}-03$ & 2.53 \\
\hline$C N N 2$ & $2.288 \mathrm{E}-06$ & 2.87 & $6.993 \mathrm{E}-04$ & 2.53 \\
\hline$Z N F X 1$ & $9.714 \mathrm{E}-05$ & 1.81 & $9.497 \mathrm{E}-04$ & 2.53 \\
\hline PLAC8 & $5.976 \mathrm{E}-05$ & 3.96 & $2.621 \mathrm{E}-04$ & 2.53 \\
\hline$N I N J 1$ & $1.400 \mathrm{E}-05$ & 2.55 & $3.734 \mathrm{E}-04$ & 2.53 \\
\hline$E G R 1$ & $3.004 \mathrm{E}-05$ & 3.05 & $3.466 \mathrm{E}-03$ & 2.53 \\
\hline$B C A R 1$ & $2.774 \mathrm{E}-03$ & 1.66 & $3.061 \mathrm{E}-05$ & 2.54 \\
\hline$C D 53$ & $1.136 \mathrm{E}-08$ & 7.50 & $4.943 \mathrm{E}-05$ & 2.54 \\
\hline$E I F 2 S 1$ & $1.423 \mathrm{E}-05$ & 1.90 & $6.079 \mathrm{E}-04$ & 2.54 \\
\hline$X P N P E P 1$ & $3.125 \mathrm{E}-04$ & 1.51 & $9.498 \mathrm{E}-05$ & 2.55 \\
\hline$E T F 1$ & $2.442 \mathrm{E}-05$ & 2.31 & $2.361 \mathrm{E}-03$ & 2.55 \\
\hline$C H S Y 1$ & $1.503 \mathrm{E}-03$ & 1.87 & $2.960 \mathrm{E}-05$ & 2.56 \\
\hline$C C T 2$ & $4.623 \mathrm{E}-07$ & 2.35 & $3.598 \mathrm{E}-04$ & 2.56 \\
\hline$R A N$ & $1.566 \mathrm{E}-06$ & 1.93 & $8.518 \mathrm{E}-05$ & 2.56 \\
\hline$M T D H$ & $2.474 \mathrm{E}-06$ & 2.25 & $6.644 \mathrm{E}-05$ & 2.58 \\
\hline$F T H 1$ & $3.253 \mathrm{E}-08$ & 2.25 & $4.562 \mathrm{E}-03$ & 2.58 \\
\hline YARS & $2.835 \mathrm{E}-03$ & 1.70 & $3.182 \mathrm{E}-04$ & 2.59 \\
\hline$C A L C R L$ & $6.151 \mathrm{E}-03$ & 2.35 & $3.593 \mathrm{E}-04$ & 2.59 \\
\hline$C D 14$ & $5.675 \mathrm{E}-05$ & 2.31 & $1.200 \mathrm{E}-03$ & 2.59 \\
\hline$L A P 3$ & $3.410 \mathrm{E}-07$ & 2.39 & $1.532 \mathrm{E}-04$ & 2.59 \\
\hline$D G A T 2$ & $7.155 \mathrm{E}-06$ & 2.49 & $4.294 \mathrm{E}-03$ & 2.59 \\
\hline$R I P K 2$ & $1.435 \mathrm{E}-04$ & 1.77 & $1.281 \mathrm{E}-03$ & 2.59 \\
\hline$S L C 39 A 1$ & $1.189 \mathrm{E}-05$ & 1.86 & $3.585 \mathrm{E}-04$ & 2.59 \\
\hline$E L L$ & $1.914 \mathrm{E}-04$ & 1.63 & $6.155 \mathrm{E}-05$ & 2.59 \\
\hline$A T P 1 B 3$ & $1.059 \mathrm{E}-05$ & 1.99 & $3.262 \mathrm{E}-04$ & 2.59 \\
\hline$H K 3$ & $3.267 \mathrm{E}-06$ & 2.56 & $4.901 \mathrm{E}-03$ & 2.60 \\
\hline PFN1 & $2.672 \mathrm{E}-05$ & 2.00 & $6.449 \mathrm{E}-05$ & 2.60 \\
\hline PSME2 & $7.783 \mathrm{E}-05$ & 2.25 & $3.356 \mathrm{E}-04$ & 2.60 \\
\hline TNFRSF $6 B$ & $4.761 \mathrm{E}-08$ & 16.81 & $3.746 \mathrm{E}-03$ & 2.61 \\
\hline$S L C 11 A 2$ & $1.086 \mathrm{E}-04$ & 2.94 & $2.950 \mathrm{E}-04$ & 2.61 \\
\hline$P T G S 2$ & $8.825 \mathrm{E}-04$ & 2.98 & $3.098 \mathrm{E}-03$ & 2.62 \\
\hline
\end{tabular}




\section{Continued}

\begin{tabular}{|c|c|c|c|c|}
\hline ZNF259 & $1.571 \mathrm{E}-08$ & 4.09 & $3.524 \mathrm{E}-05$ & 2.62 \\
\hline CTTN & $2.266 \mathrm{E}-05$ & 1.82 & $1.846 \mathrm{E}-05$ & 2.62 \\
\hline$B A S P 1$ & $1.025 \mathrm{E}-09$ & 4.61 & $9.302 \mathrm{E}-04$ & 2.62 \\
\hline PDIA3 & $7.205 \mathrm{E}-04$ & 1.54 & $2.188 \mathrm{E}-04$ & 2.62 \\
\hline TRIM25 & $2.671 \mathrm{E}-03$ & 2.10 & $5.664 \mathrm{E}-05$ & 2.63 \\
\hline$K L F 10$ & $3.607 \mathrm{E}-05$ & 2.74 & $6.115 \mathrm{E}-05$ & 2.63 \\
\hline SELL & $3.699 \mathrm{E}-09$ & 9.41 & $4.881 \mathrm{E}-05$ & 2.63 \\
\hline REXO2 & $9.668 \mathrm{E}-03$ & 1.51 & $1.273 \mathrm{E}-05$ & 2.64 \\
\hline$C L E C 2 D$ & $2.334 \mathrm{E}-05$ & 2.51 & $4.824 \mathrm{E}-04$ & 2.64 \\
\hline PLSCR 1 & $3.972 \mathrm{E}-04$ & 1.94 & $1.051 \mathrm{E}-03$ & 2.65 \\
\hline$R S L 1 D 1$ & $1.747 \mathrm{E}-06$ & 2.00 & $1.205 \mathrm{E}-04$ & 2.65 \\
\hline$S L C O 4 A 1$ & $2.121 \mathrm{E}-03$ & 2.05 & $7.528 \mathrm{E}-05$ & 2.65 \\
\hline$T S R 1$ & $1.721 \mathrm{E}-06$ & 2.04 & $2.136 \mathrm{E}-03$ & 2.65 \\
\hline MTHFD2 & $4.432 \mathrm{E}-05$ & 3.47 & $4.381 \mathrm{E}-04$ & 2.66 \\
\hline$F B L$ & $3.675 \mathrm{E}-04$ & 1.75 & $1.039 \mathrm{E}-03$ & 2.66 \\
\hline$D D X 21$ & $7.622 \mathrm{E}-04$ & 1.91 & $7.045 \mathrm{E}-04$ & 2.66 \\
\hline CCT3 & $8.468 \mathrm{E}-08$ & 2.61 & $9.208 \mathrm{E}-04$ & 2.67 \\
\hline$U G D H$ & $1.774 \mathrm{E}-08$ & 5.49 & $7.768 \mathrm{E}-04$ & 2.68 \\
\hline$A A T F$ & $1.800 \mathrm{E}-08$ & 2.60 & $1.649 \mathrm{E}-03$ & 2.68 \\
\hline$P P P 1 R 3 C$ & $2.221 \mathrm{E}-02$ & 1.73 & $5.321 \mathrm{E}-04$ & 2.68 \\
\hline TUBB6 & $9.833 \mathrm{E}-06$ & 2.01 & $7.009 \mathrm{E}-04$ & 2.69 \\
\hline$R A C 2$ & $3.791 \mathrm{E}-07$ & 3.47 & $9.361 \mathrm{E}-05$ & 2.69 \\
\hline ACTR 3 & $1.263 \mathrm{E}-07$ & 2.49 & $1.890 \mathrm{E}-05$ & 2.69 \\
\hline$H I F 1 A$ & $5.376 \mathrm{E}-03$ & 1.56 & $1.820 \mathrm{E}-04$ & 2.70 \\
\hline TRIP10 & $1.781 \mathrm{E}-04$ & 1.72 & $1.609 \mathrm{E}-04$ & 2.71 \\
\hline$T G I F 1$ & $2.745 \mathrm{E}-09$ & 4.70 & $2.080 \mathrm{E}-03$ & 2.72 \\
\hline IL 18 & $4.383 \mathrm{E}-06$ & 3.95 & $4.682 \mathrm{E}-03$ & 2.73 \\
\hline WTAP & $6.029 \mathrm{E}-07$ & 3.51 & $1.929 \mathrm{E}-03$ & 2.73 \\
\hline$T L R 2$ & $3.800 \mathrm{E}-06$ & 5.08 & $7.792 \mathrm{E}-04$ & 2.73 \\
\hline$I L 13 R A 1$ & $6.900 \mathrm{E}-08$ & 4.46 & $1.827 \mathrm{E}-04$ & 2.74 \\
\hline$R A B 8 B$ & $4.100 \mathrm{E}-06$ & 2.65 & $8.962 \mathrm{E}-05$ & 2.74 \\
\hline$D N A J B 1$ & $1.964 \mathrm{E}-04$ & 1.87 & $7.543 \mathrm{E}-05$ & 2.74 \\
\hline WARS & $2.972 \mathrm{E}-07$ & 3.75 & $1.061 \mathrm{E}-04$ & 2.75 \\
\hline$N P M 1$ & $1.562 \mathrm{E}-06$ & 1.91 & $6.562 \mathrm{E}-07$ & 2.75 \\
\hline$M K N K 1$ & $5.162 \mathrm{E}-07$ & 4.35 & $8.468 \mathrm{E}-04$ & 2.76 \\
\hline$P P P 2 R 3 C$ & $1.962 \mathrm{E}-07$ & 2.84 & $9.361 \mathrm{E}-04$ & 2.76 \\
\hline$D E N N D 2 D$ & $2.413 \mathrm{E}-05$ & 2.11 & $3.423 \mathrm{E}-04$ & 2.76 \\
\hline CREM & $4.351 \mathrm{E}-07$ & 2.86 & $7.710 \mathrm{E}-05$ & 2.77 \\
\hline CFLAR & $4.988 \mathrm{E}-05$ & 3.68 & $5.098 \mathrm{E}-05$ & 2.78 \\
\hline$I L 1 R A P$ & $7.593 \mathrm{E}-08$ & 12.26 & $1.450 \mathrm{E}-03$ & 2.79 \\
\hline$S M A D 3$ & $3.316 \mathrm{E}-04$ & 1.88 & $8.698 \mathrm{E}-05$ & 2.79 \\
\hline $\mathrm{CTSH}$ & $1.083 \mathrm{E}-08$ & 4.37 & $4.274 \mathrm{E}-04$ & 2.79 \\
\hline PTPRC & $2.453 \mathrm{E}-07$ & 3.01 & $7.043 \mathrm{E}-04$ & 2.80 \\
\hline EFHD2 & $2.703 \mathrm{E}-04$ & 2.29 & $5.093 \mathrm{E}-05$ & 2.80 \\
\hline$M Y C$ & $1.141 \mathrm{E}-05$ & 2.77 & $1.663 \mathrm{E}-03$ & 2.80 \\
\hline SPINT1 & $7.591 \mathrm{E}-07$ & 1.98 & $5.885 \mathrm{E}-04$ & 2.81 \\
\hline TNFAIP6 & $1.118 \mathrm{E}-05$ & 5.40 & $2.746 \mathrm{E}-04$ & 2.82 \\
\hline TREM1 & $2.224 \mathrm{E}-12$ & 18.55 & $1.376 \mathrm{E}-03$ & 2.82 \\
\hline
\end{tabular}




\section{Continued}

\begin{tabular}{|c|c|c|c|c|}
\hline$P D K 4$ & $2.015 \mathrm{E}-05$ & 4.29 & $2.598 \mathrm{E}-03$ & 2.82 \\
\hline$C D 48$ & $2.297 \mathrm{E}-07$ & 7.34 & $3.839 \mathrm{E}-03$ & 2.83 \\
\hline GNG5 & $7.598 \mathrm{E}-05$ & 2.21 & $1.247 \mathrm{E}-04$ & 2.83 \\
\hline IER5 & $6.385 \mathrm{E}-09$ & 4.52 & $9.829 \mathrm{E}-06$ & 2.83 \\
\hline$P L A U$ & $6.120 \mathrm{E}-07$ & 3.15 & $7.076 \mathrm{E}-04$ & 2.84 \\
\hline$A R G 2$ & $5.740 \mathrm{E}-07$ & 9.36 & $8.823 \mathrm{E}-04$ & 2.85 \\
\hline$N C L$ & $1.458 \mathrm{E}-05$ & 1.67 & $2.094 \mathrm{E}-05$ & 2.85 \\
\hline SOCS3 & $1.981 \mathrm{E}-07$ & 10.69 & $7.538 \mathrm{E}-05$ & 2.85 \\
\hline CKAP4 & $7.588 \mathrm{E}-09$ & 2.68 & $4.360 \mathrm{E}-04$ & 2.85 \\
\hline$F G L 2$ & $6.026 \mathrm{E}-07$ & 3.84 & $2.331 \mathrm{E}-03$ & 2.87 \\
\hline$N O L C 1$ & $1.100 \mathrm{E}-04$ & 1.73 & $3.343 \mathrm{E}-05$ & 2.87 \\
\hline$M F A P 1$ & $2.666 \mathrm{E}-05$ & 1.94 & $3.058 \mathrm{E}-05$ & 2.87 \\
\hline STAT3 & $3.920 \mathrm{E}-06$ & 3.56 & $7.192 \mathrm{E}-04$ & 2.87 \\
\hline$I T G A V$ & $8.828 \mathrm{E}-05$ & 3.04 & $7.350 \mathrm{E}-04$ & 2.89 \\
\hline$M A P 3 K 8$ & $4.641 \mathrm{E}-08$ & 6.06 & $2.059 \mathrm{E}-03$ & 2.90 \\
\hline$Z F P 36 L 2$ & $2.083 \mathrm{E}-07$ & 2.75 & $3.291 \mathrm{E}-04$ & 2.91 \\
\hline$O L R 1$ & $5.814 \mathrm{E}-08$ & 10.47 & $8.629 \mathrm{E}-04$ & 2.91 \\
\hline$E H B P 1 L 1$ & $2.585 \mathrm{E}-07$ & 2.76 & $8.502 \mathrm{E}-04$ & 2.92 \\
\hline$F 13 A 1$ & $6.370 \mathrm{E}-05$ & 3.35 & $8.009 \mathrm{E}-04$ & 2.92 \\
\hline$V C A M 1$ & $1.063 \mathrm{E}-05$ & 3.70 & $3.358 \mathrm{E}-05$ & 2.96 \\
\hline$P D P N$ & $3.439 \mathrm{E}-07$ & 5.14 & $8.817 \mathrm{E}-04$ & 3.01 \\
\hline$F A M 49 B$ & $1.473 \mathrm{E}-09$ & 4.03 & $1.273 \mathrm{E}-03$ & 3.01 \\
\hline$H P R T 1$ & $4.758 \mathrm{E}-09$ & 2.83 & $2.945 \mathrm{E}-05$ & 3.01 \\
\hline$I L 10 R A$ & $7.765 \mathrm{E}-06$ & 2.80 & $2.024 \mathrm{E}-04$ & 3.06 \\
\hline$C X C L 2$ & $2.015 \mathrm{E}-09$ & 94.97 & $4.469 \mathrm{E}-04$ & 3.08 \\
\hline$I L 18 B P$ & $4.330 \mathrm{E}-13$ & 19.99 & $2.502 \mathrm{E}-05$ & 3.09 \\
\hline$C A L R$ & $1.175 \mathrm{E}-03$ & 1.51 & $5.533 \mathrm{E}-05$ & 3.10 \\
\hline$P H C 2$ & $3.577 \mathrm{E}-05$ & 1.94 & $4.503 \mathrm{E}-03$ & 3.12 \\
\hline HSPA8 & $2.282 \mathrm{E}-04$ & 1.97 & $1.316 \mathrm{E}-04$ & 3.15 \\
\hline$M A R C K S$ & $1.100 \mathrm{E}-06$ & 3.38 & $2.273 \mathrm{E}-04$ & 3.16 \\
\hline PSTPIP2 & $1.473 \mathrm{E}-09$ & 9.30 & $8.168 \mathrm{E}-04$ & 3.20 \\
\hline SPI1 & $1.665 \mathrm{E}-09$ & 8.31 & $2.253 \mathrm{E}-03$ & 3.22 \\
\hline$P T X 3$ & $6.138 \mathrm{E}-05$ & 14.95 & $2.374 \mathrm{E}-05$ & 3.26 \\
\hline CCL20 & $1.492 \mathrm{E}-03$ & 4.25 & $3.011 \mathrm{E}-04$ & 3.28 \\
\hline$G N L 3$ & $6.264 \mathrm{E}-04$ & 1.51 & $8.200 \mathrm{E}-04$ & 3.32 \\
\hline$I L 1 R 2$ & $1.442 \mathrm{E}-07$ & 21.40 & $4.001 \mathrm{E}-04$ & 3.39 \\
\hline$T H B S 1$ & $1.473 \mathrm{E}-02$ & 1.92 & $3.659 \mathrm{E}-04$ & 3.44 \\
\hline CASP4 & $8.023 \mathrm{E}-09$ & 5.76 & $2.035 \mathrm{E}-04$ & 3.48 \\
\hline$L D H A$ & $2.002 \mathrm{E}-10$ & 7.36 & $2.267 \mathrm{E}-04$ & 3.51 \\
\hline ERRFI1 & $1.041 \mathrm{E}-06$ & 3.51 & $9.545 \mathrm{E}-06$ & 3.53 \\
\hline$C D 9$ & $1.353 \mathrm{E}-06$ & 1.87 & $3.570 \mathrm{E}-06$ & 3.66 \\
\hline ZFP36 & $1.841 \mathrm{E}-07$ & 3.88 & $1.258 \mathrm{E}-04$ & 3.66 \\
\hline$M X D 1$ & $1.177 \mathrm{E}-07$ & 4.43 & $2.527 \mathrm{E}-05$ & 3.76 \\
\hline FOS & $1.259 \mathrm{E}-07$ & 7.79 & $1.195 \mathrm{E}-05$ & 3.78 \\
\hline$C E B P D$ & $1.642 \mathrm{E}-06$ & 5.41 & $9.992 \mathrm{E}-05$ & 3.93 \\
\hline$B C L 3$ & $1.501 \mathrm{E}-05$ & 2.11 & $1.060 \mathrm{E}-04$ & 3.94 \\
\hline CXCL6 & $3.538 \mathrm{E}-10$ & 36.81 & $6.165 \mathrm{E}-04$ & 4.01 \\
\hline$C D 69$ & $6.630 \mathrm{E}-06$ & 7.08 & $1.879 \mathrm{E}-03$ & 4.04 \\
\hline
\end{tabular}




\section{Continued}

\begin{tabular}{|c|c|c|c|c|}
\hline$S D C B P$ & $1.953 \mathrm{E}-06$ & 2.14 & $3.513 \mathrm{E}-05$ & 4.06 \\
\hline$L T F$ & $3.092 \mathrm{E}-04$ & 2.16 & $2.757 \mathrm{E}-07$ & 4.08 \\
\hline$C D 55$ & $7.343 \mathrm{E}-11$ & 18.46 & $2.532 \mathrm{E}-04$ & 4.20 \\
\hline$E I F 4 A 1$ & $7.736 \mathrm{E}-08$ & 2.11 & $7.705 \mathrm{E}-05$ & 4.25 \\
\hline$B T G 2$ & $1.734 \mathrm{E}-03$ & 1.93 & $8.071 \mathrm{E}-04$ & 4.37 \\
\hline NFKBIA & $2.947 \mathrm{E}-05$ & 3.40 & $5.504 \mathrm{E}-05$ & 4.48 \\
\hline$I L 1 R N$ & $4.433 \mathrm{E}-09$ & 30.47 & $7.596 \mathrm{E}-05$ & 4.54 \\
\hline$T G M 3$ & $1.511 \mathrm{E}-10$ & 34.32 & $1.288 \mathrm{E}-03$ & 4.65 \\
\hline$C C R 1$ & $1.818 \mathrm{E}-12$ & 22.15 & $1.624 \mathrm{E}-04$ & 4.67 \\
\hline TIMP1 & $5.574 \mathrm{E}-07$ & 9.62 & $4.653 \mathrm{E}-05$ & 4.68 \\
\hline SELP & $2.566 \mathrm{E}-03$ & 2.24 & $1.030 \mathrm{E}-04$ & 4.69 \\
\hline$F S C N 1$ & $1.983 \mathrm{E}-04$ & 1.59 & $1.680 \mathrm{E}-05$ & 4.69 \\
\hline$R R A D$ & $1.179 \mathrm{E}-04$ & 2.54 & $1.228 \mathrm{E}-04$ & 4.74 \\
\hline IL6 & $1.157 \mathrm{E}-03$ & 7.04 & $5.230 \mathrm{E}-04$ & 4.89 \\
\hline CXCL8 & $1.015 \mathrm{E}-09$ & 82.99 & $1.332 \mathrm{E}-04$ & 5.64 \\
\hline PLAUR & $5.943 \mathrm{E}-04$ & 2.24 & $5.168 \mathrm{E}-05$ & 5.71 \\
\hline$S 100 A 2$ & $4.128 \mathrm{E}-10$ & 12.75 & $1.518 \mathrm{E}-04$ & 5.86 \\
\hline$E M R 1$ & $2.942 \mathrm{E}-11$ & 63.30 & $8.899 \mathrm{E}-05$ & 6.02 \\
\hline CTSC & $2.926 \mathrm{E}-11$ & 8.53 & $1.140 \mathrm{E}-05$ & 6.51 \\
\hline$S R G N$ & $8.525 \mathrm{E}-11$ & 10.29 & $8.856 \mathrm{E}-06$ & 6.70 \\
\hline LOC508666 & $6.325 \mathrm{E}-04$ & 4.39 & $2.602 \mathrm{E}-05$ & 6.84 \\
\hline$L Y Z$ & $2.947 \mathrm{E}-07$ & 9.10 & $8.344 \mathrm{E}-05$ & 6.93 \\
\hline$S L C 2 A 3$ & $7.758 \mathrm{E}-06$ & 4.59 & $1.488 \mathrm{E}-04$ & 7.64 \\
\hline$B C L 2 A 1$ & $1.008 \mathrm{E}-08$ & 9.25 & $9.684 \mathrm{E}-05$ & 8.12 \\
\hline$S 100 A 12$ & $1.315 \mathrm{E}-12$ & 121.83 & $4.831 \mathrm{E}-04$ & 9.02 \\
\hline BIRC3 & $1.024 \mathrm{E}-06$ & 9.27 & $2.839 \mathrm{E}-05$ & 9.61 \\
\hline MARCKSL1 & $4.891 \mathrm{E}-06$ & 2.49 & $1.610 \mathrm{E}-06$ & 9.83 \\
\hline$S 100 A 9$ & $1.288 \mathrm{E}-15$ & 262.26 & $3.313 \mathrm{E}-05$ & 12.22 \\
\hline$C C L 2$ & $1.797 \mathrm{E}-06$ & 11.15 & $2.960 \mathrm{E}-05$ & 20.21 \\
\hline
\end{tabular}

Table S2. Top 10 signalling pathways from IPA among the $505^{\#}$ common DEGs altered by experimental infections with both $E$. coli and $S$. uberis (all with $\mathrm{P}<10 \mathrm{E}-6$ ).

\begin{tabular}{|c|c|c|}
\hline Canonical pathways & Molecules & Ratio \\
\hline IL-10 Signalling & 16 & $2.05 \mathrm{E}-01$ \\
\hline Granulocyte Adhesion and Diapedesis & 24 & $1.32 \mathrm{E}-01$ \\
\hline LXR/RXR Activation & 19 & $1.37 \mathrm{E}-01$ \\
\hline IL-6 Signalling & 18 & $1.45 \mathrm{E}-01$ \\
\hline Glucocorticoid Receptor Signalling & 26 & $8.7 \mathrm{E}-02$ \\
\hline Ephrin Receptor Signalling & 21 & $1 \mathrm{E}-01$ \\
\hline Agranulocyte Adhesion and Diapedesis & 21 & $1.09 \mathrm{E}-01$ \\
\hline $\operatorname{PPAR} \alpha / \operatorname{RXR} \alpha$ Activation & 20 & $1 \mathrm{E}-01$ \\
\hline Hepatic Fibrosis/Hepatic Stellate Cell Activation & 17 & $1.1 \mathrm{E}-01$ \\
\hline Leukocyte Extravasation Signalling & 20 & $9.52 \mathrm{E}-02$ \\
\hline
\end{tabular}

\#504 Genes with known IPA-eligible human and rodent orthologs were considered. 
Table S3. Primary function analysis with IPA for the $505^{\#}$ common DEGs altered by both experimental infections with both E. coli and $S$. uberis (all with $\mathrm{P}<1 \mathrm{E}-7$ ).

\begin{tabular}{ll}
\hline \multicolumn{1}{c}{ Name } & Molecules \\
\hline Diseases and Disorders & 164 \\
Inflammatory Response & 112 \\
Connective Tissue Disorders & 246 \\
Molecular and Cellular Functions & 249 \\
Cell Death and Survival & 172 \\
Cellular Growth and Proliferation & 187 \\
Cellular Movement & 223 \\
Cellular Function and Maintenance & 110 \\
Cellular Development & 182 \\
Physiological System Development and Function & 155 \\
Immune Cell Trafficking & 165 \\
Organismal Survival & 149 \\
Tissue Morphology & \\
Hematological System Development and Function & \\
Tissue Development &
\end{tabular}

\#504 Genes with known IPA-eligible human and rodent orthologs were considered.

Table S4. Summary list of 93 significant SNPs associated with somatic cell count in seven different populations of dairy cows and 1635 genes located $2 \mathrm{Mbp}$ around them ${ }^{\#}$.

\begin{tabular}{|c|c|c|}
\hline $\mathrm{SNP}^{+}$ & BTA & Symbols of nearby genes located within $2 \mathrm{Mbp}$ \\
\hline rs41637122 & 1 & $A P P, A T P 5 J, G A B P A, J A M 2, M R P L 39$ \\
\hline BTA-47902 & 2 & ACTR3, GPR39, LYPD1, MGAT5, NCKAP5, SLC35F5 \\
\hline $\begin{array}{l}\text { Hap- } \\
\text { map29674-BTA-16031 } \\
\text { 0/rs110139290 }\end{array}$ & 2 & $A R H G A P 15, K Y N U, L R P 1 B$ \\
\hline rs110491622 & & $\begin{array}{l}\text { ABCB11, B3GALT1, BBS5, CCDC173, CERS6, DHRS9, FASTKD1, G6PC2, KBTBD10, KLHL23, } \\
\text { LRP2, METTL5, MYO3B, NOSTRIN, PHOSPHO2, PPIG, SPC25, SSB, STK39, UBR3, XIRP2 }\end{array}$ \\
\hline rs29025784 & 2 & $\begin{array}{l}\text { TNS1, AAMP, ABCB6, NKZF1, ARPC2, ASIC4, ATG9A, BCS1L, C2H2ORF24, C2ORF17, C2orf62, } \\
C C D C 108, C D K 5 R 2, C H P F, C R Y B A 2, C T D S P 1, C X C R 2, C X C R 2, C Y P 27 A 1, \text { DES, DNAJB2, } \\
\text { DNPEP, EPHA4, FEV, GLB1L, GMPPA, GPBAR1, IHH, INHA, MGC157327, NHEJ1, OBSL1, } \\
P L C D 4, \text { PNKD, PRKAG3, PTPRN, RECS1, RESP18, RNF } 25, \text { RQCD1, SLC11A1, SLC23A3, } \\
\text { SLC4A3, SPEG, STK11IP, STK16, STK36, TMEM198, TTLL4, TUBA1D, TUBA4A, USP37, VIL1, } \\
\text { WNT10A, WNT6, ZFAND2B, ZNF142 }\end{array}$ \\
\hline $\begin{array}{l}\text { rs } 41622740 / \\
\text { rs41622742 }\end{array}$ & 2 & $A C A D L, C P S 1, C R Y G F, E R B B 4, K A N S L 1 L, L A N C L 1, M A P-2, M Y L 1, P T H 2 R, R P E, U N C 80$ \\
\hline rs29020694 & 4 & $\begin{array}{l}\text { ING3, CPED1, WNT16, FAM3C, PTPRZ1, AASS, FEZF1, CADPS2, TAS2R16, SLC13A1, IQUB, } \\
\text { NDUFA5, ASB15, LMOD2, WASL, HYAL4, GPR37, POT1 }\end{array}$ \\
\hline rs41590209 & 4 & $\begin{array}{l}\text { AASS, ASB15, CADPS2, CPED1, FAM3C, FEZF1, GPR37, HYAL4, , NG3, IQUB, LMOD2, } \\
\text { NDUFA5, POT1, PTPRZ1, SLC13A1, TAS2R16, WASL, WNT16, AHCYL2, ARF5, ATP6V1F, CALU, } \\
\text { CCDC136, CEP41, COPG2, CPA1, CPA4, CPA5, FAM71F1, FAM71F2, FLNC, FSCN3, GCC1, } \\
\text { HIG2, IMPDH1, IRF5, KLHDC10, LRRC4, MEST, MGC127766, MKLN1, NRF1, OB, OPN1SW, } \\
\text { PAX4, PODXL, PRRT4, RBM28, SMO, SND1, STRIP2, TMEM209, TNPO3, TSGA13, TSPAN33, } \\
\text { UBE2H, ZC3HC1, ZNF800 }\end{array}$ \\
\hline $\begin{array}{l}\text { Hap- } \\
\text { map55237-rs29010308 }\end{array}$ & 5 & ALX1, LRRIQ1, MGAT4C, NTS, RASSF9, SLC6A15, TSPAN19 \\
\hline
\end{tabular}




\section{Continued}

rs41257360

rs29017739/rs29001782/

rs41588957/Hapmap6022 4-rs29001782/rs1103209

75/rs110289032/rs416109 91/rs109427807/rs811503 $88 /$ rs $110707460 /$ rs 110527 224/rs43338539/rs108988 $814 / \mathrm{rs} 42766480 / \mathrm{rs} 427664$ $80 /$

rs41617692/rs41655332/ rs41655339/rs41617947/r s41653149

rs41664497/

rs 110927426

rs29013992/rs109746386

rs110066189

rs110213141

rs41657989/ Hapmap50931-BTA-31235/

rs41596179

rs41665468

rs41654612

rs43619106

rs43673004

rs109934030/

rs41634110/

rs109441194

rs111004585

rs41628293
APOLD1, BCL2L14, BOTA-T2R10B, CDKN1B, CREBL2, CSDA, DDX47, DUSP16, EMP1, ETV6, GPR19, GPRC5A, GPRC5D, GRIN2B, GSG1, HEBP1, KIAA1467, KLRA1, KLRC1, KLRJ1, LOH12CR1, LRP6, MAGOHB, MANSC1, NKG2A, STYK1, T2R10C, T2R12, T2R65A, TAS2R10, TAS2R42, TAS2R46

LPHN3, ADAMTS3, AFM, AFP, ALB, AMBN, AMTN, ANKRD17, ANTXR2, ANXA3, ART3, BMP2K, BTC, CABS1, CCDC158, CCNG2, CCNI, CDKL2, CENPC1, CNOT6L, COX18, CSN1S1, CSN1S2, CSN2, CSN3, CXCL10, CXCL11, CXCL13, CXCL2, CXCL3, CXCL6, CXCL9, DCK, DKFZP564O0823, DYNLL1, ENAM, EPGN, EPHA5, EREG, FAM47E-STBD1, FRAS1, G3BP2, GC, 6 GK2, GNRHR, GRO1, GRSF1, HSTN, IGJ, CXCL8, MGC152010, MOB1B, MRPL1, MTHFD2L, NAA11, NAAA, NPFFR2, NUP54, ODAM, PAQR3, PF4, PPBP, PPEF2, RASSF6, RCHY1, RPL23A, RUFY3, SCARB2, SDAD1, SHROOM3, SLC25A16, SLC4A4, SOWAHB, STAP1, STATH, SULT1B1, SULT1E1, TECRL, THAP6, TMPRSS11A, TMPRSS11D, TMPRSS11F, UBA6, UGT2A3, USO1, UTP3, YTHDC1

ADH4, ADH5, ADH6, ADH7, BANK1, BDH2, C4orf17, CENPE, CISD2, DAPP1, DDIT4L, NHEDC1, PPP3CA, RAP1GDS1, SLC39A8, SLC9B2, TRMT10A, TSPAN5

LPHN3

ACER1, ACP5, ACTL9, ADAMTS10, ALKBH7, ANGPTL4, ANGPTL6, AP1M2, ATG4D, C19orf38, C19orf45, C19orf59, C19orf80, C3, C7H19orf52, C7H19orf66, CAMSAP3, CARM1, CCDC151, CCDC159, CCL25, CD209, CD320, CD70, CDC37, CDKN2D, CERS4, CLEC4G, CLPP, CNN1, COL5A3, CTXN1, DENND1C, DNM2, DNMT1, DOCK6, ECSIT, EIF3G, ELAVL1, ELAVL3, ELOF1, EMR1, EPOR, EVI5L, FBN3, FBXL12, FCER2, FDX1L, GPR108, GTF2F1, ICAM1, ICAM3, ICAM4, 7 ICAM5, ILF3, IR-A, KANK2, KANK3, KEAP1, KHSRP, KRI1, LDLR, LRRC8E, MAP2K7, 02-Mar, MCOLN1, MLLT1, MRPL4, MYO1F, NDUFA7, OLFM2, OR2Z1, P2RY11, PCP2, PDE4A, PEX11G, PIN1, PNPLA6, PPAN-P2RY11, PRAM1, PRKCSH, PSPN, QTRT1, RAB11B, RAB3D, RAVER1, RDH8, RETN, RGL3, RPS28, S1PR2, S1PR5, SH2D3A, SLC25A23, SLC25A41, SLC44A2, SNAPC2, SPC24, STXBP2, SWSAP1, TIMM44, TMED1, TMEM205, TNFSF14, TNFSF9, TRAPPC5, TRIP10, TSPAN16, TUBB4A, TYK2, VAV1, XAB2, YIPF2, ZGLP1, ZNF266, ZNF358, ZNF414, ZNF558, ZNF653

AKAP8, AKAP8L, AP1M1, BRD4, C19orf44, CALR3, CASP14, CCDC105, CHERP, CIB3, CYP4F2, 7 CYP4F22, CYP4F3, EPHX3, EPS15L1, FAM32A, ILVBL, NOTCH3, OR10H1, OR7C2, PGLYRP2, RAB8A, RASAL3, SLC1A6, SYDE1, TPM4, WIZ

7SK, ACSL6, ADAMTS19, ALDH7A1, C5orf63, C7H5orf48, CDC42SE2, CHSY3, CSF2, CTXN3, 7 FBN2, FNIP1, GRAMD3, HINT1, IL3, ISOC1, KIAA1024L, LMNB1, LYRM7, MEGF10, P4HA2, PDLIM4, PHAX, PRRC1, SLC12A2, SLC27A6, ZNF608

9 ADGB, GRM1, KATNA1, LATS1, LRP11, MGC133692, NUP43, PCMT1, PPIL4, PPP1R14C, RAB32, RAET1G, RYK, SAMD5, SASH1, STXBP5, TAB2, ULBP3, ZC3H12D

ADCK1, AHSA1, ALKBH1, ANGEL1, C14orf166B, DIO2, GSTZ1, IRF2BPL, ISM2, KIAA1737, NGB, 10 NOXRED1, NRXN3, POMT2, SAMD15, SLIRP, SNW1, SPTLC2, TMED8, TMEM63C, VASH1, VIPAS39, ZDHHC22

10 AQR, C10H15ORF41, DPH6, FAM98B, MEIS2, RASGRP1, SPRED1, TMCO5A, ZNF770

ABCG5, ABCG8, ATP6V1E2, CAMKMT, CRIPT, DYNC2LI1, EPAS1, LRPPRC, MCFD2, PIGF, 11 PLEKHH2, PPM1B, PREPL, PRKCE, RHOQ, SIX2, SIX3, SLC3A1, SOCS5, SRBD1, THADA, TMEM247, TTC7A, ZFP36L2

ARFGEF2, ATP9A, B4GALT5, BCAS4, CSE1L, DDX27, DPM1, FAM65C, KCNB1, KCNG1, 13 MOCS3, NCOA3, NFATC2, PARD6B, PREX1, PTGIS, PTPN1, RNF114, SALL4, SLC9A8, SNAI1, SPATA2, STAU1, SULF2, TMEM189, TSHZ2, UBE2V1, ZFP64, ZNF217, ZNFX1

13 BTBD3, C20ORF13, C20ORF82, JAG1, MKKS, SLX4IP, SNAP25, SPTLC3, SRY

ARMC4, BAMBI, BANF2, BFSP1, C13H20ORF12, C20orf26, CRNKL1, CSRP2BP, DSTN, DTD1, 13 MGME1, MKX, MPP7, NAA20, OVOL2, PCSK2, POLR3F, RAB18, RBBP9, RIN2, RPL5, RRBP1, $S C P 2 D 1, S E C 23 B, S L C 24 A 3, S L C 6 A 9, S N X 5, W A C, Z N F 133$ 
Continued

rs41694067/ rs110942493/rs41601522 /rs29022774/rs29022775 / rs41576572 rs109146371/ rs109421300/ rs109350371

rs29012803

rs41629827/ rs41630587/ rs41620570

rs110034639

rs41579632

rs41616806

rs110754697

rs29014958

rs29020544

rs41578926

rs41257403/

rs41636878

rs 109838275

rs41577870
ACSS2, ACTL10, AHCY, ANKRD60, APCDD1L, ASIP, ASXL1, ATP5E, AURKA, BASE, BCL2L1, BMP7, BORIS, BPIFA1, BPIFA2B, BPIFB1, BPIFB2, BPIFB3, BPIFB4, BPIFB6, BSP30C, BSP30D, C13H20ORF108, C13H20ORF71, C13H20ORF85, C20orf112, C20orf144, C20ORF18, C20orf96, CASS4, CBFA2T2, CCM2L, CDH26, CDH4, CDK5RAP1, CEP250, CHMP4B, COMMD7, COX4I2, CSNK2A1, CSTF1, CTSZ, DEFB119, DEFB122, DEFB122A, DEFB123, DEFB124, DEFB129, DNMT3B, DUSP15, DYNLRB1, E2F1, EDEM2, EDN3, EIF2S2, EIF6, FAM110A, FAM209B, 13 FAM217B, FAM83C, FKBP1A, FOXS1, GCNT7, GDF5, GGT7, GNAS, GSS, HCK, HM13, ID1, ITCH,KIF3B, MAP1LC3A, MAPRE1, MMP24, MYH7B, MYLK2, NCOA6, NECAB3, NELFCD, NPEPL1, NRSN2, NSFL1C, PCK1, PDRG1, PHACTR3, PIGU, PLAGL2, PMEPA1, POFUT1, PPP1R3D, PROCR, PSMF1, PXMP4, RAB22A, RAD21L1, RAE1, RALY, RBM38, REM1, RSPO4, RTFDC1, SDCBP2, SIRPB2, SIRPD, SLC52A3, SLMO2, SNPH, SNTA1, SPAG4L, SPO11, SRXN1, SS18L1, STX16, SYCP2, TAF4, TBC1D20, TCF15, TFAP2C, TM9SF4, TMEM74B, TP53INP2, TPX2, TRIB3, TRPC4AP, TTLL9, TUBB1, UQCC, VAPB, XKR7, ZBP1, ZCCHC3, ZNF341, ZNF831

ADCK5, ARC, ARHGAP39, BAI1, C14H8orf82, C8orf33, CCDC166, COMMD5, CPSF1, CYC1, CYHR1, DENND3, DGAT1, EEF1D, EXOSC4, FAM83H, FBXL6, FOXH1, GML, GPAA1, GPR172B, GPR20, GPT,GRINA ,GSDMD ,HSF1 ,KIAA1875 ,KIFC2 , LRRC14, LRRC24, LY6D, LY6E, LY6H, 14 LY6K, LYNX1, LYPD2, MAF1, MAFA, MAPK15, MFSD3, MROH1, MROH6, NAPRT1, NRBP2, OPLAH, PARP10, PLEC, PPP1R16A, PSCA, PTK2, PTP4A3, PUF60, PYCRL, RECQL4, RHPN1, RPL8, SCRIB, SCRT1, SHARPIN, SLC39A4, SLC45A4, SLURP1, SPATC1, THEM6, TIGD5, TMEM249, TMEM60, TONSL, TSNARE1,TSTA3 , VPS28, ZC3H3, ZNF16, ZNF34, ZNF623, ZNF7

ANXA13, ATAD2, DERL1, FAM83A, FAM91A1, FBXO32, FER1L6, H3F3C, HAS2, KLHL38, PRKDC, SPIDR, TBC1D31, UBE2V2, WDYHV1, ZHX1, ZHX2

AARD, COLEC10, CSMD3, EIF3H, EXT1, FABP12, FABP4, FABP5, FABP9, HEY1, IL7, MAL2, 14 MED30, MRPS28, NOV, PAG1, PKIA, PMP2, RAD21, SAMD12, STMN2, TNFRSF11B, TPD52, TRPS1, UTP23, ZBTB10,ZC2HC1A ,ZNF704

16 ESRRG, GPATCH2, LYPLAL1, RRP15, TGFB2, USH2A

ATP1B1, BLZF1, C1orf112, CCDC181, CEP170, CHML, DPT, EXO1, F5, FH, KIFAP3, KMO, MAP1LC3C, METTL11B, METTL18, NME7, PLD5, RGS7, SCYL3, SELE, SELL, SELP, SLC19A2, WDR64, XCL1

17 ANKRD50, BBS12, CETN4, FAT4, FGF2, NUDT6, SPATA5, SPRY1

ACSF3, ANKRD11, APRT, BANP, C16orf95, C18H16orf87, CA5A, CBFA2T3, CDH15, CDK10, CDT1, CHMP1A, CPNE7, CTU2, CYBA, DBNDD1, DEF8, DNAJA2, DPEP1, FANCA, FBXO31, 18 FOXC2, FOXF1, FOXL1, GALNS, GAS8, GPT2, IL17C, IRF8, ITFG1, JPH3, KLHDC4, LAT, MAP1LC3B, MC1-R, MGC157263, MTHFSD, MVD, MYLK3, NETO2, ORC6, PABPN1L, PIEZO1, RNF166, RPL13, SHCBP1, SNAI3, SPATA2L, SPG7, SPIRE2, TCF25, TRAPPC2L, TUBB3, VPS35, VPS9D1, ZC3H18, ZCCHC14, ZFPM1, ZNF276, ZNF469

AARS, ADAT1, BCAR1, BCNT, CFDP1, CNTNAP4, COG4, CTRB1, DDX19A, DDX19B, EEF1A1, 18 FA2H, FUK, GABARAPL2, GLG1, IL34, KARS, LDHD, MLKL, MRCL, MTSS1L, P97BCNT2, PDPR, RFWD3, SF3B3, SIAT4B, TERF2IP, TMEM170A, TMEM231, UQCRFS1, VAC14, VSTM2B, WDR59, ZFP1, ZNRF1

ANKRD27, CEBPG, CEP89, CHST8, DPY19L3, FAAP24, GPATCH1, GPI, KCTD15, KIAA0355, 18 LRP3, LSM14A, NUDT19, PDCD2L, PDCD5, PEPD, RGS9BP, RHPN2, SLC7A10, SLC7A9, TDRD12, TSHZ3, UBA2, WDR88, WTIP, ZNF507

$18 M O N 1 B, S Y C E 1 L$

AATK, ACTG1, ALYREF, ANAPC11, ARHGDIA, ARL16, ASPSCR1, AZI1, BAIAP2, BPTF, C17orf62, C17orf70, C1QTNF1, CANT1, CARD14, CBX2,CBX4,CBX8,CCDC137, CCDC40, CCDC47, CCDC57, CD7, CD79B, CEP95, CHMP6, CSNK1D, CYTH1, DCXR, DDX42, DDX5, DNAH17, DUS1L, EIF4A3, ENDOV, ENGASE, ENPP7, ENTHD2, ERN1, FAM195B, FASN, FN3K, FN3KRP, FOXK2, FSCN2, FTSJ3, GAA, GCGR, GH1, GPS1, HEXDC, HGS, ICAM2, KPNA2, 19 LGALS3BP, LRRC45, MAFG, METRNL, MILR1, MRPL12, MYADML2, NARF, NOL11, NPB, NPLOC4, NPTX1, OGFOD3, OXLD1, P4HB, PCYT2, PDE6G, PGS1, POLG2, PPP1R27, PSMC5,PSMD12 ,PYCR1 ,RAB40B , RAC3, RBFOX3, RFNG, RNF213, RPTOR, SCN4A, SECTM1, SGSH, SIRT7, SLC16A3, SLC26A11, SLC38A10, SMARCD2, SMURF2,STRA13 ， STRADA, TBC1D16, TBCD, TEX2, TIMP2, TSPAN10, USMG5, USP36, UTS2R, WDR45L,ZNF750

20 ADAMTS16, ADCY2, IRX1, KIAA0947, MED10, NSUN2, PAPD7, SRD5A1,

$20 \quad C D H 10, C D H 9$ 


\section{Continued}

rs41628334/

rs41639270/rs41639268/ rs41940571/rs29021255/ rs41942930/ rs41578305

rs41654340

BFGL-NGS-119848

Hap-

map25382-BTC-000577

rs41606777

rs41650611

rs41648482

rs29027496

rs41608052

Hap-

map42724-BTA-91683

rs109224945/

BTA-94079-no-rs

rs41629005
ADAMTS12, AGXT2, AMACR, BRIX1, C1QTNF3, C20H5ORF22, C20H5orf34, C5orf28, C5orf42, C5orf51, C6, C7, C9, CAPSL, CARD6, CCDC152, CCL28, CDH6, DAB2, DNAJC21, DROSHA, EGFLAM, EMB, FBXO4, FYB, GDNF, GHR, GOLPH3, HCN1, HMGCS1, IL7R, LIFR, LMBRD2, 20 MROH2B, MRPS30, MTMR12, NADK2, NIM1K, NIPBL, NNT, NPR3, NUP155, OSMR, OXCT1, PAIP1, PARP8, PLCXD3, PRKAA1, PRLR,PTGER4, RAD1, RAI14, RANBP3L, RICTOR, RPL37, RXFP3, SKP2, SLC1A3, SLC45A2, SPEF2, SUB1, TARS, TTC23L, TTC33, UGT3A1, WDR70, ZFR, ZNF131

ABT1, ALDH5A1, BTN1A1, C23H6ORF62, DCDC2, FAM65B, GMNN, GPLD1, H2B, HFE, HIST1H1A, HIST1H1C, HIST1H1D, HIST1H1E, HIST1H2AC, HIST1H2AD, HIST1H2AG, HIST1H2AJ, HIST1H2BA, HIST1H2BB, HIST1H2BI, HIST1H2BJ, HIST1H2BK, HIST1H3A, 23 HIST1H3B, HIST1H3E,HIST1H3H, HIST2H4B, HIST4H4, HMGN4, KIAA0319, LRRC16A, MGC157324, MRS2, NKAPL, OR12D3, OR14J1, OR2B6, PGBD1, POM121L2, PRSS16, SCGN, SLC17A1, SLC17A2, SLC17A3, SLC17A4, TDP2, THEM2, TRIM27, TRIM38, ZNF165, ZNF184, ZNF192, ZNF311, ZNF323, ZNF391, ZSCAN12, ZSCAN16, ZSCAN9

ATF7IP2, BCAR4, CIITA, CLEC16A, CPPED1, DEXI, EMP2, ERCC4, GSPT1, LITAF, MKL2, 25 NUBP1, PRM1, PRM2, PRM3, RMI2, RSL1D1, SHISA9, SNN, SNX29, SOCS1, TEKT5, TNP2, TVP23A, TXNDC11, ZC 3H7A

ADCY9, ALG1, ANKS3, C16orf89, C25H16ORF71, CDIP1, CORO7, DNAJA3, FAM86A, GLIS2, 25 GLYR1, HMOX2, MGC142811, MGRN1, NAGPA, NMRAL1, NUDT16L1, PAM16, PPL, RBFOX1, ROGDI, SEC14L5, 12-Sep, SRL, TFAP4, UBN1, VASN, ZNF500

ATRNL1, C10orf82, CACUL1, CCDC172, EIF3A, EMX2, ENO4, FAM204A, FAM45A, GFRA1, 26 GRK5, HSPA12A, KCNK18, KIAA1598, PDZD8, PNLIP, PNLIPRP2, PNLIPRP3, PRDX3, PRLHR, RAB11FIP2, SFXN4, SLC18A2, VAX1

ALDH18A1, ANKRD2, AVPI1, BLNK, C10orf12, CCNJ, CRTAC1, CYP2C18, CYP2C19, CYP2C87, DNTT, ENTPD1, EXOSC1, FRAT1, FRAT2, GOLGA7B, HELLS, HOGA1, HPS1, LCOR, LOXL4, 26 MARVELD1, MMS19, MORN4, NOC3L, OPALIN, PDLIM1, PGAM1, PI4K2A, PIK3AP1, PLCE1, PYROXD2, R3HCC1L, RRP12, SFRP5, SLIT1, SORBS1, TBC1D12, TCTN3, TLL2, TM9SF3, UBTD 1, ZDHHC16, ZFYVE27

ACTN2, ARID4B, B3GALNT2, EDARADD, ERO1LB, GGPS1, GNG4, GPR137B, HEATR1, 28 IRF2BP2, KCNK1, LGALS8, LYST, MTR, NID1, RBM34, RYR2, SLC35F3, TARBP1, TBCE, TOMM20

ADRBK1, AIP, ALDH3B1, ALDH3B2, ANKRD13D, AP5B1, ARL2, ATG2A, ATL3, B3GNT1, BAD, BANF1, BATF2, BRMS1, C11orf80, C11 orf85, C29H11orf68, C29H11orf84, C29H11orf86, CABP2, CABP4, CAPN1, CARNS1, CATSPER1, CCDC85B, CCDC87, CCDC88B, CCS, CD248, $C D C 42 B P G, C D C 42 E P 2, C D C A 5, C D K 2 A P 2, C F L 1, C H K A, C L C F 1, C O R O 1 B, C S T 6, C T S F$, CTSW, DNAJC4, DOC2G, DPF2, DPP3, DRAP1, EFEMP2, EHBP1L1, EHD1, EIF1AD, ESRRA, FAU, FERMT3, FIBP, FKBP2, FLRT1, FOSL1, FRMD8, GAL3ST3, GPHA2, GPR137, GPR152, GSTP1, KAT5, KCNK4, KCNK7, KDM2A, KLC2, LGALS12, LRFN4, LTBP3, MACROD1, 29 MAP3K11, MAP4K2, MARK2, MEN1, MGC140823, MRPL11, MRPL49, MUS81, NAALADL1, NAT11, NDUFS8, NDUFV1, NPAS4, NRXN2, NUDT22, NUDT8, OTUB1, OVOL1, PACS1, PC, PCNXL3, PELI3, PITPNM1, PLA2G16, PLCB3,POLA2 ,POLD4 ,PPP2R5B, PRDX5, PTPRCAP, PYGM, RAB1B, RAD9A, RASGRP2, RBM14, RBM4, RBM4B, RCE1, RCOR2, RELA, RHOD, RIN1, RNASEH2C, RPS6KA4, RPS6KB2, RTN3, SAC3D1, SART1, SCYL1, SF1, SF3B2, SIPA1, SLC22A11, SLC22A12, SLC25A45, SLC29A2, SNX15, SNX32, SPDYC, SPTBN2, SSH3, SSSCA1, STIP1, SUV420H1, SYT12, SYVN1, TBC1D10C, TBX10, TCIRG1, TIGD3, TM7SF2, TMEM134, TMEM151A, TRMT112, TRPT1, TSGA10IP, UNC93B1, VEGFB, VPS51, YIF1A, ZDHHC24, ZFPL1, ZNHIT2

29 ARHGAP32, BARX2, ETS1, FLI1, IGSF9B, JAM3, KCNJ1, KCNJ5, NTM, OPCML, SPATA19

ACTRT1, AIFM1, APLN, BCORL1, CCDC169, CXHXorf64, ELF4, GPR119, IRF2BP1, OCRL, RAB33A, RBMX2, SASH3, SLC25A14, SMARCA1, UTP14A, XPNPEP2, ZDHHC9, ZNF280C

X CASK, DDX3X, DUSP21, FUNDC1, GPR34, GPR82, MAOA, MAOB, MED14, , NDP, NYX, USP9Y

$\mathrm{X} \quad A F F 2, C X O R F 23, F M R 1, F M R 1 N B, I D S, M A P 7 D 2$, SLITRK2

${ }^{\#}$ Gene selection is based on UMD 3.1 genome assembly.

${ }^{+}$Underscore denotes SNPs which appear in different GWAS files. 
Table S5. IPA function analysis on the $1635^{\#}$ candidate genes selected from genome-wide association study with SCC in dairy cows.

\begin{tabular}{cc}
\hline Name & Molecules \\
Diseases and Disorders & 1130 \\
Cancer & 526 \\
Gastrointestinal Disease & 73 \\
Inflammatory Response & 17 \\
Hepatic System Disease & 24 \\
Infectious Disease & 76 \\
Molecular and Cellular Functions & 76 \\
Cell-To-Cell Signalling and Interaction & 8 \\
Cellular Movement & 42 \\
Energy Production & 254 \\
Small Molecule Biochemistry & 181 \\
Cell Morphology & 53 \\
Physiological System Development and Function & 150 \\
Haematological System Development and Function & 10 \\
Immune Cell Trafficking & 105 \\
Tissue Development & \\
Auditory and Vestibular System Development and Function & \\
\hline
\end{tabular}

${ }^{*} 1568$ Genes with known IPA-eligible human and rodent orthologs were considered.

Table S6. Top 10 signalling pathways from IPA among the $1635^{\#}$ candidate genes selected from genome-wide association study with SCC in dairy cows.

\begin{tabular}{ccc} 
Canonical pathways $^{*}$ & Molecules & Ratio \\
\hline Agranulocyte Adhesion and Diapedesis & 28 & $1.47 \mathrm{E}-01$ \\
Granulocyte Adhesion and Diapedesis & 25 & $1.4 \mathrm{E}-01$ \\
NAD Phosphorylation and Dephosphorylation & 6 & $3 \mathrm{E}-01$ \\
Proline Biosynthesis I & 5 & $3.57 \mathrm{E}-01$ \\
Role of JAK2 in Hormone-like Cytokine Signalling & 8 & $2.29 \mathrm{E}-01$ \\
IL-17A Signalling in Gastric Cells & 6 & $2.4 \mathrm{E}-01$ \\
Protein Kinase A Signalling & 41 & $1.04 \mathrm{E}-01$ \\
Remodelling of Epithelial Adherens Junctions & 11 & $1.62 \mathrm{E}-01$ \\
Serotonin Degradation & 12 & $1.54 \mathrm{E}-01$ \\
Ethanol Degradation II & 8 & $1.86 \mathrm{E}-01$ \\
\hline
\end{tabular}

${ }^{*}$ All pathways with $\mathrm{P}<0.01$

${ }^{\#} 1568$ genes with known IPA-eligible human and rodent orthologs were considered. 

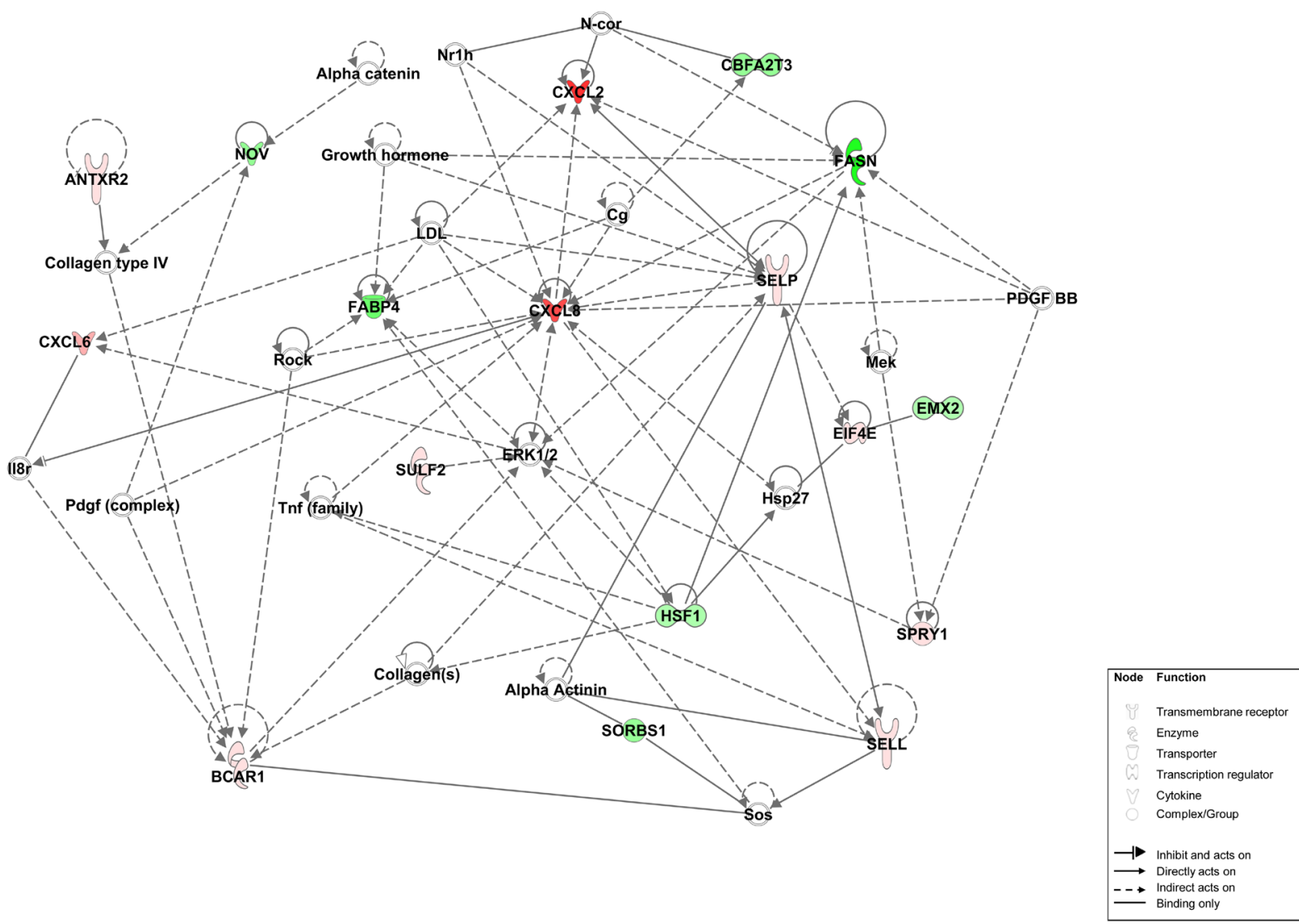

Figure S1. IPA Network 1 based on candidate genes for mastitis involved in Cancer, Organismal Survival, Cellular Movement. Red denotes up-regulation and green down-regulation of the gene. The shapes of nodes indicate different types of gene product as shown in the insert. Note that although the pathway is classified in IPA under "cancer" the same genes are also involved in proliferation and migration of normal cells and are thus relevant to the cellular changes to infection in the bovine mammary gland. 